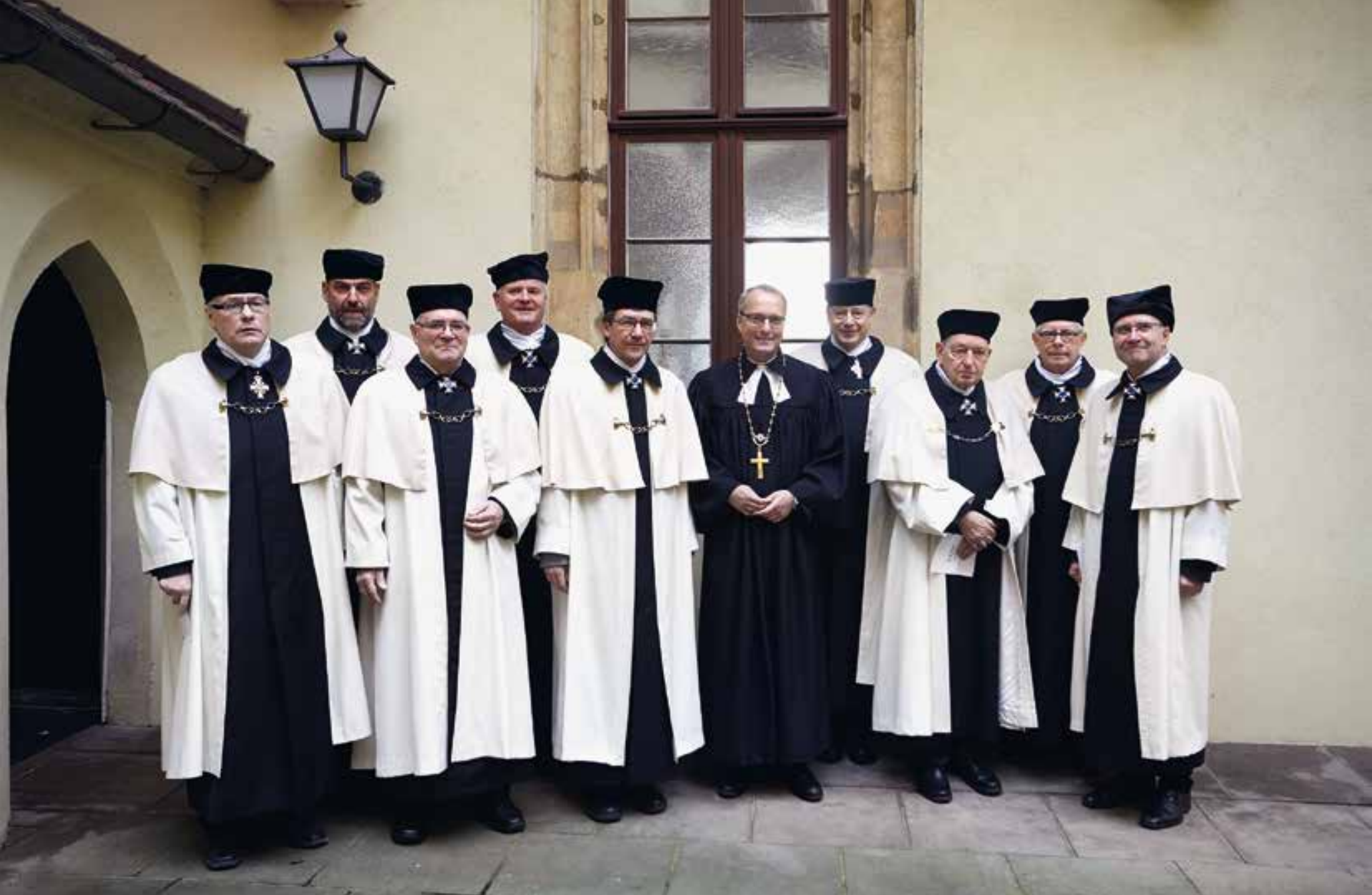

\title{
Das Meißner Domkapitel im 20. Jahrhundert
}

\author{
Matthias Donath
}

Das Meißner Domkapitel mit Stiftsherr Landesbischof Dr. Carsten Rentzing am 31. Oktober 2016 Foto: Mirko Stelzner

1 Vgl. Kunz von Brunn, genannt von Kauffungen: Das Domkapitel von Meißen im Mittelalter. Ein Beitrag zur Verfassungs- und Verwaltungsgeschichte der deutschen Domkapitel. In: Mitteilungen des Vereins für Geschichte der Stadt Meißen 6, Heft 2 (1902), S. 121-253.
Das Meißner Domkapitel besteht ohne Unterbrechung seit dem Mittelalter. Es kann zwar erst seit der Mitte des 11. Jahrhunderts verbindlich nachgewiesen werden, doch es wird angenommen, dass bereits der erste Bischof von Meißen, Burchard, der am Weihnachtstag des Jahres 968 in sein Amt eingeführt wurde, auch eine Gemeinschaft von Geistlichen einsetzte, die ihn unterstützte. ${ }^{1}$ Zur Geschichte des Meißner Domkapitels im Mittelalter liegen mehrere wissenschaftliche Arbeiten und Einzelstudien vor. ${ }^{2}$

Dagegen ist die Geschichte des Domkapitels nach der Reformation bisher nur überblicksartig behandelt worden. ${ }^{3}$ Der Meißner Dom gehört zu den Bischofskirchen, an denen trotz Einführung der Reformation die aus dem römisch-katholischen Kirchenrecht stammende Institution eines Domkapitels bestehen blieb. Das Erfordernis einer geistlichen Weihe und damit des Zölibats für eine Aufnahme ins Domkapitel wurde aufgehoben und die Verpflichtung, am Chorgebet teilzunehmen oder dieses durchführen zu lassen, gestrichen. Geblieben war die staatsrechtliche Stellung des Domkapitels als Wahlund Aufsichtsgremium für das Hochstift Meißen und den Stiftsherrn, den reichsfürstlichen Vertreter an der Stelle des früheren Bischofs. Seit der Resignation des letzten Bischofs und der Wahl Kurfürst Augusts von Sachsen (1526-1586) zum Stiftsherrn hatte das evangelische Domkapitel den Stiftsherrn zu wählen, der die Hoheit im Hochstiftsgebiet ausübte und die Stiftsregierung einsetzte, doch seit der sogenannten Perpetuierlichen Kapitulation von 1663, die das Amt des Stiftsherrn erblich mit dem sächsischen Kurhaus verband, war das Wahlrecht praktisch aufgehoben. So blieb als wichtigste Aufgabe die Aufrechterhaltung des Gottesdienstes in der Domkirche in Meißen. Das Vermögen des Domkapitels wurde von einem Juristen, dem Stiftssyndikus, verwaltet. Entscheidend für das Fortbestehen des Domkapitels war, dass die Domherren mit Geld- und Sachleistungen verbundene Präbenden (Pfründen) innehatten und somit beträchtliche Einnahmen erzielten. Seit 
1413 waren zwei Kanonikate (Domherrenstellen) für Professoren der Theologischen Fakultät der Universität Leipzig reserviert. ${ }^{4}$ Die Theologieprofessoren benötigten die Präbendenzahlungen für ihren Lebensunterhalt. Für die übrigen sechs Kanonikate war eine adlige Abstammung gefordert. Diese Regelung wurde im Jahr 1700 soweit verschärft, dass eine lückenlose Abfolge adliger Vorfahren über vier Generationen nachzuweisen war. Mitglieder sächsischer Adelsfamilien setzten ihre Kinder auf eine Warteliste zur Aufnahme ins Domkapitel. Hier konnten die Expektanten (Anwärter) aufrücken, und, wenn sie an der Reihe waren, ins Domkapitel gewählt werden. Die Pfründe garantierte den adligen Domherren ein sicheres Einkommen, ohne dass dafür etwas zu tun gewesen wäre.

Erstaunlich erscheint, dass das Domkapitel unter diesen Umständen die Reformen des 19. Jahrhunderts überstand. Während der Revolution 1848/49 wurde eine Auflösung beantragt und beinahe umgesetzt. Nur um Haaresbreite hatte sie verhindert werden können, weil die Staatsminister den bereits ausgehandelten Aufhebungsvertrag vom 5. März 1851 nicht dem König zur Ratifizierung vorlegten und ab 1853 eine Reform anstelle einer Aufhebung anstrebten. Der Reformvertrag vom 15. Dezember 1859, den König Johann von Sachsen (1801-1873) am 25. Februar 1860 ratifizierte, reduzierte die Höhe der Präbenden und hob das Erfordernis der adligen Abstammung auf. Ins Domkapitel konnten fortan Männer sächsischer Staatsangehörigkeit und evangelisch-lutherischen Glaubens gewählt werden, die sich um die Kirche, den Staat oder das Unterrichtswesen Verdienste erworben hatten. So blieb das Domkapitel mit nur geringen Änderungen der Stiftsverfassung weiter bestehen.

Noch erstaunlicher ist es, dass das Domkapitel auch die Brüche des 20. Jahrhundert überlebte, insbesondere die Novemberrevolution 1918, die Herrschaft der Nationalsozialisten, die radikalen Veränderungen in der sowjetischen Besatzungszone und den nahezu vollständigen Verlust des Vermögens. Die Herrschaftsordnungen änderten sich vollkommen, doch das Domkapitel fand einen Weg, den Bedrängnissen zu entgehen.

Bis zum 19. Jahrhundert ist die Geschichte des Meißner Domkapitels wenigstens in Grundzügen in der Literatur nachvollziehbar. ${ }^{5}$ Dagegen fehlte bisher eine zusammenfassende Darstellung zur Geschichte des Domkapitels im 20. Jahrhundert. ${ }^{6}$ Aus Anlass des Jubiläums „1050 Jahre Hochstift Meißen“ soll nun versucht werden, den Weg des Meißner Domkapitels durch die Umbrüche des 20. Jahrhunderts nachzuzeichnen. Die Darstellung folgt überwiegend der Aktenüberlieferung im Archiv des Hochstifts Meißen ${ }^{7}$ und im Landeskirchenarchiv in Dresden.

\section{Das Meißner Domkapitel zu Beginn des 20. Jahrhunderts}

Seit der Einführung der Reformation umfasst das Domkapitel acht Domherrenstellen. Wie darge- legt, waren zwei für Professoren der Universität Leipzig reserviert. Die Leipziger Theologieprofessoren wurden von der Theologischen Fakultät der Universität Leipzig ernannt und vom Rektor dem Domkapitel präsentiert. Wenn sie nicht im Amt verstarben, sondern emeritiert wurden, erlosch ihr Kanonikat mit der Emeritierung. Wie in den Jahrhunderten zuvor, gehörten dem Domkapitel auch zu Beginn des 20. Jahrhunderts anerkannte Theologen mit hoher wissenschaftlicher Reputation an, etwa die Professoren Ernst Luthardt (18231902), Gustav Adolf Fricke (1822-1908), Rudolf Hofmann (1825-1917), Theodor Brieger (18421915), Albert Hauck (1845-1918) und Rudolf Kittel (1853-1929). Im Mai 1918, wenige Monate vor der Revolution, wurde Prof. Dr. Ludwig Ihmels (1858-1933), Professor für Dogmatik in Leipzig und später erster Landesbischof Sachsens, ins Domkapitel aufgenommen.

Die sechs anderen Domherrenstellen wurden gemäß Reformvertrag von 1859 auf Lebenszeit durch Wahl besetzt. Das Domkapitel erstellte einen Dreiervorschlag, und der Stiftsherr, also der König von Sachsen, wählte in Abstimmung mit den in Evangelicis beauftragten Staatsministern einen von ihnen aus. Obwohl keine adlige Abstammung gefordert war, besetzten die meist adligen Domherren die freigewordenen Stellen praktisch nur mit Angehörigen der gleichen sozialen Schicht. So bestand das Domkapitel überwiegend aus hohen Staatsbeamten, die angesehenen Adelsfamilien Sachsens angehörten. Die wichtigsten Minister der königlichen Regierung, so Hermann von NostitzWallwitz (1826-1906), Georg Graf von MetzschReichenbach (1836-1927) oder Paul von Seydewitz (1843-1910), waren zugleich Mitglieder des Meißner Domkapitels. Metzsch-Reichenbach war als Vorsitzender des Gesamtministeriums von 1901 bis 1906 sogar Regierungschef Sachsens. Richard Leo Graf von Könneritz (1828-1910) war zugleich Präsident der Ersten Kammer des sächsischen Landtags und der Landessynode der Evangelisch-Lutherischen Landeskirche, was abermals verdeutlicht, wie eng Staat und Kirche damals miteinander verwoben waren. Hinzu kamen Staatsbeamte, wie Carl von Kirchbach (1847-1929), Präsident der Königlich Sächsischen Staatseisenbahnen, oder Rudolf Carl Toussaint von Charpentier (1822-1903), Regierungsrat im Innenministerium, sowie adlige Rittergutsbesitzer aus verschiedenen Landesteilen Sachsens wie Bernhard Edler von der Planitz (1828-1907) auf Naundorf bei Oschatz, Hans Dietrich Konrad von Trützschler Freiherr zum Falkenstein (1830-1907) auf Dorfstadt bei Falkenstein im Vogtland oder Clemens Graf zur Lippe (1860-1920) auf Döberkitz bei Bautzen. Die einzigen Nichtadligen neben den Theologieprofessoren waren der um die Errichtung der Meißner Domtürme hochverdiente Geheime Studienrat Dr. Herrmann Peter (18371914), vormals Rektor der Fürstenschule St. Afra, sowie der Kultusminister und Vorsitzende des Gesamtministeriums Dr. Heinrich Gustav Beck
2 An erster Stelle ist hier Brunn (wie Anm. 1) zu nennen. Die neuere Literatur zu Bistum und Domkapitel zu Meißen ist zu finden bei Enno Bünz: Das Bistum Meißen im späten Mittelalter und in der Reformationszeit (1485-1539). In: Claudia Kunde/André Thieme (Hrsg.): Ein Schatz nicht von Geld. Benno von Meißen. Sachsens erster Heiliger. Katalog zur Sonderausstellung in der Albrechtsburg Meissen. Petersberg 2017, S. 168-179. Hervorzuheben sind ferner Jörg Rogge: Zum Verhältnis von Bischof und Domkapitel des Hochstifts Meißen im 14. und 15. Jahrhundert. In: Römische Quartalsschrift 91 (1996), S. 182206; Hermann Kinne: Die Meißner Dompröpste des 15. Jahrhunderts. Eine prosopographische Studie. In: Blätter für deutsche Landesgeschichte 148 (2012), S. 153-237; Manfred Josef Thaler: Die Domkapitel der Reichskirche vom Wiener Konkordat bis zur Säkularisation (14481803). Grundzüge ihrer Verfassung im Vergleich. Frankfurt am Main 2017, S. 51-52, 146-147, 290-291, 436-437.

3 Alfred Schultze: Stiftsherr und Domkapitel zu Meißen einst und jetzt in rechtlicher Betrachtung. In: Der Dom zu Meißen. Festschrift des Hochstifts Meißen 1929. Dresden 1929; Matthias Donath: Der Meißner Dom. Monument sächsischer Geschichte. Beucha 2002, v.a. S. 148-188.

4 Markus Cottin: Die Leipziger Universitätskanonikate an den Domkapiteln von Meißen, Merseburg und Naumburg sowie am Kollegiatstift Zeitz im Mittelalter (14131542). Rechtliche, wirtschaftliche und prosopographische Aspekte. In: Detlef Döring (Hrsg.): Universitätsgeschichte als Landesgeschichte. Die Universität Leipzig in ihren territorialgeschichtlichen $\mathrm{Be}$ zügen. Tagung der Historischen Kommission der Sächsischen Akademie der Wissenschaften zu Leipzig vom 7. bis 9. Oktober 2004. Leipzig 2007, S. 279-312.

5 Gerhard Schmidt: Die Reform des Hochstifts Meißen im 19. Jahrhundert. In: Franz Lau (Hrsg.): Das Hochstift Meißen. Aufsätze zur sächsischen Kirchengeschichte. Berlin 1973, S. 301-322. 


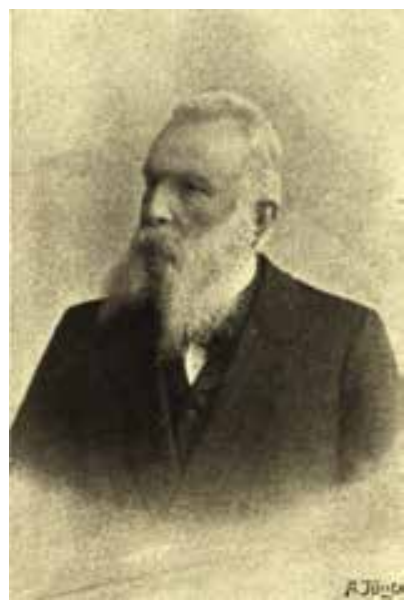

Domdechant Richard Leo Graf von Könneritz, um 1900

() Hochstift Meißen

6 Die zur 1000-Jahrfeier des Bistums Meißen konzipierte und von Franz Lau herausgegebene Aufsatzsammlung endet mit der Geschichte des Domkapitels im 19. Jahrhunderts. Lediglich der Aufsatz von Helmar Junghans zur geistlichen Versorgung des Doms zu Meißen vom Reformationszeitalter bis 1949 reicht bis ins 20. Jahrhundert hinein. Zur Geschichte der letzten 100 Jahre vgl. Dieter Auerbach: Domdechant Prof. Dr. Karlheinz Blaschke in Ehrerbietung und Dankbarkeit zum 75. Geburtstag. In: Ecclesia Misnensis 5 (2002), S. 4-13; Gerhard Steinecke: Der tausendjährige Meißner Burgberg im Tausendjährigen Reich. In: Monumenta Misnensia. Jahrbuch für Dom und Albrechtsburg zu Meißen 8 (2007/2008), S. 152-168; Gerhard Steinecke: Der Meißner Burgberg im Nachkriegszwielicht 1945 bis 1949. In: Monumenta Misnensia. Jahrbuch für Dom und Albrechtsburg Meißen 9 (2009/2010), S. 97-109; Dieter Auerbach: Verpflichtung und Gefährdung. Ereignisse aus der Geschichte des Domkapitels zu Meißen von den Anfängen bis zur friedlichen Revolution 1989. In: Monumenta Misnensia. Jahrbuch für Dom und Albrechtsburg zu Meißen 8 (2007/2008), S. 169-184; Dieter Auerbach: Zum Gedenken an Kirchenrat Hugo Hickmann (1841-1922) und Dompropst Hugo Hickmann (1877-1955). In: Monumenta Misnensia. Jahrbuch für Dom und Albrechtsburg zu Meißen 12 (2015/2016), S. 117-120.
(1854-1933). Letzterer wurde nach seiner Entlassung aus der Regierung im Oktober 1918 in den erblichen Adelsstand erhoben. Es war die letzte Nobilitierung vor der Revolution und der Abdankung des letzten sächsischen Königs.

Bemerkenswert ist weiterhin, dass eine Mehrheit der Mitglieder des Domkapitels der Ersten Kammer des sächsischen Landtags angehörte - entweder, weil sie auf Lebenszeit ernannte Mitglieder waren, weil sie als Rittergutsbesitzer in die Parlamentskammer gewählt worden waren oder weil sie das Hochstift Meißen in dieser Kammer vertraten. Denn nach der Verfassung des Königsreichs Sachsen von 1831 durfte das Hochstift Meißen einen Abgeordneten in die Erste Kammer entsenden - gewissermaßen als Ausgleich für die 1831 verlorene Eigenstaatlichkeit und den bis zu den Reformen bestehenden Sitz in der ersten Kurie der sächsischen Ständeversammlung. Zu Beginn des 20. Jahrhundert nahmen Rudolf Carl Touissant von Charpentier, Rudolf Hofmann, Dr. Herrmann Peter und Carl von Kirchbach den staatsrechtlich bedeutsamen Parlamentssitz des Hochstifts Meißen wahr.

Man kann sagen, dass im Domkapitel Meißen die evangelische Elite des Königreichs Sachsen vertreten war, einschließlich der Spitzen von Regierung und Parlament. Der König selbst war der Stiftsherr des Hochstifts. König Friedrich August III. von Sachsen (1865-1932) besuchte den Meißner Dom am 27. Oktober 1908 zur Weihe der Glocken des Meißner Doms und am 28. Oktober 1912 zur Einweihung der erneuerten Domkirche. ${ }^{8}$ Obwohl selbst römisch-katholischen Glaubens, nahm er jeweils am evangelischen Gottesdienst teil.

Nach der Hofrangordnung des Dresdner Hofs rangierten die Meißner Domherren hinter den Kammerherren, aber vor nahezu allen anderen Amtsträgern des Königreichs Sachsen, auch vor den Geheimen Räten, dem Rektor der Universität Leipzig und vor den Oberbürgermeistern von Dresden und Leipzig. Bei offiziellen Anlässen trugen die Domherren den 1764 von Prinzregent Xaver von Sachsen (1730-1806) gestifteten Stiftsorden. Die traditionelle Anrede war „Euer Hochwürden“ beziehungsweise „Hochwürden“.

Das ranghöchste Mitglied des Domkapitels war der Dompropst. Ihm folgte der Domdechant, der die Vertretung des Domkapitels nach außen wahrnahm. Weitere Rangstufen waren die des Propstes zu Bautzen, des Seniors und des Subseniors. Der Dompropst nahm das Kollatur- und Patronatsrecht über die Kirche und Schule in Boritz wahr, der Senior hatte das Kollatur- und Patronatsrecht über die Kirche und Schule in Rüsseina inne. Das bedeutete, dass diese beiden Domherren an der Auswahl und Einsetzung der Pfarrer und Lehrer in den Patronatsdörfern mitwirkten.

Seit Bestehen des Kollegiatkapitels St. Petri in Bautzen stammte der Propst dieses Kapitels aus den Reihen der Meißner Domherren. Die Reformation hatte dabei zu Verwerfungen geführt, weil das Kollegiatkapitel in Bautzen beim römisch-ka- tholischen Glauben blieb, während sich das Meißner Domkapitel zur Reformation bekannte. ${ }^{9}$ Dennoch war es dabei geblieben, dass der Kurfürst und später der König von Sachsen in seiner Eigenschaft als Stiftsherr einen Meißner Domherrn zum Propst von Bautzen ernannte. ${ }^{10}$ Das katholische Domkapitel zu Bautzen protestierte regelmäßig gegen die Ernennung, musste sich aber der Rechtslage beugen und die Installation, das heißt die Amtseinführung des evangelischen Propstes zu Bautzen, zulassen. Allerdings musste sich der Propst verpflichten, den Propstsitz im Kapitel nicht einzunehmen und kein Recht des Propstes innerhalb des katholischen Domkapitels St. Petri auszuüben. Der Propst zu Bautzen hatte Anspruch auf das Einkommen der Propstei Bautzen. Diese Vermögensmasse blieb im Eigentum des Domkapitels zu Bautzen, doch durfte der Propst zu Bautzen die Erträge nutzen. 1871 schlossen die beiden Kapitel ein Abkommen, bei dem die Verwaltung und Nutznießung der Propsteipräbende dem Domkapitel zu Meißen übertragen wurde. Seitdem verwaltete das Hochstift Meißen den Grundbesitz der Bautzener Propstei, die 31 Hektar umfassenden Propsteifelder nordöstlich der Bautzener Innenstadt, sowie die zur Präbende gehörenden Kapitalien, Wertpapiere und Hypothekenbriefe.

Mit dem Kollegiatkapitel St. Marien in Wurzen gab es keine institutionelle Verbindung mehr, da der Propst zu Wurzen seit Ende des 15. Jahrhunderts nicht mehr dem Meißner Domkapitel angehören musste. Das Wurzener Kollegiatkapitel war ebenfalls evangelisch-lutherischer Konfession und hatte den gleichen Stiftsherrn, den sächsischen König. Es war aber dem Rang nach dem Meißner Domkapitel nachgeordnet.

Alle Meißner Domherren erhielten Präbenden (Pfründen) aus dem Vermögen des Domkapitels. Mit der Ablösung der Grunddienstbarkeiten im Königreich Sachsen nach 1833 hatte das Domkapitel auf sämtliche Abgaben und Fronen der Untertanen der Stiftsdörfer verzichten müssen. ${ }^{11}$ Aus den bei der Ablösung gutgeschriebenen Geldbeträgen wurde der Präbendenfonds gebildet, dessen Vermögen in Staatsanleihen und Schuldverschreibungen angelegt war. Die jährlichen Erträge des Präbendenfonds beliefen sich auf rund 12.000,00 Mark. Die Höhe der Präbende richtete sich nach dem Rang und nach der Reihenfolge des Eintritts in das Domkapitel. Ein neu aufgenommener Domherr bezog jährlich 900,00 Mark; Dompropst, Domdechant und Propst zu Bautzen erhielten jährlich je 2.100,00 Mark.

Einnahmen geringerer Höhe erbrachten die drei Häuser, die das Domkapitel in der Nachbarschaft des Meißner Doms in Besitz hatte: die Domdechantei (Domplatz 5), die Dompropstei (Domplatz 7) und der Domkeller (Domplatz 9). Das Hochstift Meißen hatte außerdem Rechte gegenüber dem Prokuraturamt, das im 16. Jahrhundert aus Vermögensteilen des Meißner Domkapitels gebildet worden war. Das Ministerium für Kultus und öffentlichen Unterricht fasste mit Verordnung 
vom 24. April 1917 insgesamt 31 Rechtstitel zusammen, die mit einer jährlichen Zahlung von 3.694,92 Mark an das Domkapitel abgegolten wurden. So speiste sich die Einnahmen des Hochstifts Meißen aus Kapitalerträgen, den Einnahmen der Propstei Bautzen, der Prokuraturrente und sonstigen Einnahmen.

Die Domherren kamen in der Regel einmal im Jahr, am Sonntag Exaudi, zu Kapitelsitzungen zusammen. Die wichtigsten Entscheidungen des Domkapitels in den beiden Jahrzehnten vor der Revolution waren die Zustimmung zum Bau der Meißner Domtürme und zur Neuregelung des Dompfarramts. Der Weiterbau der Westturmfront des Meißner Doms war indes kein Projekt des Domkapitels, sondern einer breiten Bürgerbewegung, die sich im 1895 gegründeten Meißner Dombauverein organisierte. ${ }^{12}$ Die Geldmittel kamen aus einer von der Regierung genehmigten Lotterie. 1912 konnte die Einweihung des vollendeten Meißner Doms gefeiert werden. Nach dem Eintritt des langjährigen und umstrittenen Dompredigers Emil Körner (1855-1940) ${ }^{13}$ in den Ruhestand einigten sich Domkapitel und Evangelisch-Lutherisches Landeskonsistorium ${ }^{14}$ auf eine Neuordnung der Pfarrstellen. Mit Verordnung des Landeskonsistoriums vom 12. August 1916 wurde ein Dompfarramt begründet. Die Stelle des Dompfarrers verband man im Nebenamt mit der Stelle des Superintendenten des Kirchenbezirks Meißen. Darüber hinaus wurde beschlossen, die Stelle des Dompredigers ohne besondere Vergütung einem Geistlichen der Meißner Frauenkirche zu übertragen. Der erste Dompfarrer war der 1917 eingeführte Superintendent Dr. Arthur Neuberg (18661961). Bereits seit 1916 übte Pfarrer Gottfried Schönknecht (1891-1953), Inhaber der dritten Pfarrstelle der Frauenkirche, das Amt des Dompredigers aus.

Ein wichtiger Inhalt der Kapitelsitzungen war die Vergabe von Stipendien an begabte und bedürftige Studenten, die sich beim Domkapitel um diese Stipendien bewerben konnten. Das Domkapitel verfügte über fünf Stiftungsfonds mit zum Teil langer Geschichte: Die älteste Stiftung war die des Meißner Domherrn und Leipziger Theologieprofessors Andreas Rüdiger (gest. 1496). Sie war 1496 eingerichtet und mit 400 Gulden ausgestattet worden. Die Erträge waren ursprünglich für Nachkommen der Familien Langschneider und Schwoffheim bestimmt. Nach deren Aussterben war der Stiftungsfonds 1824 dem Domkapitel Meißen übertragen worden, der aus den Erträgen ein Stipendium finanzierte. 1918 verfügte die Rüdiger'sche Stiftung über 3.983,78 Mark. Die Haugwitz-Stiftung war 1581 vom letzten Bischof von Meißen, Johann IX. von Haugwitz (1524-1595), wenige Tage vor seiner Resignation errichtet worden. Die Erträge aus einem Kapital in Höhe von 4.000 Gulden waren für zwei studierende Mitglieder der Familie von Haugwitz zu verwenden. Später erfolgte eine Umwidmung. Seit dem 19. Jahrhundert waren die Erträge je zur Hälfte an den Präbendenfonds und an

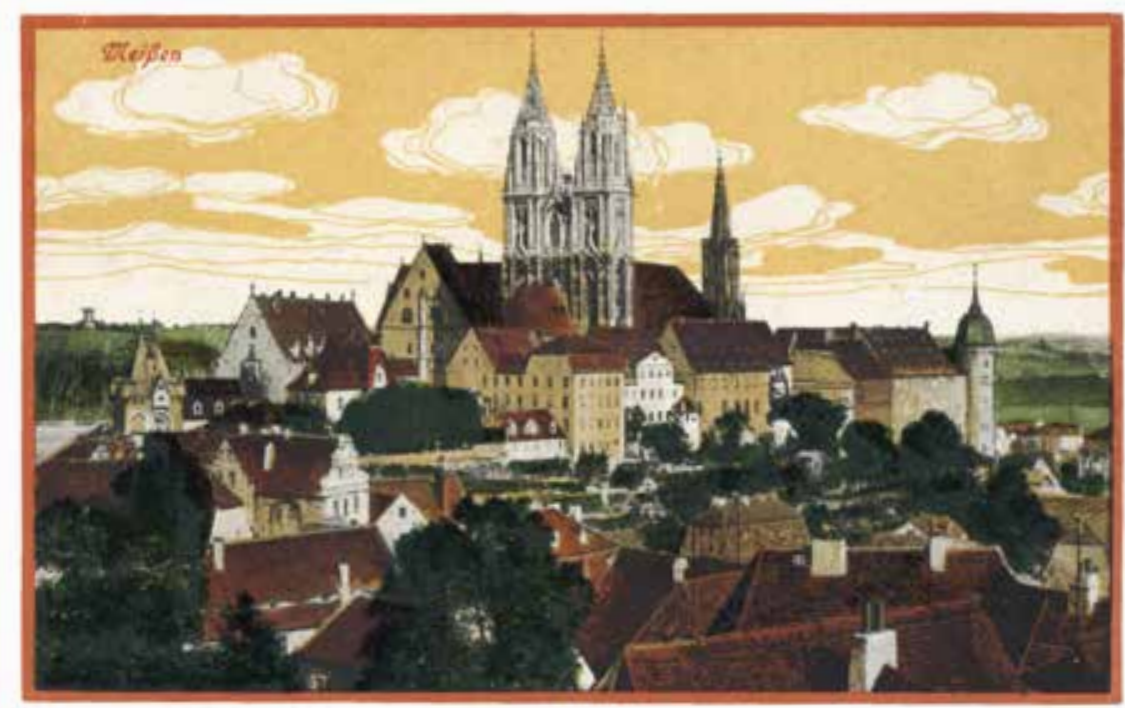

die Baumeistereikasse anzuführen. Dompropst Johann Ernst von Knoch (1641-1705), Präsident des Oberkonsistoriums in Dresden, hatte am 29. Mai 1682 die Knoch'sche Stipendienkasse gestiftet. Aus den anfangs 2.000 Talern waren 1918 23.743,66 Mark geworden. Aus den Erträgen des Kapitals wurden drei Stipendien für Studenten der evangelischen Theologie ausgegeben. Die Überschüsse kamen der Baumeistereikasse zugute. Domdechant August Philipp von Mergenthal (1683-1748), der letzte seines Geschlechts, hatte testamentarisch am 18. April 1748 die Mergenthal'sche Stipendienkasse gestiftet, der 660 Taler, 8 Groschen und 5 Pfennige zuflossen. 1911 betrug das Vermögen 9.735,94 Mark. Aus dem jährlichen Ertrag wurden zwei Stipendien für Studenten bezahlt.

Nicht mit Stipendien verbunden war die Gersdorff'sche Stiftungskasse. Sie war am 18. April 1770 durch Dechant Georg Ernst von Gersdorff zur Erhaltung des öffentlichen Gottesdienstes am Sonntagvormittag im Meißner Dom und zur Unterhaltung der 1773 eingerichteten drei wöchentlichen Betstunden in der Domkirche gegründet und mit 4.000 Talern ausgestattet worden. 1918 betrug das Vermögen 13.527,98 Mark. Die Erträge flossen der Baumeistereikasse zu, einem Sondervermögen zum Unterhalt des Doms und zur Bezahlung der Aufwendungen für den Gottesdienst. Auch die Baumeistereikasse war früher mit Grundbesitz und Untertanen ausgestattet gewesen. ${ }^{15}$ Aber wie beim Präbendenvermögen des Domkapitels waren diese Grunddienstbarkeiten abgelöst und in Kapitalien umgewandelt worden.

Im April 1919 belief sich das Vermögen des Domkapitels auf 3.477.656,43 Mark. Davon entfielen 2.268.688,41 Mark auf den Präbenden- und Baumeisterfonds. Die gesondert ausgewiesenen Propstei Bautzen hatte ein Vermögen von 123.983,00 Mark. Den fünf Stiftungsfonds waren insgesamt 85.045,02 Mark zugeordnet. Das Vermögen erbrachte 1918/19 einen Jahresertrag von 46.613,09 Mark.

Als der Erste Weltkrieg zu Ende ging, verfügte das Meißner Domkapitel über einen vollständig ausge-
Der Meißner Dom mit den 1908 vollendeten Domtürmen, Postkarte, um 1910
7 Die Bestände im Meißner Domarchiv zum 20. JahrhunEs wurden bisher weder inhaltlich eindeutige Akten gebildet noch Nummern vergeben. Daher ist ein genauer Nachweis der Einzelinformation etwa durch Aktennummer und Blattzahlen nicht möglich.

8 Matthias Donath: Die Meiß ner Dombaufeste. In: Günter Donath/Matthias Donath (Hrsg.): Himmelszeichen. 100 Jahre Meißner Domtürme. Meißen 2008, S. 222 233.

9 Vgl. Johannes Heinrich Seyin Bautzen. In: Neues Lausitzisches Magazin 106 (1930), S. 80-129; Siegfried Seifert: Beziehungen zwischen dem Hochstift Meißen und dem Domkapitel St. Petri in Bautzen. In: Uwe John/Josef Matzerath (Hrsg.): Landesgeschichte als Herausforderung und Programm. Karlheinz Blaschke zum 70 Geburtstag. Leipzig/Stuttgart 1997, S. 339-350. Seifert verweist auf die Quellen im Domstiftsarchiv Bautzen, zitiert aber nicht die ältere rechtsgeschichtliche Literatur, etwa Seyler.

10 Das Ernennungsrecht des Landesfürsten beruhte auf den päpstlichen Bullen vom 9. Juli 1476 und 24. Dezember 1481 . dert sind noch ungeordnet. ler: Die Propstei zu St. Petri 
11 Vgl. Matthias Donath: Zur Verwaltungsgeschichte der Lommatzscher Pflege. In: Sächsische Heimatblätter 64 (2017), S. 311-318, hier S. 314-315 und Karte mit Eintragung der Dörfer des Domkapitels: Abend, Boritz, Domselwitz, Löbtau, Lüttnitz, Mettelwitz, Noßwitz, Prositz, Rüsseina, Schirmenitz, Sörnewitz, Wölkau, Zschaitz und Zschannewitz.

12 Matthias Donath: Der Meißner Dombauverein. In: Günter Donath/Matthias Donath (Hrsg.): Himmelszeichen. 100 Jahre Meißner Domtürme. Meißen 2008, S. 98-141.

$13 \mathrm{Zu}$ ihm Donath 2008 (wie Anm. 11), S. 141.

141933 erfolgte die Umbenennung in Landeskirchenamt.

15 Vgl. Donath 2017 (wie Anm. 10), S. 315. Zur Baumeisterei gehörten Oberwartha, Zöllmen, Kemnitz, Saultitz, ein Anteil von Toppschädel und das Mühlengut Dreikutten.

16 Claus Peter: Das Geläut des Meißner Domes. In: Monumenta Misnensia 10 (2011/ 2012), S. 6-30, hier S. 12.

17 Das Gutachten wurde gedruckt, vgl. Alfred Schultze: Die Rechtslage der evangelischen Stifter Meißen und Wurzen. Zugleich ein Beitrag zur Reformationsgeschichte. Leipzig 1922

18 Heinrich Magirius: Die Sophienkirche in Dresden. Eine neugotische Kathedrale des lutherischen Sachsen? In: Monumenta Misnensia. Baumeister der Gotik und der Neugotik. Festschrift für Günter Donath. Meißen 2016, S. 82-106.

Erklärung des Dompropstes Georg Graf von Metzsch-Reichenbach zum Verzicht Friedrich Augusts III. auf seine Rechte als Stiftsherr bauten und durchgehend restaurierten Dom. Dieses Baudenkmal hatte jedoch vorwiegend eine symbolische Bedeutung, jedoch keine sinnstiftende Nutzung. Eine Domgemeinde gab es nicht. Auch die Einrichtung eines Dompfarramts hatte daran nichts ändern können. So machten sich verschiedene Domherren Gedanken, wie eine Nutzung nach Kriegsende aussehen könne. Der Leipziger Theologieprofessor Albert Hauck stellte in einem Schreiben vom 27. April 1917 die Frage, welche neue Aufgabe der Meißner Dom erhalten könne: „Die mächtige Zeit, in der wir leben, an die man noch nach vielen Jahrhunderten denken wird, scheint mir die Antwort nach dieser Frage nahezulegen: Der Meissener Dom sollte ein Denkmal sächsischer Geschichte werden, der grossen Männer, die Sachsen entstammen und die in Sachsen wirkten. Er sollte das werden, was die Westminsterabtei für England, die Kirche Sa. Croce für Florenz ist: eine von Geschlecht zu Geschlecht bereicherte Gedächtniskirche der grossen Männer des Landes.“ Diese Idee ist später nicht weiter verfolgt worden. Der Erste Weltkrieg machte sich insofern bemerkbar, dass der Dom 1917 zwei seiner 1908 gegossenen Glocken abgeben musste. Sie wurden ebenso wie die 1864 gegossene Glocke aus dem Höckrigen Turm eingeschmolzen. ${ }^{16}$

\section{Die Novemberrevolution 1918 und ihre Folgen}

Die konservativen und königstreuen Mitglieder konnten nicht verstehen, warum die hergebrachte Herrschaftsordnung durch die Revolution 1918 gestürzt wurde. Sie waren entsetzt, das Ende der Monarchie, die Einführung der Republik und die Trennung von Staat und Kirche miterleben zu müssen. Die Evangelisch-Lutherische Landeskirche Sachsens war nicht mehr die Staatskirche und

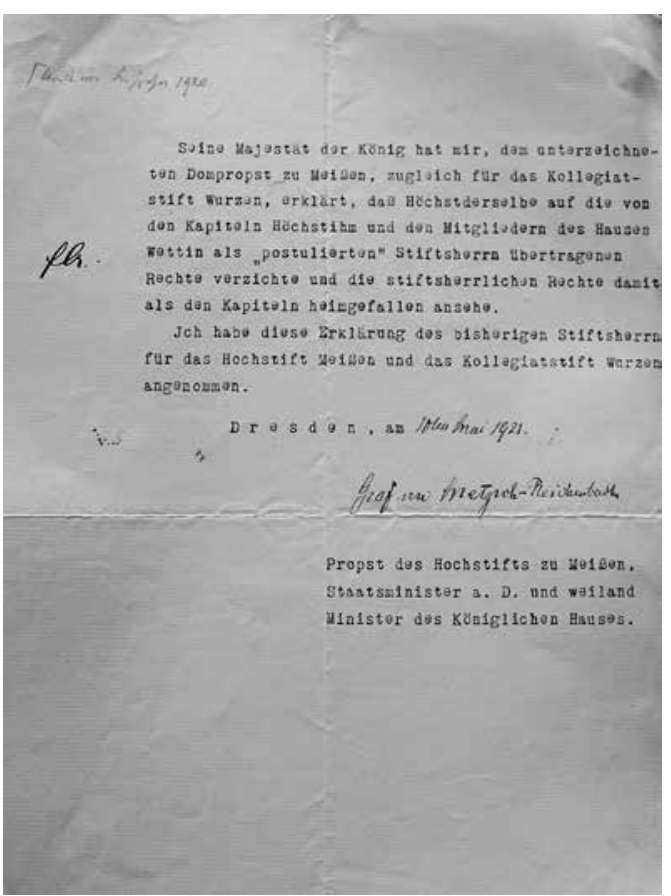

damit auch nicht mehr privilegiert. Sie musste ihre innere Ordnung neu regeln.

Nach dem Thronverzicht Friedrich Augusts III. und der Ausrufung der Republik war zu fragen, ob der vormalige König Stiftsherr des Hochstifts Meißen geblieben war. Dompropst Georg Graf von Metzsch-Reichenbach, der Minister des Königlichen Hauses, hatte die Revolution in unmittelbarer Nähe des Königs miterlebt. Er gehörte auch nach 1918 zum Hofstaat, den der frühere Monarch weiterhin um sich scharte. Er fragte Friedrich August und erhielt von diesem die Aussage, dass er und die Mitglieder des Königshauses auf die stiftsherrlichen Rechte verzichteten. Das legte MetzschReichenbach in einer Erklärung vom 10. Mai 1921 mit folgendem Wortlaut nieder: „Seine Majestät der König hat mir, dem unterzeichneten Dompropst zu Meißen, zugleich für das Kollegiatstift zu Wurzen, schon in dem Jahre 1920 erklärt, daß Höchstderselbe auf die von den Kapiteln Höchstihm und den Mitgliedern des Hauses Wettin als ,postulierten' Stiftsherrn übertragene Rechte verzichte und die stiftsherrlichen Rechte damit als den Kapiteln heimgefallen ansehe."

Von Seiten des Ministeriums für Kultus und öffentlichen Unterricht (später Ministerium für Volksbildung) gab es Überlegungen, das Hochstift Meißen und das Kollegiatstift Wurzen aufzulösen und das Vermögen der Staatskasse zu übertragen. Das gründete sich auf die Rechtsauffassung, dass mit dem Ende der Monarchie die Rechte des Stiftsherrn auf das Volk übergangen seien. Wenn die Staatsgewalt vom Volk ausgehe, dann sei die vom Volk eingesetzte Regierung berechtigt, die Vermögenswerte zugunsten des Staates einzuziehen. Um die Rechtslage zu prüfen, beauftragte das Ministerium am 8. Oktober 1920 die Juristische Fakultät der Universität Leipzig mit der Erstellung eines Gutachtens. Die Bearbeitung übernahm Prof. Dr. Alfred Schultze (1864-1946), der später - auch als Dank für seine Verdienste um den Erhalt des Hochstifts Meißen - in das Domkapitel aufgenommen wurde. In dem ausführlichen Gutachten vom 3. Dezember $1921^{17}$ argumentierte er, dass die stiftsherrlichen Rechte des Landesfürsten nie Bestandteil der Staatsgewalt gewesen waren und auch nie dem Staatsoberhaupt als solchem zustanden. Vielmehr habe die Kirche diese Rechte durch Verträge - erst durch die Schutzverträge der Bischöfe von Meißen, später durch die Kapitulation von 1581 und die Perpetuierliche Kapitulation von 1663 - dem Landesfürsten eingeräumt. Mit dem Ende der Monarchie sei die Stellung des Stiftsherrn weggefallen, ohne dass es dazu einer Erklärung oder eines Verzichts des früheren Stiftsherrn bedurfte. Die Rechte seien damit an das Muttergemeinwesen des Hochstifts Meißen, das evangelisch-lutherische Kirchenwesen, zurückgefallen. Das Domkapitel habe daher das Recht, einen neuen Stiftsherrn zu ernennen und seine inneren Angelegenheiten ohne Beteiligung des Staates selbst zu regeln. Diese Argumentation überzeugte die Verantwortlichen in der sächsischen Regierung. 
Am 9. Januar 1923 teilte das Kultusministerium mit, dass es den evangelischen Stiftern Meißen und Wurzen die Neuordnung ihrer inneren Angelegenheiten selbst überlasse.

Dieses Ergebnis führte dazu, dass das Domkapitel und die Landeskirche in Verhandlungen über eine Neuregelung ihrer Beziehungen eintraten. Diese hatte nach dem Ende des landesherrlichen Kirchenregiments eine neue Verfassung erhalten. 1922 war der Meißner Domherr Dr. Ludwig Ihmels zum ersten Landesbischof der EvangelischLutherischen Landeskirche Sachsens gewählt worden. Die Landeskirche hatte sich aber nicht entschlossen, den Meißner Dom zu ihrer Bischofskirche zu machen. Vielmehr wurde die Sophienkirche, die frühere evangelische Hofkirche, die Hauptkirche des Bischofs. ${ }^{18}$

In Meißen wurde mit großer Sorge betrachtet, dass Papst Benedikt XV. (1854-1922) am 4. Juni 1921 die Apostolische Präfektur Meißen zum neuen Bistum Meißen erhoben hatte. Der Sitz blieb in Bautzen, das Domkapitel St. Petri in Bautzen wurde zum Domkapitel des neuen Bistums erhoben. Damit gab es wieder eine katholische Kirchenorganisation in Sachsen und mit dem am 18. September 1921 eingeführten Christian Schreiber (18721933) auch einen Bischof von Meißen. Nach außen wurde diese Neugründung einer katholischen Diözese als „Wiedergründung des Bistums Meißen“ dargestellt. Der Anspruch, das alte Bistum Meißen fortzusetzen, und die Verwendung des Namens „Meißen“ lösten die Besorgnis aus, die katholische Kirche wolle den Dom zu Meißen in Besitz nehmen und zum Bischofssitz machen. Insbesondere der Meißner Superintendent Dr. Arthur Neuberg schürte diese Angst. In einem wohl von ihm lancierten Artikel im „Meißner Tageblatt“ vom 11. August 1921 heißt es: „Die evangelischen Kreise Sachsens glauben daher mit der Möglichkeit rechnen zu müssen, daß von Rom aus systematisch angelegte Versuche zur ,Wiedereroberung des verlorengegangenen Sachsenlandes' unternommen werden, daß man Bautzen sagt und Meißen meint. Das heißt, daß man sich in katholischen Kreisen mit dem Gedanken befaßt, den wundervollen Meißner Dom und die angrenzenden Wohngebäude zu einem repräsentativen Bischofssitz zu machen."

Durch die Inflation verlor das Meißner Domkapitel nahezu sein gesamtes Vermögen, das mit Ausnahme der drei Häuser am Meißner Domplatz und der Ländereien der Bautzener Propstei nur aus Kapitalien und Wertpapieren bestanden hatte. Durch die Abwertung der Mark waren die Wertpapiere und Schuldverschreibungen praktisch wertlos. Es konnten keine Präbenden mehr gezahlt und keine Stipendien mehr ausgegeben werden.

\section{Die Verfassung des Hochstifts}

Meißen von 1924

Die Neuordnung der inneren und äußeren Ordnung erfolgte mit einem Abkommen, das am 30.
April 1924 zwischen dem Domkapitel des Hochstifts Meißen und der „einstweiligen Führung des Kirchenregiments" geschlossen wurde. Dr. Franz Böhme (1856-1932), der Präsident des Landeskonsistoriums, vertrat die Kirchenleitung und Domdechant Dr. Heinrich Gustav von Beck das Domkapitel. Das Kirchenregimente erkannte an, dass das Domkapitel eine „kirchliche Körperschaft öffentlichen Rechts in der sächsischen Landeskirche“ sei. Die Landeskirche werde den Schutz des Hochstifts ausüben und versprach die „tunlichste Förderung seiner stiftungsmäßigen Interessen“. Diesem Abkommen folgend, beschloss das Domkapitel am 12. Oktober 1924 eine neue Verfassung des Hochstifts Meißen. Der Inhalt des Abkommen wurde mit Kirchengesetz vom 4. November 1924 genehmigt.

Die Verfassung ersetzte den Reformvertrag vom 15. Dezember $1859 / 25$. Februar 1860 und alle älteren Verträge und Ordnungen. Sie definierte das Hochstift Meißen als „evangelisch-lutherisches Stift der sächsischen evangelisch-lutherischen Landeskirche“ und als „kirchliche Körperschaft des öffentlichen Rechts“ in der Landeskirche, die wiederum selbst eine eigene Körperschaft des öffentlichen Rechts darstellte. Somit war das Hochstift Meißen einerseits eine Einrichtung neben der Landeskirche, andererseits eine Einrichtung in der Landeskirche. Die gesetzliche Vertretung und Verwaltung des Hochstifts war Aufgabe des Domkapitels. Die Frage der Stiftsherrschaft wurde wie folgt geregelt: „Die Wahl des Stiftsherrn steht dem Domkapitel frei. Bis auf weiteres wird die Stiftsherrschaft dem jeweiligen Landesbischof der evangelisch-lutherischen Landeskirche für die Dauer seines Amtes übertragen.“ Damit wurde Landesbischof Dr. Ludwig Ihmels 1924 der erste nichtfürstliche Stiftsherr des Hochstifts Meißen.

Die acht Stellen im Domkapitel und die bisher üblichen Rangstufen blieben erhalten, die Bedingungen an eine Aufnahme etwas modifiziert: „Die Verleihung von Kapitelstellen erfolgt nur an her-

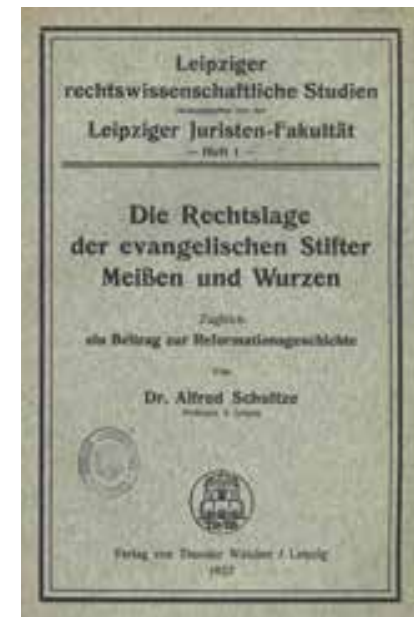

Buchtitel des Gutachtens von Alfred Schultze zur Rechtslage der Stifter Meißen und Wurzen, 1922 - SLUB Dresden
Verfassung und Ordnungen des Hochstifts Meißen, 1937

(๑) Hochstift Meißen 
19 Seifert 1997 (wie Anm. 9), S. 348.

20 Seyler (wie Anm. 9), S. 110113. vorragende, um die Landeskirche verdiente Mitglieder derselben. Außerdem sind Erfordernisse für die Zugehörigkeit zum Domkapitel sächsische Staatsangehörigkeit, die Erfüllung des 30. Lebensjahres und in der Regel ein durch eine Prüfung abgeschlossenes akademisches Studium." Der Wahlvorgang sollte wie bisher erfolgen, indem das Domkapitel dem Stiftsherrn drei Namen vorschlug und der Stiftsherr einen davon zum Domherrn ernannte. Der Propst, der Dechant, der Propst zu Bautzen und die übrigen Kapitelämter waren vom Kapitel aus den Reihen der Domherren zu wählen. Hier ergab sich insofern eine Änderung, weil der Propst zu Bautzen bisher ohne Wahl durch das Domkapitel vom Stiftsherrn ernannt worden war. Die Mitglieder des Domkapitels erhielten weiterhin Präbenden aus dem Präbendenfonds. Als Aufgaben des Hochstifts und Domkapitels definierte die Verfassung „die Unterhaltung des Domes und der dem Hochstifte gehörigen Gebäude, die Fürsorge für den evangelisch-lutherischen Gottesdienst im Dome, die Verwaltung der ihm unterstellten Stipendien und die Ausübung seiner Patronats- und Kollaturrechte“.

Das Ministerium für Volksbildung bestätigte am 19. Januar 1925 den Empfang der Verfassung des Hochstifts Meißen vom 12. Oktober 1924. Indem es keinen Widerspruch äußerte und auch keine Zustimmung des Staates einforderte, war hinsichtlich des Hochstifts Meißen die Trennung von Staat und Kirche vollzogen.

Nur eine Institution meldete Protest an. Das katholische Domstift St. Petri in Bautzen erhob beim Landeskonsistorium Einspruch gegen das Kirchengesetz. Dieser bezog sich auf die Regelung, dass das Meißner Domkapitel die Bautzener Propsteistelle besetzen dürfe, was bislang eine Aufgabe des Landesfürsten als Stiftsherrn gewesen war. Die katholische Seite argumentierte, dass nach dem Artikel 137 der Weimarer Reichsverfassung jede Religionsgesellschaft ihre Angelegenheiten selbständig ordnen und verwalten dürfe. Außerdem sei mit der Erhebung des Kollegiatkapitels zum Kathedralkapitel des wiedererrichteten Bistums Meißen eine neue Rechtslage eingetreten. Das Bautzener Domkapitel widerrief daher das Abkommen von 1871, entzog dem Meißner Domkapitel die Verwaltung der Propstei Bautzen und forderte die überlassenen Vermögenswerte $\mathrm{zu}$ rück. ${ }^{19}$ Gegen die Verpachtung der Propsteifelder konnte das Bautzener Domkapitel indes nicht vorgehen, weil die Verträge direkt zwischen dem Hochstift Meißen als dem im Grundbuch eingetragenen Inhaber des Nießbrauchsrechts und den Pächtern geschlossen worden waren.

Um dem Einspruch zu begegnen, holte das Domkapitel ein juristisches Gutachten des ehemaligen Dresdner Ministerialdirektors Dr. Walter Schelcher ein. Dieser zeigte am 10. Februar 1925 zwei Wege auf, wie das fortbestehende Recht des Hochstifts Meißen an der Bautzener Propstei zu begründen sei. Zum einen könne man nach Alfred Schultze argumentieren, dass die stiftsherrlichen Rechte nach dem Ende der Monarchie an die evangelische Kirche zurückgefallen und nun einem neuen Stiftsherrn übertragen worden seien. Zum anderen könne das Ernennungsrecht als dem Staat zugehörig betrachtet werden. Dann sei es bei der Trennung von Kirche und Staat dem Hochstift Meißen übertragen worden. Schelcher kam zu dem Schluss: „Die Einrichtung und der Bestand der Dompropsteistelle zu Bautzen an sich ist Angelegenheit des katholischen Domstifts S. Petri zu Bautzen, also der katholischen Kirche, ihre Besetzung aber aus der Mitte der Meissner Domherren eine Angelegenheit des Hochstiftes Meißen und damit der ev. luth. Kirche.“ 1930 nahm der Referendar Johannes Heinrich Seyler nochmals eine juristische Bewertung vor. Er legte dar, dass das Propstamt gemäß dem Westfälischen Frieden und dem sächsischen Katholikenmandat von 1807 zu den Benefizien der evangelischen-lutherischen Landeskirche gehöre. Daran habe auch die Reichsverfassung nichts geändert. Diese schütze sogar dieses Recht der Landeskirche auf die Propstei. Das Ernennungs- und Besetzungsrecht sei durch das Abkommen von 1924 auf den Landesbischof auf Stiftsherrn übergegangen, der es jedoch dem Domkapitel abgetreten habe. ${ }^{20}$ Infolge dieser juristischen Bewertungen blieben die Vermögenswerte der Propstei Bautzen in den Händen des Meißner Domkapitels.

Als 1927 das Meißner Domkapitel die Wahl des Domherrn Carl von Kirchbach zum Bautzener Dompropst anzeigte, antwortete das Domkapitel St. Petri, dass es die Wahl nach den Vorschriften des kirchlichen Gesetzbuchs nicht anerkenne. Auch verweigerte es die Installation, wie sie zuletzt 1914 nach der Ernennung des Bautzener Propstes Dr. Rudolf von Oppen vorgenommen worden war. Das Landeskonsistorium wiederum teilte dem Domkapitel St. Petri mit, dass es der Anerkennung der Wahl seitens des Bautzener Kapitels überhaupt nicht bedürfe, worauf die katholische Seite wiederum protestierte. Beide Seiten blieben bei ihrer Rechtsauffassung.

\section{Domkapitel, Domverwaltung und Domgottesdienst zwischen 1924 und 1945}

Die Verfassung vom 12. Oktober 1924 und die Einführung des Landesbischofs Ihmels zum Stiftsherrn ermöglichten es, freigewordene Kapitelstellen wieder zu besetzen. Die früheren Minister und Spitzenbeamten des Königreichs Sachsen schieden durch Tod aus dem Kapitel aus: 1927 Georg Graf von Metzsch-Reichenbach, 1929 Carl von Kirchbach, 1933 Dr. Heinrich Gustav von Beck. Es rückten aber überwiegend nichtadlige Personen nach: Ministerialdirektor Dr. Georg Schmaltz, ein früherer Mitarbeiter des Ministers Dr. Beck, Prof. Dr. Alfred Schultze, Jurist an der Universität Leipzig, Otto Hartlich, der Rektor der Landesschule St. Afra, und Gymnasialprofessor Prof. Dr. Hugo Hickmann, Vizepräsident der Synode der sächsischen Landeskirche und Abgeordneter der natio- 
nalliberalen Deutschen Volkspartei (DVP) im sächsischen Landtag. Die Domherrenstellen der Theologischen Fakultät der Universität Leipzig nahmen Prof. Dr. Karl Otto Frenzel (1865-1934), Prof. Dr. Hans Haas (1868-1934), Prof. Dr. Frantz Rendtorff (1860-1937), Prof. Dr. Albrecht Alt (1883-1956) und Prof. Dr. Johannes Leipoldt (1880-1965) ein. Die einzigen Adligen, die in der Zwischenkriegszeit in das Domkapitel eintraten, waren 1926 Dr. Alfred Freiherr von Welck (18661963), ein Mann mit großer Verwaltungserfahrung, vor 1929 Woldemar Graf Vitzthum von Eckstädt (1863-1936), der Präsident der Landessynode, und 1929 Dr. Benno von Heynitz (18871979), der Besitzer des Ritterguts Heynitz bei Meißen. Diesem Wandel folgend, wurde Georg Schmaltz als erster Nichtadliger in ein höheres Kapitelamt gewählt. Er war von 1928 bis 1933 Dechant und von 1933 bis 1940 Propst. Nach seinem Tod war die Spitze des Domkapitels allerdings wieder in adliger Hand: Dr. Alfred Freiherr von Welck war seit 1933 Domdechant und seit 1941 Dompropst. Ihm folgte Dr. Benno von Heynitz als Domdechant nach.

Das Domkapitel traf sich oft mehrmals im Jahr, um Beschlüsse zu fassen, nicht nur in Meißen, sondern auch in Dresden. Der wichtigste Kapiteltag fand, wie früher schon, am Sonntag Exaudi in Meißen statt. Er wurde mit einem Festmahl beendet, zu dem auch Dompfarrer, Domprediger, Domkantor, Dombaumeister, Stiftssyndikus und Stiftssekretär geladen waren.

Das Kapitalvermögen des Domkapitels erhöhte sich durch Aufwertung wertlos gewordener Wertpapiere und Schuldverschreibungen. Dieser Prozess der Umwandlung alter in neuer Wertpapiere dauerte mehrere Jahre. Der Präbendenfonds erhielt etwa die Hälfte seines Vorkriegsvermögens zurück. Bereits 1930 erbrachte er wieder einen Jahresertrag von 8.469,89 Reichsmark. Gemäß der Verfassung von 1924 wurde dieser Ertrag in elf Anteile geteilt, die sogenannten Kopfteile. Die einfachen Domherren erhielten ein Kopfteil, die Prälaten (Dompropst, Domdechant, Propst zu Bautzen) zwei Kopfteile. 1930 betrug ein Kopfteil 704,30 Reichsmark, 1932 stieg dieser Betrag auf 769,99 Reichsmark. Die Auszahlung der Prokuraturrente wurde nach der Revolution vom Volksbildungsministerium zunächst verweigert. Nach Einspruch und Hinweis auf die Rechtslage bot das Ministerium an, ab 1929 jährlich 2.000 Reichsmark in zwei Raten zu bezahlen. Ab der zweiten Jahreshälfte 1940 verweigerte das Ministerium jedoch die Zahlung. Sie wurde 1950 wieder aufgenommen, dann aber endgültig eingestellt.

Die Stiftungen profitierten ebenfalls von der Aufwertung, doch waren die verbliebenen Vermögen zu gering, um erneut Stipendien ausgeben zu können. Daher wurde 1938 der Vereinigte Stiftungsstock der Gersdorff-, Haugwitz-, Knoch-, Mergenthal- und Rüdigerstiftung des Hochstifts Meißen gebildet. Die Erträge der zusammengelegten Einzelvermögen waren zu 3/12 für Stipendien auszu- geben. 1/12 fiel dem Präbendenfonds, 4/12 der Baumeistereikasse zu und 4/12 waren als Rücklage anzusparen. Nach dieser Neuordnung konnten 1939 erstmals wieder zwei Stipendien vergeben werden. Seit 1942 vergab das Domkapitel keine Stipendien mehr, und aufgrund des weiteren Vermögensverlustes konnte diese traditionelle Aufgabe auch nach dem Krieg nicht wiederbelebt werden.

Aus der Baumeistereikasse waren die Erhaltung des Doms, aber auch der gesamte Verwaltungsaufwand zu begleichen. Seit Ende des 19. Jahrhunderts war der Direktor des Amtsgerichts Meißen im Nebenamt zugleich Syndikus des Hochstifts Meißen. Die täglichen Verwaltungsaufgaben nahm ein Beamter des Amtsgerichts ebenfalls im Nebenamt wahr. Nach mehreren Vertretungen wurde der 1923 nach Meißen versetzte Amtsgerichtsdirektor Dr. Müller zum Stiftssyndikus berufen. Dieser war Mitglied der linksliberalen Deutschen Demokratischen Partei (DDP), weshalb er 1933 von den Nationalsozialisten abgesetzt wurde. Dafür kam Oberlandesgerichtsrat Gottfried von Hopffgarten (1877-1945) nach Meißen, der als Direktor des Amtsgerichts zugleich zum Stiftssyndikus berufen wurde. Er bezog die Dienstwohnung des Syndikus im Haus Domplatz 5 und erhielt eine jährliche Vergütung von 890,00 Reichsmark. Hopffgarten war von 1923 bis 1939 Mitglied der Synode der sächsischen Landeskirche gewesen. Als Stiftssekretär führte über viele Jahre der Justizamtssekretär und spätere Justizrentmeister Alfred Vetterling (gest. 1946) die laufenden Verwaltungsgeschäfte. Infolge der Inflation war das Vermögen der Baumeistereikasse stark zusammengeschmolzen. Die wichtigste Einnahme waren die Führungsgelder, denn nach dem Ersten Weltkrieg und der Nachkriegswirren hatte sich der Meißner Dom zu einem beliebten touristischen Anziehungspunkt entwickelt. Wer den Meißner Dom besuchen wollte, musste sich einer Domführung anschließen. Das Führungsgeschäft oblag dem Domküster. Er erhielt monatlich 246,06 Reichsmark und 20 Prozent der Führungsgelder, musste davon aber die Hilfskräfte bezahlen, die ihn bei den Führungen unterstützte. 1933 hatte Domküster Julius Schubert drei Hilfskräfte angestellt. Nach Abzug des Küsteranteils fielen der Baumeistereikasse 9.287,07 Reichsmark zu. Nach Abzug der Verwaltungskosten blieb nur wenig Geld für die Erhaltung und Heizung des Doms übrig. Daher bezog das Hochstift Meißen vom Landeskonsistorium eine Heizungsbeihilfe in Höhe von 2.000,00, später 3.000,00 Reichsmark.

Im Meißner Dom wurde jeden Sonntag Gottesdienst gefeiert. Die Regelung von 1916 über das Dompfarramt blieb bestehen. Der erste Dompfarrer, Superintendent Dr. Arthur Neuberg, trat 1932 in den Ruhestand. Sein Nachfolger wurde Herbert Böhme (1879-1971). Der Dompfarrer hatte gemäß Beschluss des Landeskonsistoriums vom 26. April 1924 in der Regel einmal monatlich zu predigen. Dafür erhielt er aus landeskirchlichen Mitteln

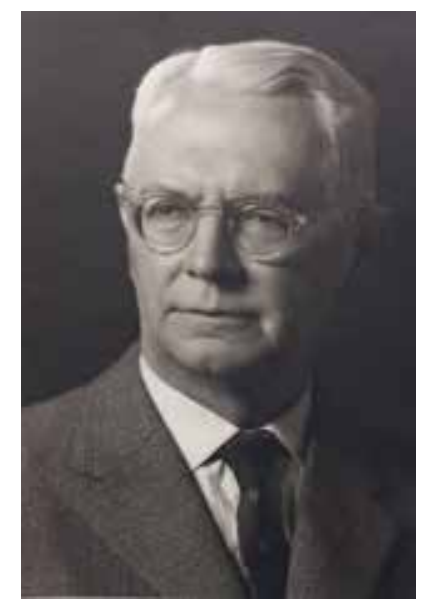

Domdechant Benno von Heynitz, vor 1945

(c) Hochstift Meißen 
Einholung der neu gegossenen Johannesglocke am 20. September 1929 auf dem Meißner Domplatz $\odot$ Hochstift Meißen

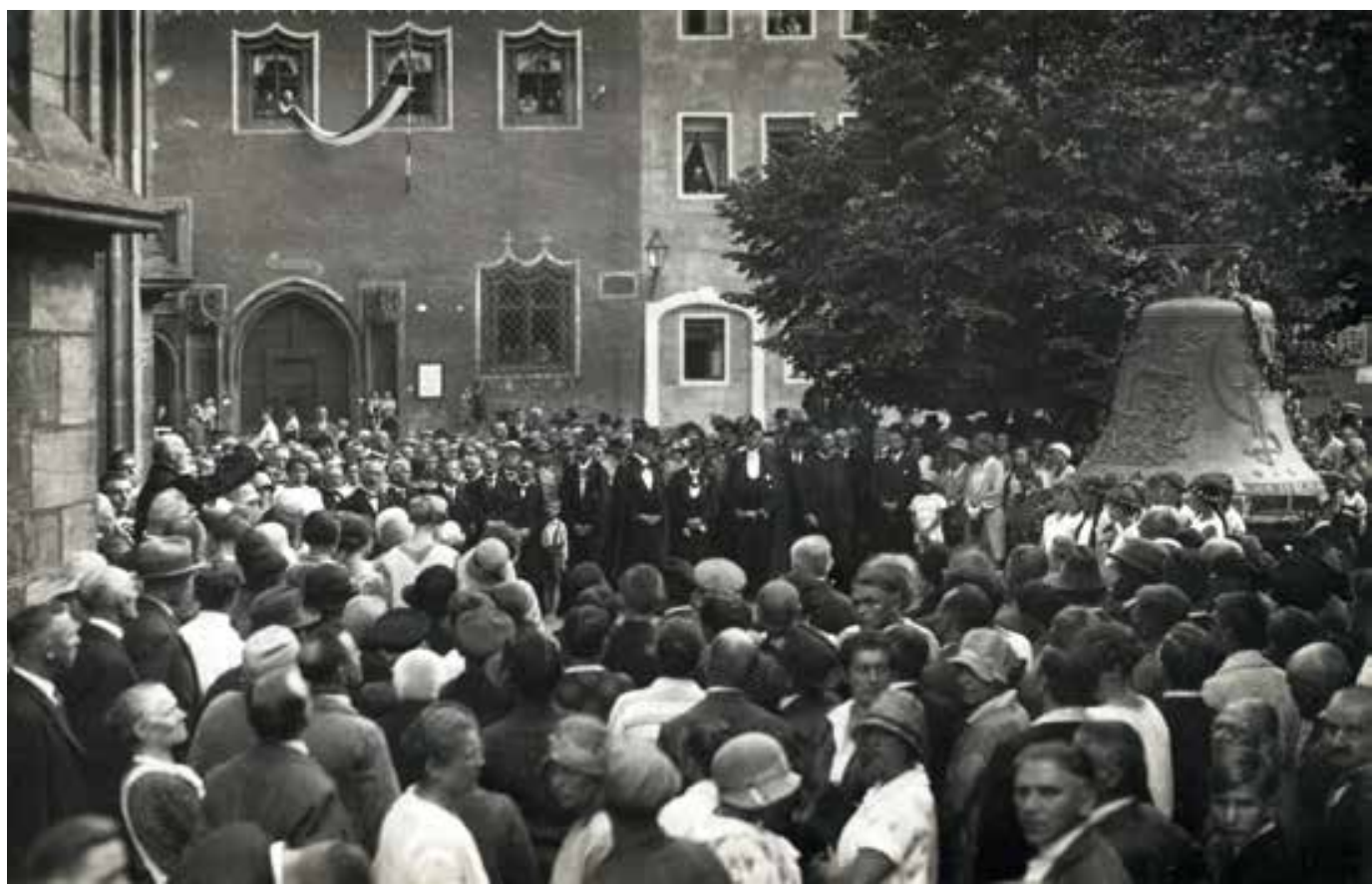

eine jährliche Sondervergütung von 300,00 Reichsmark. Die anderen Gottesdienste oblagen dem Domprediger, einem Pfarrer der Frauenkirche. Das waren von 1925 bis 1934 Max Karl Schröder (1871-1945) und 1935 bis 1947 Walter Pangritz (1888-1974). Die jährliche Sondervergütung des Dompredigers betrug 600,00 Reichsmark und kam ebenfalls aus Mitteln der Landeskirche. ${ }^{21}$

Für die öffentliche Wahrnehmung des Meißner Doms war die Jahrtausendfeier Meißens im Jahr 1929 von großer Bedeutung. Zu diesem Anlass erhielt der Dom ein neues Geläut, das die im Ersten Weltkrieg eingeschmolzenen Glocken ersetzte. ${ }^{22}$ Der Porzellankünstler Emil Paul Börner (18881970) verzierte die Glocken mit aufwendigen Reliefs. So erhielt der Meißner Dom mit der Johannesglocke die figurenreichste Glocke der Welt. Außerdem gab das Domkapitel eine eigene Festschrift zum Jubiläum heraus. ${ }^{23}$

Die Frage nach der sinnvollen Nutzung des Domes und nach einer Domgemeinde war nie zufriedenstellend beantwortet worden. 1921 schlug ein Beitrag im „Meißner Tageblatt“ vor, am Meißner Dom ein Predigerseminar der sächsischen Landeskirche einzurichten, doch wurde dieser Vorschlag von der Kirchenleitung nicht weiter verfolgt. Desgleichen blieb der 1945 von Superintendent Herbert Böhme geäußerte Vorschlag, in Meißen ein Kandidaten- oder Katechetenstift, also eine Ausbildungsstätte für Pfarrer oder Religionslehrer einzurichten, ohne Folgen.

Nach dem Ersten Weltkrieg wurden zwei Versuche unternommen, durch Gründung eines Dombauvereins dem Dom eine eigene Gemeinde zu geben. Der erste Dombauverein, der die Westturmanlage errichtet hatte, war 1918 voreilig aufgelöst worden. Am 20. September 1920 lud Studienrat Dr. Georg Fraustadt (1886-1968) von der Landesschule St. Afra zu einer Versammlung ein, um zu beraten, „welche Mittel und Wege sich finden lassen, um der Gefährdung der Erhaltung des Domes und des Domgottesdienstes rechtzeitig zu begegnen“. ${ }^{24}$ Da das Domkapitel nicht mehr in der Lage war, die „bauliche Unterhaltung des Domes und der übrigen dem Domstift gehörenden Gebäude aus Stiftsmitteln zu bestreiten“, beschloss man die Gründung eines Dombauvereins. Die Gründungsversammlung fand am 17. November 1922 im Meißner Ratssitzungssaal statt. Doch dem Verein, der am 11. Mai 1923 schon 149 Mitglieder hatte, war kein Erfolg beschieden. Die Mitgliedsbeiträge wurden von der Inflation gefressen und das Interesse erlosch. So wurde der Verein, der seit 1924 nur noch auf dem Papier bestand, am 24. Mai 1932 aufgelöst, wobei der Kassenbestand von 42,11 Mark dem Hochstift zufiel. 1934 wurde ein neuer Versuch der Vereinsgründung gewagt. Im Aufruf zur Gründung des Meißner Dombauvereins heißt es: „Der Dom steht allein. Es fehlt ihm der engere Zusammenhang mit dem kirchlichen und staatlichen Leben in Sachsen. Da er Stiftskirche ist und nicht Parochialkirche, kann er sich nicht auf eine Gemeinde stützen, die ihn mit innerer Anteilnahme und äusserer Hilfe trägt.“ Domherr von Welck rief dazu auf, einen Verein zu gründen, der die fehlende Gemeinde ersetzt. Das Vorhaben scheiterte an zu geringer Beteiligung.

Anfang der 1930er Jahre erhielt der Meißner Dom wieder einen Dombaumeister. ${ }^{25}$ In dieses Amt wurde der Dresdner Regierungsbaurat Hermann von Glaßer (1882-1939) berufen, der nebenberuflich den Dom betreute. 1942 folgte ihm der Architekt Dr.-Ing. Hubert Ermisch (1883-1951) nach, der sich bei der Restaurierung des Zwingers und des Japanischen Palais in Dresden einen Namen gemacht hatte. Er betreute auch die benachbarte Albrechtsburg. 


\section{Das Domkapitel und der Nationalsozialismus}

Die Mitglieder des Domkapitels in den 1930er Jahren waren gestandene Männer mit konservativen oder liberalen Überzeugungen. Im Königreich Sachsen groß geworden, standen sie revolutionären Neuerungen skeptisch gegenüber, erst recht, wenn sich diese Neuerungen auf die evangelische Kirche auswirken sollten. Diese konservative Position schützte sie vor dem Nationalsozialismus. Mit dem kam der Meißner Dom erstmals am 13. August 1931 in Berührung, als die Ortsgruppe Meißen der NSDAP beantragte, im Meißner Dom innerhalb des Gottesdienstes eine Totengedenkfeier abzuhalten. Das lehnte das Domkapitel mit Schreiben vom 24. August 1931 ab: „Das Domkapitel begrüßt es jederzeit mit Freude, wenn auf Grund ernster christlicher Gesinnung für eine Feier und insbesondere eine Totengedenkfeier die Weihe im Gotteshaus begehrt wird; doch kann einer solchen Feier nicht [...] der sonntägliche Hauptgottesdienst eingeräumt werden, der nach landeskirchlicher Vorschrift und Sitte vielmehr der ganzen evangelischen Gemeinde vorbehalten ist." Obwohl das Domkapitel an der „ernsten christlichen Gesinnung“ der NSDAP-Ortsgruppe zweifelte, erlaubte es einen Sondergottesdienst zum Gedächtnis der Gefallenen des Weltkriegs. Dieser fand am 15. November 1931 statt. Domprediger und Superintendent Dr. Arthur Neuberg hielt vor rund 200 uniformierten Nationalsozialisten eine Predigt, in der er sich dazu verstieg, Gewalt im politischen Kampf zu rechtfertigen. Offenbar in Anspielung auf den Tod des 21-jährigen Sozialdemokraten und Reichsbanner-Angehörigen Arno Wolf, der am 3. November 1931 von SA-Männern ermordet worden war, sagte Neuberg: „Und wenn im schweren Kampf der Gegenwart in der Notwehr auch einmal gegnerisches Blut fließt, so das schmerzlich und tief zu beklagen, und ihr beklagt es gewiß selbst. Aber vor allen Dingen geht ihr selbst mit Todesmut euren schweren Weg, das weiß jeder aufrichtige und verständige Mann. Darum, wenn ihr ein gutes Gewissen habt, so behüte euch Gott. Wer ein gutes Gewissen hat, kann getrost den schwersten Weg gehen." ${ }^{26}$ Zwei Tage später berichtete ein namentlich nicht genannter Teilnehmer dem Dechanten Dr. Schmaltz: „Der Kirchgang der Nationalsozialistin ist friedlich verlaufen. Auf dem Domplatze hielten sich nur Kirchgänger auf. In der Meissner Volkszeitung erschien bisher nur ,Gedanken zum Nazikirchgang', dagegen brachte das Meissener Tageblatt einen ausführlichen Bericht über die Predigt. Nach meinem politischen Geschmack hätte die Predigt etwas weniger politisch sein können, dann wäre wohl auch nicht so eingehend über sie berichtet worden. Ich befürchte, dass die Volkszeitung die Gelegenheit zu einem Angriffe auf die Kirche und vielleicht auch auf das Hochstift benutzen wird." Infolge dieser Predigt, die das Domkapitel im Nachhinein missbilligte, wurden weitere Sondergottesdienste dieser Art abgelehnt.
Die „Machtergreifung“ wirkte sich sogleich auch auf das Hochstift Meißen aus. Der arbeitslose Justizpraktikant Fritz Muntschick, der 1932 wegen einer Verfehlung seine Stelle beim Amtsgericht Meißen verloren hatte, richtete am 5. und 12. Mai ter Christ sowie als Nationalsozialist" Eingaben an das Landeskonsistorium, in denen er dem Domkapitel Verschwendung vorwarf. Stiftssyndikus und Stiftssekretär seien „Doppelverdiener“, der Domküster erhalte eine zu hohe Vergütung und das Domkapitel verprasse das Stiftungsvermögen, etwa beim Festmahl am Konventstag. Zudem erstattete Muntschick Anzeige bei der Staatsanwaltschaft Dresden. Domdechant Welck antwortete dem Landeskonsistoriums, der Denunziant handele aus „Rach- und Skandalsucht“. Am 26. Juli 1933 verfügte Pfarrer Friedrich Coch (1887-1945) im Namen des Landeskonsistoriums: „1. Ich stelle dem Domstift anheim, in Zukunft das Konventsmahl zu unterlassen. Bei der heute überaus großen Notlage breiter Bevölkerungskreise dürfte es nicht mehr verstanden werden. 2. Ferner gebe ich anheim, ob die Herren Mitglieder des Domstiftes 1933 ,als Kirchensteuer zahlender und überzeug-

21 Landeskirchenarchiv Dresden, Bestand 135, Nr. 6

22 Peter 2011/2012 (wie Anm. 16), S. $12-17$.

23 Der Dom zu Meißen. Festschrift des Hochstifts Meißen 1929. Dresden 1929.

24 Günter Donath: Das Ringen um die Erhaltung der Meißner Domtürme. In: Günter Donath/Matthias Donath (Hrsg.): Himmelszeichen. 100 Jahre Meißner Domtürme. Meißen 2008, S. 250265, hier S. 252

25 Donath 2008 (wie Anm. 8), S. 252-253.

26 Dazu Steinecke 2007/2008 (wie Anm. 6), S. 153.

Silvestergottesdienst im Meißner Dom, undatiert, möglicherweise 1929 zu 1000-Jahrfeier Meißens ๑ SLUB Dresden, Deutsche Fotothek, Foto: Johannes Müller

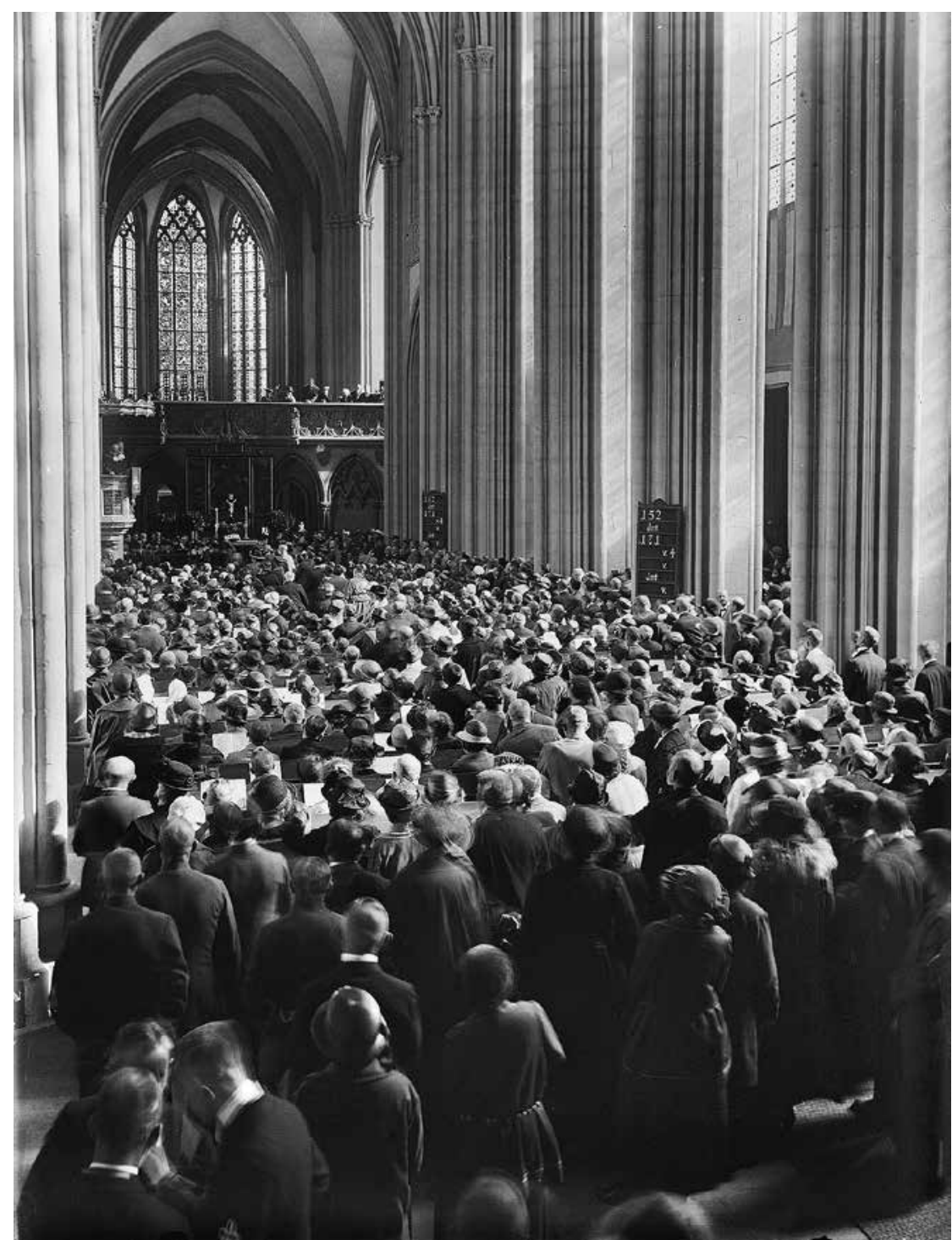


Gottesdienst im Meißner Dom, wohl zum Heldengedenktag 1934

๑ Archiv Gerhard Steinecke, Meißen

27 Vgl. Joachim Fischer: Die sächsische Landeskirche im Kirchenkampf. Halle/Saale 1972, S. 15-18.

28 Vgl. Steinecke 2007/2008, S. $156-157$

29 Vgl. Fischer 1972, S. 85-88; Gerhard Lindemann: Johannes Klotsche. Ein Vertrauensmann Mutschmanns an der Spitze der Landeskirche. In: Christine Pieper/Mike Schmeitzner/Gerhard Naser (Hrsg.): Braune Karrieren. NS-Protagonisten in Sachsen am Beispiel Dresdens. Dresden 2012, S. 208-213.

30 Vgl. Steinecke 2007/2008 (wie Anm. 6), S. 160-162; Peter 2011/2012 (wie Anm. 16), S. 15 nicht freiwillig auf ihre Anteile aus dem Präbendenfonds verzichten könnten, damit das Domstift ohne Beihilfe des Landeskonsistoriums getragen werden kann." Damit war klar, dass Coch das Domkapitel als eine überkommene Einrichtung betrachtete.

Eben diesem Friedrich Coch hatte der Innenminister Dr. Karl Fritsch am 1. Juli 1933 nach dem Tod des ersten Landesbischofs Dr. Ihmels alle Vollmachten und Rechte der Kirchenleitung übertragen. Am 11. August wurde Coch, der schon 1931 Mitglied der NSDAP geworden war, von der „braunen Synode“ in Dresden zum Landesbischof gewählt. ${ }^{27}$ Am 27. September 1933 beschloss das Kapitel, gemäß der Verfassung dem neuen Landesbischof das Amt des Stiftsherrn anzutragen. Der Gottesdienst $\mathrm{zu}$ seiner Einführung sollte am 19. November 1933 stattfinden und aus Anlass von Martin Luthers 350. Geburtstag als Lutherfeier gestaltet sein. Bei einer Besprechung im Landeskirchenamt hatte Coch am 20. Oktober seiner Verpflichtung als Stiftsherr zugestimmt. Wie es weiter ging, berichtete Domdechant Welck zum Jahresende 1933: „Am 16.11. - 3 Tage vor der geplanten Lutherfeier - wurde uns im Auftrag des Landesbischofs mitgeteilt, dass er sich bis zu einer grundsätzlichen Klärung der Kapitelfrage jeder officiellen und inofficiellen Beteiligung am Kapitel fernhalten möchte“. Später hielt er fest: „Die uns in Aussicht gestellte Begründung ist er uns schuldig geblieben. Der Beschluß, ihm die Stiftsherrschaft anzutragen, hat damit seine tatsächliche Erledigung gefunden.“ Damit entfiel Cochs Einführung, und dem Meißner Dom blieb eine Vereinnahmung durch die Deutschen Christen erspart. Doch zugleich geriet das Hochstift in eine Verfassungskrise, da ohne einen Stiftsherrn keine neuen Domherren ernannt werden konnten.

Die Glaubensbewegung „Deutschen Christen“, zu der Friedrich Coch gehörte, strebte ein „arisches Christentum“ und eine Einführung des Führerund Rassegedankens in der evangelischen Kirche an. Gegen die nationalsozialistische Vereinnahmung der Kirche und die Verfälschung der christlichen Lehre richtete sich die Bekennende Kirche, die aus dem 1933 gebildeten Pfarrer-Notbund entstand. Die Mehrheit der Domherren und Stiftssyndikus Hopffgarten gehörten der Bekennenden Kirche an oder neigten ihr zu. Losungen wie „Mit Luther und Hitler für Glaube und Volkstum“ und die Überlassung des Meißner Doms an Deutsche Christen lehnten sie ab. Lediglich Prof. Dr. Johannes Leipoldt war Befürworter der Deutschen Christen. Allerdings hatte er insofern unter der NS-Ideologie zu leiden, als dass seine Frau Käte Leipoldt, die psychische Probleme hatte, im Rahmen des Euthanasie-Programms am 29. Januar 1941 in Pirna-Sonnenstein getötet wurde. Hugo Hickmann konnte den neuen Machthabern schon deshalb keine Sympathie entgegenbringen, weil er als Mitglied einer der „Systemparteien“ der Weimarer Republik 1933 seine Anstellung verloren und Berufsverbot erhalten hatte.

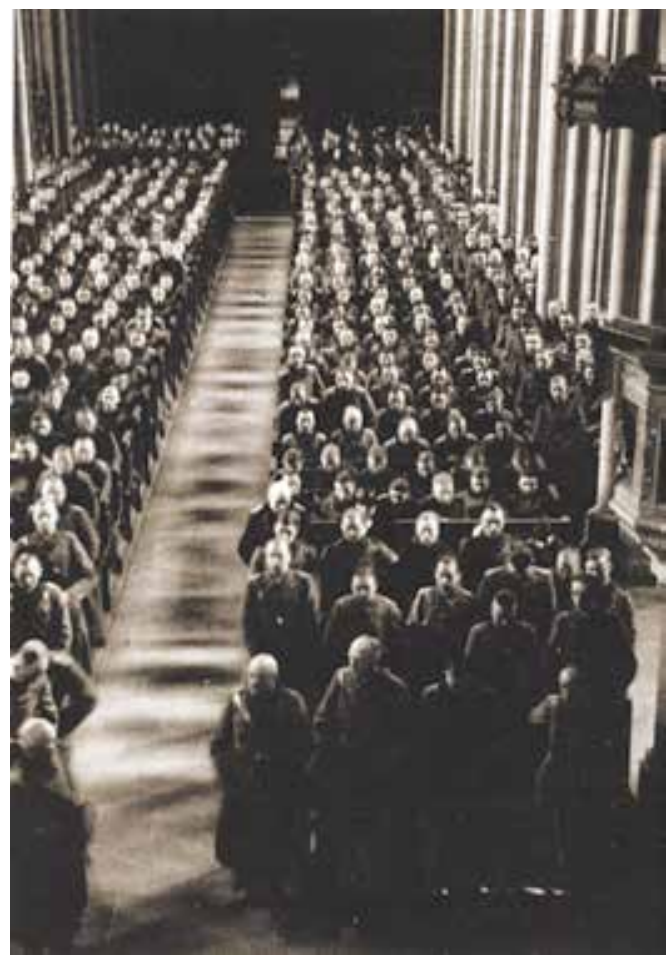

Als im Juni 1935 bekannt wurde, die Deutschen Christen wollten Reichsbischof Ludwig Müller (1883-1945), einer der führenden Köpfe ihrer Bewegung, zu einem Besuch im Meißner Dom bewegen, schrieb Domdechant von Welck an die Kapitelsmitglieder: „Ein Domgottesdienst mit dem Reichsbischof als Festprediger und mit Begrüßung desselben durch den Landesbischof nebst üblichem Gepränge (Spalierbildung auf dem Domplatz durch S. A. und Hitler-Jugend, Domgeläut, Begrüßung am Portal durch die Domgeistlichkeit) ist mit dem Kapitel ebenso undenkbar wie ohne dasselbe. Soll das Kapitel, mit dem der Landesbischof erklärt hat, jede offizielle und inoffizielle Berührung vermeiden zu wollen, ihn und den Reichsbischof begrüßen oder ohne Begrüßung es über sich ergehen lassen, wie die deutschen Christen tatsächlich vom Dome Besitz ergreifen, ja im Sinne der deutschen Christen von der Domkanzeln aus Propaganda gemacht wird?" Andererseits stellte er die Frage, ob es nicht ratsam und geboten sei, „den Übergang des bisher nur latenten Konflikts in einen akuten zu vermeiden?" Am 2. Juli 1935 beschloss das Domkapitel in Dresden: „Ein von den Deutschen Christen gestellter Antrag auf Ueberlassung des Domes ist im ablehnenden Sinn zu beantworten mit der Begründung, daß der Dom zu kirchenpolitischen Parteikundgebungen nicht zur Verfügung gestellt werden könne.“

Reichsbischof Müller kam doch nicht nach Meißen, dafür beantragte die Gebietsführung der Hitlerjugend in Dresden die Überlassung des Doms für eine Feier zu Hitlers Geburtstag am 20. April 1936. Landesbischof Coch hatte die Nutzung des Doms bereits genehmigt. Dagegen protestierte das Hochstift Meißen mit einem Schreiben vom 26. Februar an den Landeskirchenausschuss. Coch habe kein 
Recht, über den Dom zu verfügen. Allein das Domkapitel sei zur Vertretung des Hochstifts befugt. In einem Entwurf zu einem Brief an die Gebietsführung der HJ hießt es: „Es stellte sich nun aber leider heraus, daß nach den Grundsätzen, die für solche Hitlerjugend-Feiern von maßgebender Stelle festgesetzt sind, für das christliche Gepräge derselben keine Möglichkeit besteht. Unter diesen Umständen ist das Domkapitel zu seinem Bedauern nicht in der Lage, den Dom zu dem beabsichtigten weltlichen Zweck zur Verfügung zu stellen.“ Man spreche aber die Einladung zu einer ,jugendmäßig gestalteten gottesdienstlichen Feier für die Hitlerjugend" aus. Schließlich fuhren Domdechant, Dompropst und der Dresdner Superintendent Johannes Ficker (1861-1945) nach Berlin, um ihre Ablehnung im Reichskirchenministerium vorzubringen, doch hatte die Hitlerjugend ihren Antrag wieder zurückgezogen. Der Antrag der Deutschen Christen, am 18. September 1938 eine „Gottesfeier“ im Dom zu halten, lehnte das Kapitel ab.

Andere „Nazifeiern“ aber konnten nicht verhindert werden. Das Feiertagsgesetz vom 27. Februar 1934 hatte den Volkstrauertag in einen „Heldengedenktag“ umgewandelt. Entsprechend der bisherigen kirchlichen Ausrichtung des Volkstrauertags bot der Meißner Dom zum ersten „Heldengedenktag“ am 25. März 1934 einen Gottesdienst an, zu dem Dompfarrer Herbert Böhme die Predigt hielt. Dieser Gottesdienst war als Hauptveranstaltung dieses Gedenktags in Meißen ausgewiesen, weshalb Nationalsozialisten in Uniform die Bankreihen des Meißner Doms füllten. Die zunehmende Ablehnung der Kirche führte aber dann dazu, dass weitere Heldengedenkfeiern in weltlichem Rahmen stattfanden. Am 8. März 1936 blieb es bei einem Requiem und der Rede eines Kommandeurs, während zum Heldengedenktag am 21. Februar 1937 ein Aufmarsch auf dem Domplatz erfolgte, dessen Teilnehmer den Dom gar nicht mehr betraten. ${ }^{28}$

In Sachsen führte die Einsetzung eines Landeskirchenausschusses, dem Mitglieder verschiedener kirchlicher Gruppierungen angehörten, 1935 zu einer vorläufigen Beruhigung des „Kirchenkampfes“. Der Landeskirchenausschuss unter Vorsitz des Superintendenten Johannes Ficker, der selbst der Bekennenden Kirche angehörte, agierte als kollektive Kirchenleitung. Landesbischof Coch war seitdem weitgehend entmachtet. Am 13. März 1936 beschloss das Domkapitel, Johannes Ficker in seiner Eigenschaft als Vorsitzendem des Landeskirchenausschusses die Stiftsherrschaft anzutragen. Er stimmte zu und wurde zum Kapiteltag am 24. Mai 1936 verpflichtet. Um eine „Machtübernahme“ durch einen dem Domkapitel nicht gewogenen Landesbischof zu verhindern, vereinbarte das Domkapitel mit dem Landeskirchenausschuss eine Neuformulierung des $\S 2$ der Verfassung des Hochstifts Meißen, der die Stiftsherrschaft regelte. Die Neufassung vom 5. Juli 1937 lautete: „Wenn Fühlungnahme zwischen Kapitel und Kirchenregiment vor der Wahl Übereinstimmung ergeben hat, werden die in $\S 6$ des Abkommens dem Kirchenregiment eingeräumten Rechte durch den Stiftsherrn auf die Dauer seiner Stiftsherrschaft ausgeübt. Im übrigen hat sich das Kirchenregiment die Übertragung der ihm in $\S \S 5$ und 6 des Abkommens eingeräumten Rechte auf den Stiftsherrn vorbehalten." Das bedeutete, dass Rechte des Stiftsherrn, etwa die Ernennung neuer Domherren, auch von der Kirchenleitung ausgeübt werden durften.

Anfang August 1937 übernahm Johannes Klotsche (1895-1965), ein Vertrauensmann des Gauleiters Martin Mutschmann (1879-1947), die Herrschaft in der Evangelisch-Lutherischen Landeskirche Sachsens. ${ }^{29}$ Er entmachtete den Landeskirchenausschuss und wurde alleiniger Leiter der Landeskirche. Damit verlor Johannes Ficker bereits nach einem Jahr wieder sein Amt als Stiftsherr. Das Domkapitel beschloss nach diesem gescheiterten Versuch einer Neuregelung, die Frage der Stiftsherrschaft bis auf Weiteres ruhen zu lassen.

Domdechant Welck erwartete eine grundlegende Neuregelung nach Kriegsende. „Daß nach Beendigung des Krieges auch die Rechts- und Vermögensverhältnisse des Hochstiftes Meißen und des Kollegiatstiftes Wurzen zum Gegenstand von Erörterungen und Entschließungen der zuständigen kirchlichen und staatlichen Stellen gemacht werden, ist wahrscheinlich“, heißt es in seiner Denkschrift vom 10. August 1940. Er befürchtete stärkere Eingriffe des Staates nach dem Vorbild der Neuordnung der Domstifter in Preußen 1935. In seiner Denkschrift schlug er vor, die Stiftsherrschaft wegfallen zu lassen und neue Kapitelmitglieder durch den Dompropst nach Anhörung des Kapitels zu berufen. Präbendenfonds, Propstei Bautzen und Baumeistereikasse sollten zusammengelegt werden. Außerdem sprach er sich für einen Wegfall der Präbenden und ihren Ersatz durch eine Aufwandsentschädigung in Höhe von 600,00 Reichsmark im Jahr aus.

\section{Zusammenbruch und Neuanfang}

Zu Beginn des Krieges äußerte Welck in christlichnationaler Gesinnung, „daß Gott die Opfer [...] mit einem das Lebensrecht der Nation in vollem Ausmaß sicherstellenden Frieden krönen möge." Sein Schreiben zum Jahresende 1939 beendete er mit dem Gruß „Mit Gott für Volk und Vaterland.“ Die Kriegslage machte sich auch in Meißen bemerkbar. Es fehlten Heizstoffe, so dass die Gottesdienste in den Wintermonaten in die Domsakristei verlegt werden musste. Ab 1943 wurden Maßnahmen ergriffen, um die Kunstschätze vor Bombenangriffen zu schützen. Das Ostfenster im Hohen Chor wurde demontiert, die Stifterfiguren durch Holzverschläge verdeckt und das Domarchiv in die Dompropstei verlegt. Resignierend musste Dombaumeister Dr. Ermisch mit ansehen, dass das gesamte Domgeläut bis auf die kleinste Glocke abgenommen und zum Einschmelzen abtransportiert wurde. In den Nordwestturm hatte man zum Abtransport der großen Johannesglocke eine große Bresche einfügen müssen. ${ }^{30}$ 


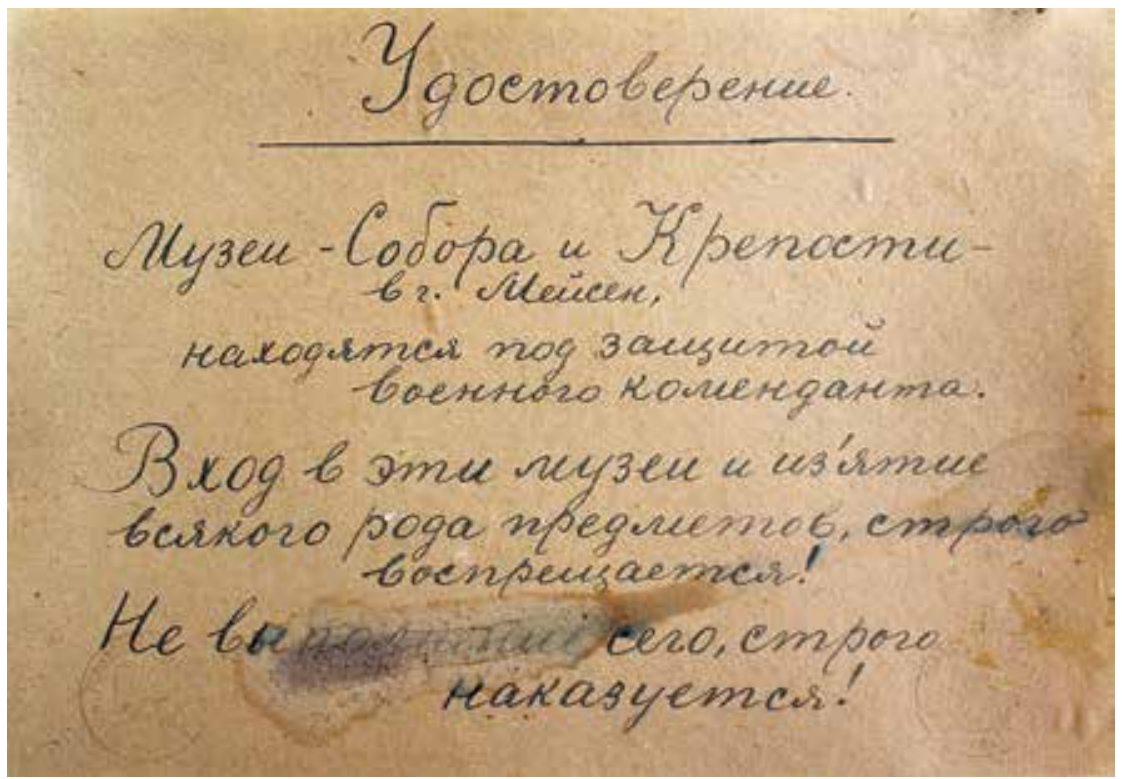

Schild zum Schutz des Doms mit russischer Beschriftung, Mai 1945

(c) Hochstift Meißen

31 Vgl. Steinecke 2007/2008 (wie Anm. 6), S. 165-166.

32 Vgl. Steinecke 2009/2010 (wie Anm. 6), S. 97

33 Vgl. Steinecke 2009/2010 (wie Anm. 6), S. 102-103.

34 Landeskirchenarchiv Dresden, Bestand 2, Nr. 209.

Domdechant Hugo Hickmann, vor 1955 ๑ Archiv Dieter Auerbach

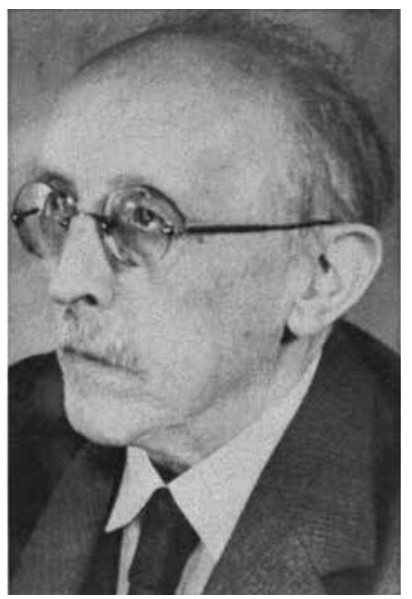

Lange schien es so, dass Meißen von Krieg verschont bleiben würde, doch ab dem 15. April 1945 wurde der Meißner Burgberg von der SS zur Verteidigungsstellung und zum „Eckpfeiler der Ostfront“ ausgebaut. ${ }^{31}$ Der Kampfkommandant, SSObersturmbannführer Voss, verfügte, den Elbübergang und die Stadt bis zum letzten Mann zu verteidigen. Burg und Dom sollten als letzter Kampfstand gehalten und im Notfall in die Luft gesprengt werden. Die Rote Armee erreichte am 24. April 1945 die Meißner Stadtteile rechts der Elbe und beschoss den Burgberg mit Artillerie. Dabei erhielt die Westturmfront des Meißner Doms mehrere Volltreffer. Um die völlige Zerstörung der Stadt zu verhindern, begab sich Dompfarrer Böhme, der bereits im Februar 1945 fünf geflohene belgische Zwangsarbeiter in der Dompropstei versteckt hatte, am 28. April 1945 mit zwei Vertretern der Meißner Kirchgemeinden zu Bürgermeister Kaule, um ihn zu bitten, sich für die Freigabe der Stadt einzusetzen. Gemeinsam sprachen sie beim Kommandeur der Waffen-SS auf der Albrechtsburg vor, der das Ansinnen ablehnte. Nachdem Böhme auf dem Markt eine Gruppe von Gemeindegliedern informiert hatte, wurde er vom NSDAPKreisleiter Helmut Böhme (1902-1945) festgenommen, der ihm Defätismus, Verrat und Zersetzung des Wehrwillens vorwarf. Er wollte ihn durch ein Standgericht zum Tod verurteilen, doch ein Urteilsspruch kam nicht zustande, weil sich die angefragten Juristen der Mitwirkung entzogen. So wurde Böhme am 2. Mai 1945 in das Landgerichtsgefängnis Dresden überführt, aus dem er mit Ende des Krieges freikam. Am 6. Mai 1945 besetzte die Rote Armee den bereits geräumten Burgberg und die Meißner Innenstadt ohne weitere Kämpfe.

Der 1950 in den Ruhestand getretene Herbert Böhme wurde 1956 auch in Würdigung seines Mutes bei Kriegsende in das Domkapitel aufgenommen. Er wollte aber von einer Ehrung als „,Retter Meißens“ nichts wissen. In einem an das Domkapitel gerichteten Bericht schrieb er: „Später bin ich wohl gelegentlich in der Zeitung in Hinsicht auf das hier geschilderte Geschehen als eine Art ,Retter von Meißen' angesprochen worden. Es ist mir lieb, hier ausdrücklich erklären zu können, daß mir ein Anspruch auf eine solche Einschätzung meines Schrittes fernliegt. Ich habe nur einen ernstgemeinten Versuch gemacht."

Die Gebäude am Domplatz waren im April 1945 geräumt worden, doch im Mai kehrten die Bewohner und ebenso die Domverwaltung wieder zurück. ${ }^{32}$ Am Dom hatte der sowjetische Militärkommandant eine russische Aufschrift angebracht, die das Baudenkmal vor Plünderungen schützen sollte. Die Aufschrift lautet in deutscher Übersetzung: „Die Museen - Dom und Burg - in der Stadt Meißen befinden sich unter dem Schutz des Militärkommandanten. Das Betreten und die Entnahme sämtlicher Gegenstände ist streng verboten! Jede Zuwiderhandlung wird streng bestraft!“ So blieb der Dom vor einer Ausplünderung bewahrt. Am 16. Juni 1945 setzte die Stadtverwaltung einen Kommissar ein, der die politischen und wirtschaftlichen Belange der Stadt an der Burg und am Dom wahrnehmen sollte. Es kam aber nie zu einer Beschlagnahmung des Domes oder zu einer Enteignung. Stiftssyndikus Gottfried von Hopffgarten sorgte dafür, dass das Hochstift weiter handlungsfähig blieb. Am 8. Juli 1945 konnte wieder ein sonntäglicher Gottesdienst im Dom stattfinden. Außerdem wurden Maßnahmen ergriffen, um die Kriegsschäden zu beseitigen. Dechant Benno von Heynitz, der von Heynitz wiederholt nach Meißen kam, berichtete am 1. August 1945 an Hugo Hickmann „Der Dom hat durch Art[illerie]-Beschuss und durch die Brückensprengung leider erhebliche Schäden erlitten. Ebenso sind unsere Häuser, wenn auch nicht stark, in Mitleidenschaft gezogen worden."

Die Zuversicht des Dechanten, dass sich die Lage rasch bessern werde, wurde enttäuscht. Die sowjetische Besatzungsmacht, die sich zunächst im Amtsgericht einquartiert hatte, beschlagnahmte sämtliche Häuser am Domplatz, der am 15. Oktober 1945 gänzlich abgesperrt wurde. Das abgeschlossene, gut $\mathrm{zu}$ bewachende Sperrgebiet wurde vom sowjetischen Geheimdienst GPU genutzt. ${ }^{33}$ Auch der Dom durfte nicht mehr betreten werden. Domprediger Böhme hatte hier am 9. September 1945 den letzten Gottesdienst gehalten. Am 8. Juli 1946 berichtete er an Dompropst und Domdechant: „Infolge Absperrung des Burgbergs sind leider die Domgottesdienste stillgelegt. Wir haben aber die Erlaubnis für Gottesdienste an hohen kirchlichen Festtagen und für Domkonzerte erreicht. Ein solches hat der Kreuzchor am Sonntag Rogate abgehalten, das einen Reinertrag von etwa 1.000.- RM ergab." In einem Bericht des Stiftssekretärs Vetterling an Dompropst Welck vom 28. Juli 1946 heißt es: „Das Propsteigebäude dürfen wir nicht mehr betreten, die darin untergebrachten Sachen sind fortgebracht worden. Es wurde mir versichert, daß wir die Sachen wieder bekommen würden. Der ganze Domplatz ist geräumt, so, daß seit September 1945 keine deutsche Familie mehr den Domplatz bewohnt. Hoffen wir, 
daß in absehbarer Zeit die Wohnungen wieder bezogen werden können." Erst im Januar 1947 räumte der sowjetische Geheimdienst den Burgberg und damit auch die Häuser des Hochstifts am Domplatz. Vetterling berichtete am 20. Juni 1947 an Welck: „Im Dom und in den Grundstücken sah es wüst aus. Wir haben soweit alles wieder in Ordnung gebracht, sodaß ab Ostern wieder regelmäßig der sonntägliche Gottesdienst abgehalten werden konnte. Auch mit den Führungen haben wir seit Pfingsten wieder begonnen."

Im Herbst 1945 verlor das Hochstift seine führenden Köpfe. Stiftssyndikus Hopffgarten starb am 16. September 1945. Die Bodenreform in der sowjetischen Besatzungszone führte dazu, dass Dompropst Dr. Alfred Freiherr von Welck und Domdechant Dr. Benno von Heynitz im Oktober 1945 ihren Besitz und ihre Heimat verloren. Wie andere Enteignete aus Sachsen wurde Welck auf die Insel Rügen deportiert. Von dort konnte er in den Westen flüchten. Heynitz teilte am 28. Oktober 1945 Hugo Hickmann mit, dass er aufgrund der restlosen und entschädigungslosen Enteignung Sachsen verlassen müsse und dass er ihm als Stellvertreter die Geschäfte des Dechanten übertrage. Heynitz flüchtete in die britische Besatzungszone. Er hoffte aber, eines Tages zurückkehren zu können, weshalb er das Amt des Dechanten nicht niederlegte. Dagegen trat Welck, der in Aalen in Württemberg Zuflucht gefunden hatte, am 30. Dezember 1947 von seinem Amt als Dompropst zurück.

Nach dem Ende des Zweiten Weltkriegs verlor das Meißner Domkapitel eine weitere verfassungsgemäße Aufgabe, nämlich seine Rechte als Kirchenpatron für die Kirchen in Boritz und Rüsseina. Mit der Enteignung der Rittergüter waren zahlreiche Patronate erloschen. So beschloss das Landeskirchenamt, alle Patronatsrechte, auch die nach der Bodenreform noch bestehenden, als ruhend zu behandeln. 1946 wurde in einem Runderlass verfügt: „Wegen der unklaren Rechtslage hinsichtlich des Fortbestehens der Patronate werden diese bis auf weiteres bei der Besetzung von Pfarrstellen als ruhend behandelt." Mit Schreiben vom 9. Januar 1948 wehrte sich das Domkapitel gegen diese Bestimmung, denn es war ja noch vorhanden und wollte auch weiterhin bei der Einsetzung der Pfarrer in Rüsseina und Boritz mitwirken. ${ }^{34}$ Es blieb jedoch dabei, dass die Kirchenpatronate erloschen waren.

In der mehr als unsicheren Situation der sowjetischen Besatzungsherrschaft sicherte Domherr Hugo Hickmann, der stellvertretend die Geschäftsführung übernahm, das Überleben des Domkapitels. Der überzeugte Christ hatte enge Kontakte zur sowjetischen Militäradministration, da er beim Neuaufbau eines Mehrparteiensystems in der sowjetischen Besatzungszone eine wichtige Rolle einnahm. Nach dem Zweiten Weltkrieg gehörte Hickmann zu den Mitbegründern der CDU in Sachsen, die er als überkonfessionelle Sammlungsbewegung konservativer und nationalliberaler Kräfte organisierte. Seit Dezember 1945 gehörte Hickmann der Führungsspitze der CDU in der

\section{Christlich-Demokratische Union Deutschlands Landeswerband Sachsen}
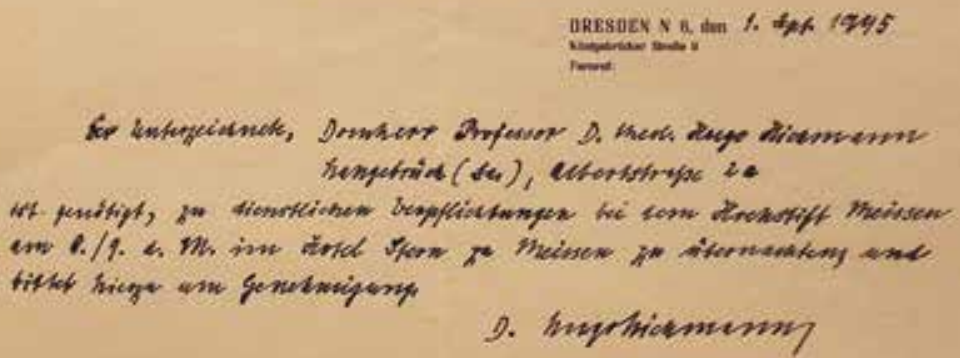

D. huptrianemy

sowjetischen Besatzungszone an. Als Vorsitzender der CDU in Sachsen und als stellvertretender Vorsitzender der Ost-CDU versuchte er, christlichkonservative Werte in die sich neu formierende Gesellschaft einzubringen. Hickmann kritisierte allerdings die führende Rolle der SED, sprach sich gegen Enteignungen aus und verteidigte die private Wirtschaft. Daher schalteten ihn die Befürworter des SED-Staats nach Gründung der DDR aus. Hickmann musste nach massivem Druck am 30. Januar 1950 von allen Parteiämtern zurücktreten.

\section{Neue Aufgaben für den Meißner Dom}

Nach dem Ende der nationalsozialistischen Herrschaft musste die Evangelisch-Lutherische Landeskirche Sachsens, die infolge des Kirchenkampfes als „zerstört“ galt, erneuert und von den

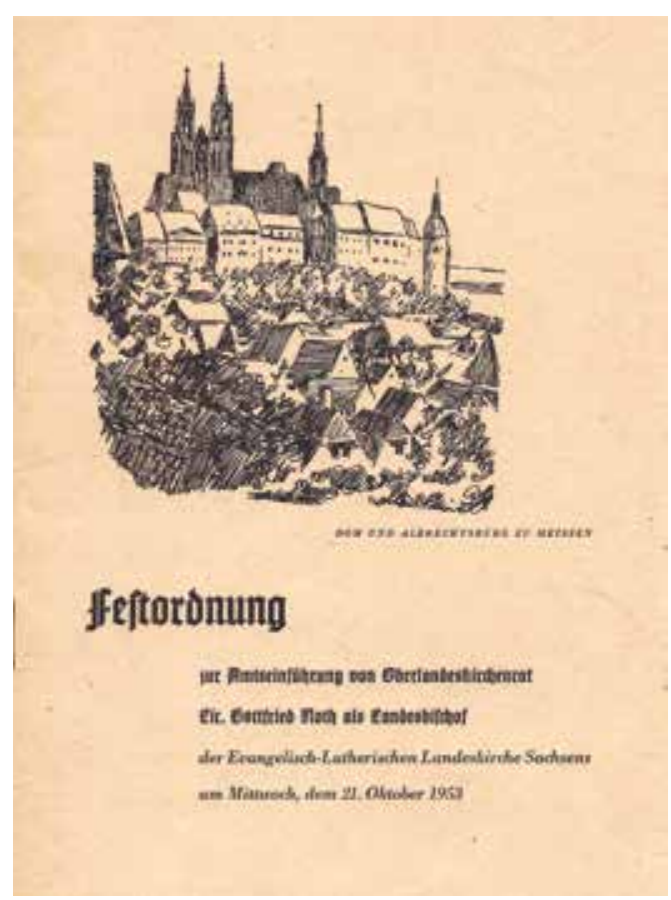

Bescheinigung Hickmanns für sich selbst, 1. September 1945 ๑ Hochstift Meißen
Festordnung zur Einführung von Landesbischof Gottfried Noth im Meißner Dom, 21. Oktober 1953 ๑ Hochstift Meißen 


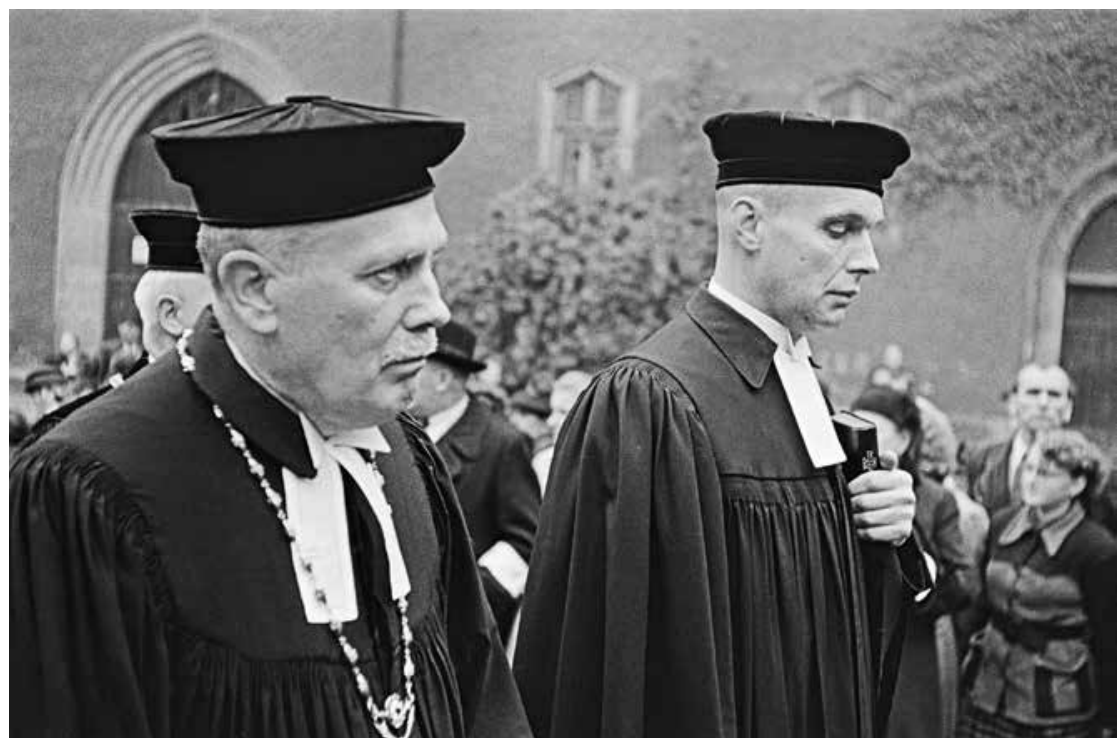

Landesbischof Hugo Hahn und sein Nachfolger, Gottfried Noth, vor dem Meißner Dom,

21. Oktober 1953

- SLUB Dresden, Deutsche Fotothek, Foto: Erich Höhne/Erich Pohl
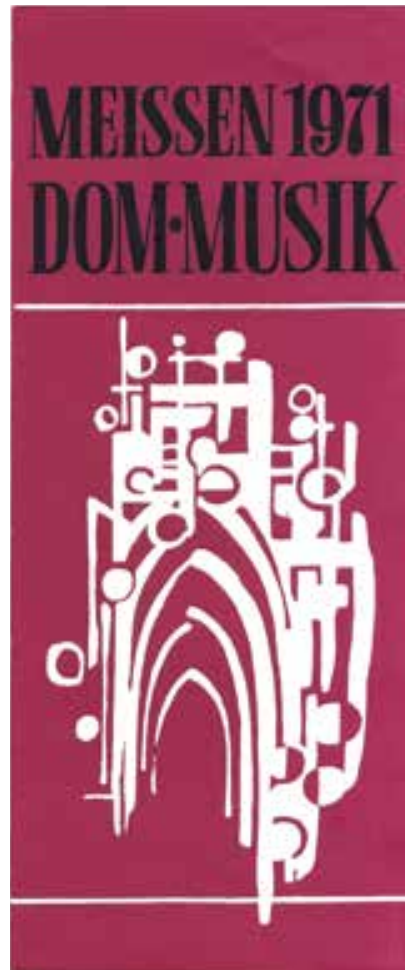

Programm der Dommusik, 1971 () Hochstift Meißen
Einflüssen der Deutschen Christen und der NSIdeologie befreit werden. Dieser Aufgabe nahm sich der Dresdner Pfarrer Franz Lau (1907-1973) an. Als Landessuperintendent übernahm er die Leitung der Landeskirche. ${ }^{35} 1947$ wählte der Beirat des Landeskirchenamts den früheren Superintendenten Hugo Hahn (1886-1957), einen der führenden Köpfe der Bekennenden Kirche, zum Landesbischof. Vermutlich aufgrund der Zerstörung Dresdens, wo man in der Innenstadt keine einzige Kirche mehr nutzen konnte, beschloss die Kirchenleitung, die feierliche Einführung am 21. Oktober 1947 im Meißner Dom vorzunehmen. So wurde der Meißner Dom nun doch zur Bischofskirche der Evangelisch-Lutherischen Landeskirche Sachsens. Über die Einweisung des neuen Landesbischofs schrieb Hickmann am 23. Dezember 1947 an Dompropst Welck: „Unser Dom hat einen grossen Tag gehabt. Bei der Einweisung des Landesbischofs am 21. Oktober repräsentierte evangelisches Kirchentum in würdiger und eindrucksvoller Gestalt. Unser erhabenes Gotteshaus trat als Kathedrale unserer Landeskirche in Erscheinung und prägte sich als solche eindringlich in das Bewusstsein der feiernden landeskirchlichen Gemeinde ein. In unserer verwüsteten und ausgebombten Propstei konnte ich noch einen Sitzungssaal würdig herstellen, um hier vor der kirchlichen Feier den Landesbischof als Stiftsherrn feierlich zu verpflichten. Bei dem Einzug im Dom begrüßte ich ihn am Portal, und nach dem Einweisungsakt durfte ich dann am Altar noch das Grusswort des Kapitels vor der Gemeinde entbieten. In dem anschliessenden Akte in der Albrechtsburg folgte noch meine Ansprache für die CDU. So kam auch das Kapitel zu gebührender Geltung, wenn auch ohne Domherrentalar." Auch die Einführung des nachfolgenden Landesbischofs Gottfried Noth (1905-1971) am 21. Oktober 1953 wurde im Meißner Dom begangen. Auf dem Marktplatz formierte sich ein Festzug, der unter dem Geläut aller Glocken der Meißner Kirchen dem Dom zustrebte, wo der Einführungsgottes- dienst unter Beteiligung zahlreicher ost- und westdeutscher sowie ausländischer Bischöfe abgehalten wurde. Weil der Dom nicht alle Gäste aufnehmen konnte, wurde die Feier in die Frauenund Johanniskirche übertragen. Dagegen verfügte Johannes Hempel (geb. 1929), der im Oktober 1971 von der Landessynode zum Landesbischof gewählt wurde, dass seine Einführung in der Dresdner Kreuzkirche stattfinden solle. Auch alle seine Nachfolger wurden in der Kreuzkirche in ihr Amt eingeführt. Formell blieb es aber bei der Sprachregelung, dass der Meißner Dom die Bischofskirche der Landeskirche sei. Alle Landesbischöfe wurden nach ihrer Amtseinführung auch als Stiftsherren verpflichtet.

Von großer Bedeutung war ferner, dass die Landeskirche zum 31. Oktober 1949 eine Evangelische Akademie gründete und diese in Meißen ansiedelte. Die prägende Gestalt beim Aufbau dieser Bildungseinrichtung war Pfarrer Dr. Georg Muntschick (1897-1966). Die Evangelische Akademie vermittelte Wissen und christliche Prägungen ganz ohne die sozialistische Ideologie, die den Alltag in der DDR bestimmte. Ihre Tagungen, die sich zum Beispiel an bestimmte Berufsgruppen richteten, waren sehr gefragt. Die Evangelische Akademie nutzte die Villa Muntschicks am Jüdenberg und mehrere Räume in der Dompropstei. Zudem wurde die Evangelische Akademie eng mit dem Meißner Dom verbunden. So verband das Landeskirchenamt die Stelle des Akademiedirektors mit der des Dompredigers. Seit 1949 bildeten die Sonntagsgottesdienste im Dom in der Regel zugleich den Abschluss der Akademietagungen. So erhielt der Dom mit den Tagungsteilnehmern eine - wenn auch ständig wechselnde - Gemeinde.

Dass der Superintendent als Dompfarrer auftritt und der Akademiedirektor als Domprediger die Gottesdienste hält, hat aber wiederholt zu Konflikten geführt. Der gemeinsame Dienst am Dom mit ungleich verteilten Pflichten, Weisungsbefugnissen und Besoldungen - rief Unmut hervor und beförderte Rivalitäten, die etwa darin zum Ausdruck kamen, dass Superintendent Dr. Hermann Klemm (1904-1983) 1963 auf seine Rechte als Dompfarrer verzichtete und sich zeitweise weigerte, weiterhin Gottesdienste im Dom zu halten. Die Superintendenten Dr. Arthur Neuberg und Dr. Hermann Klemm waren unzufrieden, nicht ins Domkapitel aufgenommen worden zu sein. Das Domkapitel wiederum beschwerte sich beim Landeskirchenamt, dass es keine Möglichkeit habe, bei der Auswahl des Superintendenten und des Akademiedirektors mitzureden, obwohl diese als Dompfarrer und Domprediger das geistliche Leben am Dom bestimmten. 1924 war dem Domkapitel noch die Kollatur über das Dompredigeramt eingeräumt worden. 1965 traf das Landeskirchenamt die Entscheidung, vor Ernennung eines Superintendenten das Domkapitel anzuhören. Das konnte das Grundproblem, die Trennung zwischen Domgeistlichkeit und Domkapitel, nicht lösen. Eine Beruhigung trat erst ein, als 2004 mit Andre- 
as Stempel (geb. 1950) erstmals ein amtierender Superintendent und Dompfarrer in das Domkapitel aufgenommen wurde. Seine Vorgänger Herbert Böhme und Dieter Auerbach (geb. 1933) waren erst nach ihrem Dienst in Meißen Mitglieder des Domkapitels geworden. Die Evangelische Akademie wurde nach dem Ruhestand ihres Gründers Georg Muntschick von Günter Heidrich-Meisner (1911-1983), Dieter Ackermann (1932-1985), Hermann Schleinitz (geb. 1938), Christof Ziemer (geb. 1941), Dr. Matthias Flothow (geb. 1949), Peter Vogel (geb. 1944) und Johannes Bilz (geb. 1962) geleitet, die als Domprediger auch die überwiegende Anzahl der Gottesdienste im Meißner Dom hielten.

Einen neuen Impuls erhielt das kirchliche Leben am Meißner Dom durch die Einstellung des Domkantors Dr. Erich Schmidt (1910-2005), der 1950 sein Amt antrat. ${ }^{36}$ Der promovierte Psychologe und begabte Musiker machte den Meißner Dom zu einem Zentrum der Kirchenmusik in Sachsen. 1950 gründete er den noch heute bestehenden Domchor, der anfangs rund 40 Sängerinnen und Sänger umfasste und am 28. Oktober 1950 erstmals auftrat. Dr. Schmidt organisierte darüber hinaus die Singwochen an der Evangelischen Akademie und gestaltete als Dozent und stellvertretender Direktor die Ausbildung von Kirchenmusikern an der Kirchenmusikschule der sächsischen Landeskirche mit. Im Sommer 1961 gründete er einen Projektchor zur Aufführung eines modernen Stückes, des Ezzolieds des Schweizer Komponisten Willy Burkhard (1900-1987). Aus dieser Gemeinschaft entstand die Meißner Kantorei 1961, die sich auf die Aufführung zeitgenössischer Kirchenmusik spezialisierte. 1980 trat Dr. Erich Schmidt nach dreißig Jahren fruchtbaren Schaffens in den Ruhestand. Sein Nachfolger Andreas Weber (geb. 1944) führte Schmidts Anspruch, im und am Meißner Dom Menschen für Musik zu begeistern, weiter. Die von Weber geleiteten Chöre, darunter die Kinder- und Jugendkantorei, die Domspatzen, die Dompiepser und der Knabenchor, sprachen ein breites Publikum an. Die Meißner Kantorei 1961 konnte sich jedoch nicht mit Andreas Weber anfreunden. Die Sängerinnen und Sänger wählten 1981 den Chorpräfekten Christfried Brödel (geb. 1947) zu ihrem neuen Chorleiter. Die Probenarbeit findet seitdem überwiegend in Dresden statt, jedoch ist der traditionelle Name geblieben.

\section{Domkapitel und Domverwaltung nach 1945}

Oberkirchenrat Richard Weidauer (1867-1967), seit 1925 Domherr und seit 1927 Dechant in Wurzen, sorgte sich um den Fortbestand des Wurzener Domkapitels. Infolge von vier Todesfällen und einem Austritt waren Mitte 1945 nur noch drei Domherrenstellen besetzt. Erst nach der Einführung von Landesbischof Hahn, der Stiftsherr in Meißen und Wurzen wurde, konnten wieder Ernennungen von Domherrn vorgenommen werden. Doch Weidauer zweifelte, ob sein Domkapitel dau-

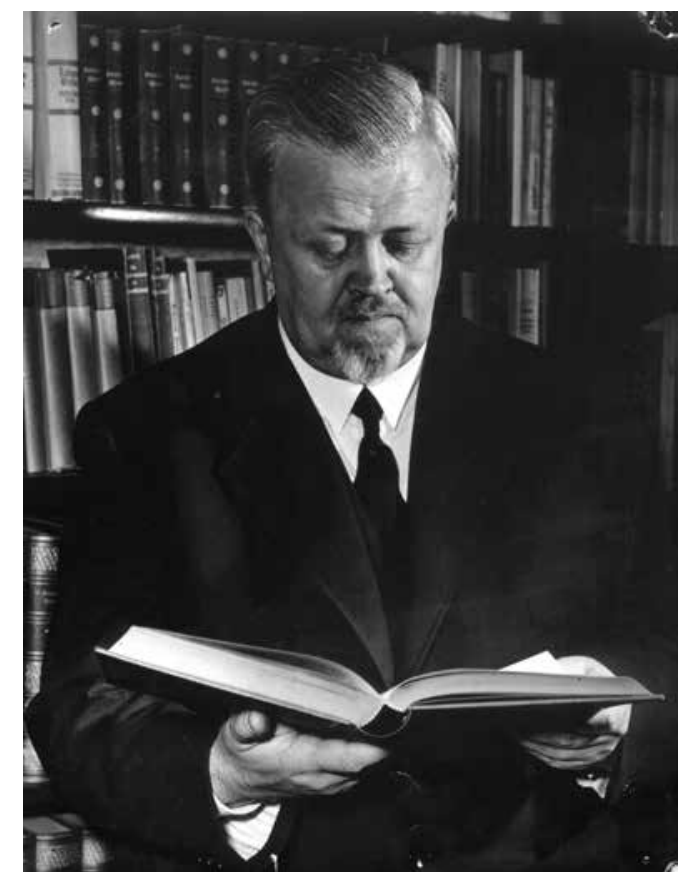

Domdechant Franz Lau, um 1960

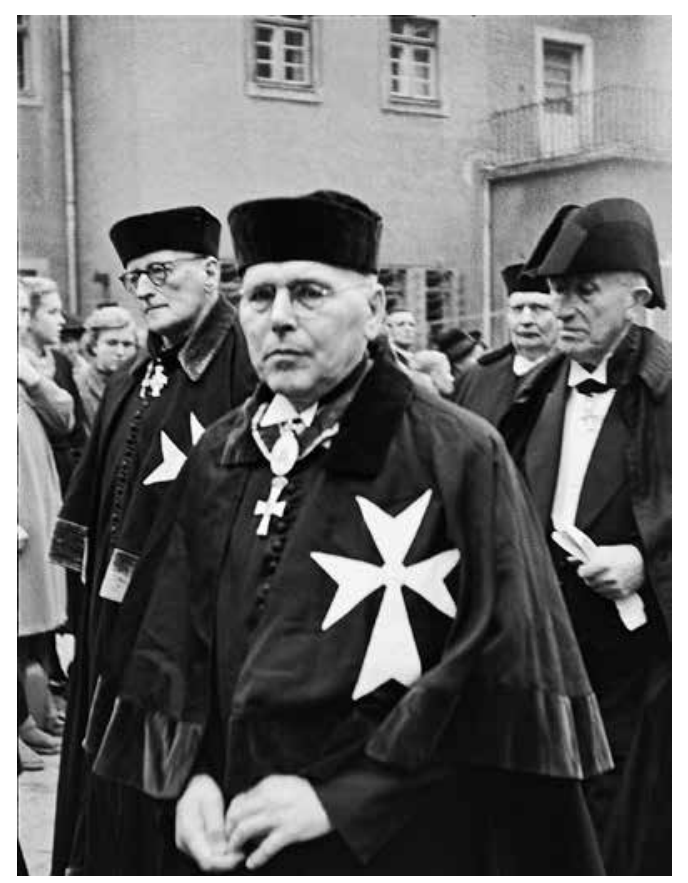

Das Meißner und Wurzener Domkapitel bei der Einführung von Bischof Gottfried Noth, 21. Oktober 2018, vorn Dompropst Ernst Sommerlath ๑ SLUB Dresden, Deutsche Fotothek, Foto: Erich Höhne/Erich Pohl

erhaft als eigenständige Einrichtung überleben könne. Als Lösung kam ihm der Gedanke, die Domkapitel in Meißen und Wurzen zu fusionieren. Die sollte ohne Änderung der Verfassung vollzogen werden, indem die Mitglieder des einen die Mitglieder des anderen übernehmen. Hugo Hickmann stimmte diesem Plan zu, und so wurden am 9. Mai 1948 der Theologieprofessor Ernst Sommerlath (1889-1983), der Oberkirchenrat Hans Schulz-Blochwitz (1888-1967) und der schon genannte Wurzener Dechant Richard Weidauer in das Meißner Domkapitel aufgenommen. Umgekehrt traten die Meißner Domherren Hickmann und Leipoldt in das Wurzener Domkapitel ein. Landesbischof Hahn wusste um diese gegenseitigen Berufungen. Er kritisierte in einem Schreiben
35 Vgl. Markus Hein: Die säch- sische Landeskirche nach dem Ende des Zweiten Welt- krieges (1945-1948). Neu- bildung der Kirchenleitung und Selbstreinigung der Pfarrerschaft. Leipzig 2002. 36 Zur Musik am Meißner Dom seit 1950 vgl. Elke Ber- ger: Domchorchronik aufge- schrieben von Frau Grete Merbach. Meißen 2001 [nur in kopierter Verfassung her- gestellt, umfasst den Zeit- raum 1950 bis 2001].


vom 23. April 1948 die Zusammenlegung und stellte die Frage, ob nicht eine andere Möglichkeit der Ergänzung der Kapitel bestehe. Dennoch nahm er die Ernennungen vor. Das Landeskirchenamt allerdings legte mit Schreiben vom 22. Juni 1948 Widerspruch gegen die gegenseitige Ergänzung ein. Damit wurde die Idee eines Zusammenschlusses beider Domkapitel wieder obsolet. Hugo Hickmann gab sein Amt als stellvertretender Dechant 1949 an den Leipziger Theologieprofessor Johannes Leipoldt ab, einen Parteifreund in der Ost-CDU. Dafür wurde er Dompropst, was er bis zu seinem Tod 1955 blieb. Da Heynitz aufgrund seines Wohnorts in Westdeutschland sein Amt als Domdechant niederlegte und Leipoldt als stellvertretender Dechant zurücktrat und sogar aus dem Domkapitel ausschied, mussten die Spitzenpositionen neu besetzt werden. Das Amt des Dompropstes übernahm der Theologieprofessor Ernst Sommerlath, der schon seit 1937 dem Domkapitel angehörte. Er gewann seinen Kollegen Franz Lau, der seit 1947 Kirchengeschichte an der Universität Leipzig lehrte, für die Geschäftsführung des Domkapitels. Lau wurde am 21. Oktober 1956 aufgenommen und in der gleichen Kapitelsitzung zum Domdechanten gewählt. Als eine seiner ersten Maßnahmen verfügte er am 14. Dezember 1956, die Anrede „Euer Hochwürden“ nicht mehr zu gebrauchen.

Franz Lau und Ernst Sommerlath blieben über 15 Jahre die prägenden Gesichter des Meißner Domkapitels. Lau gewann in Meißen einen eigenen Machtbereich, gewissermaßen als Ersatz dafür, dass er, der erste Leiter der Landeskirche nach dem Zweiten Weltkrieg, nicht zum Landesbischof gewählt worden war. Er wachte streng darüber, dass Landesbischof und Landeskirchenamt nicht in Belange des Hochstifts hineinredeten. So lehnte Lau eine Visitation des Hochstifts durch Landesbischofs Noth zu Exaudi 1962 ab. Zur Begründung schrieb er an Noth: „Das Kapitel ist der Meinung, dass seine Rechte von der Leitung der Landeskirche laufend versetzt werden." Noth antwortete, daß er „aus bischöflicher Großmut“ auf eine Visitation verzichte, drohte aber an, nie wieder an $\mathrm{Ka}^{-}$ pitelsitzungen teilnehmen zu wollen.

1956 wurde letztmals ein Mitglied der Theologischen Fakultät der Universität Leipzig nach dem seit Jahrhunderten üblichen Verfahren zum Domherrn zu Meißen ernannt. Dabei handelte es sich um Prof. Dr. Alfred Dedo Müller (1890-1972). Er wurde vom Akademischen Senat auf Vorschlag der Theologischen Fakultät gewählt, am 22. August 1956 von Prof. Dr. Georg Mayer (1892-1973), dem Rektor der Karl-Marx-Universität Leipzig, ernannt und am 21. Oktober 1956 aufgrund dieser Ernennung ins Domkapitel aufgenommen. Seither verweigerte die Karl-Marx-Universität, die sich mehr und mehr von ihren Traditionen löste, die Zusammenarbeit mit dem Meißner Domkapitel. Das warf die Frage einer Neubesetzung der beiden Domherrenstellen der Leipziger Professoren auf, hatte die Verfassung von 1924 doch verfügt, dass es beim alten Herkommen bleibe. Eine Wahl durch die Domherren und eine Ernennung durch den Stiftsherrn waren für die beiden Professorenkanonikate nicht vorgesehen.

Die anderen Kapitelstellen wurden weiterhin besetzt, indem das Domkapitel dem Landesbischof einen Dreiervorschlag unterbreitete. Der Landesbischof konnte auswählen, mehrfach entschied er sich nicht für den Namen an erster Stelle. So hatte das Domkapitel 1968 den Archivar und Historiker Dr. Karlheinz Blaschke (geb. 1927) zur Aufnahme vorgeschlagen, doch Landesbischof Noth lehnte seine Ernennung mit der Begründung ab, er habe sich keine Verdienste um die Landeskirche erworben. Erst vier Jahre später stimmte er seiner Aufnahme zu. Mehrere Vorschläge fanden keine Berücksichtigung, etwa die Aufnahme des Dresdner Kreuzkantors Dr. Rudolf Mauersberger (1889-1971).

Das Meißner Domkapitel war darauf bedacht, mindestens einen Kirchenjuristen in seinen Reihen zu haben. Mit Oberkirchenrat Hans Schulz-Blochwitz hatte man 1948 einen versierten Juristen gefunden. Allerdings verlor Schulz-Blochwitz noch im gleichen Jahr seine Stelle im Landeskirchenamt. Ohne berufliche Perspektive in der DDR, flüchtete er 1951 nach West-Berlin, wo er eine neue Anstellung fand. Damit lebten nunmehr drei Domherren außerhalb der DDR. Als Ersatz für ihn nahm das Domkapitel 1965 den Bautzener Kirchenamtsrat Dr. Walther Thomas (1881-1973) auf. Er erfüllte die in ihn gesetzten Erwartungen nicht, da er bereits im September 1967 nach Bayern übersiedelte und seither nur brieflich den Kontakt mit dem Domkapitel halten konnte. Ein kluger Gedanke war es, den Dresdner Denkmalpfleger Dr.-Ing. Hans Nadler (1910-2005) in das Domkapitel aufzunehmen. Als Leiter des Instituts für Denkmalpflege, Arbeitsstelle Dresden, hatte er prägenden Einfluss auf die Denkmalpflege in der DDR. Dr. Nadler fühlte sich persönlich für den Meißner Dom verantwortlich und half, wo es nur ging, die in der DDR stets knappen Mittel und Baukapazitäten für die Erhaltung des Ensembles aus Dom und Albrechtsburg zu beschaffen. 1967 wurde der vielfach talentierte Dr. Christian Rietschel (19081997) ins Domkapitel aufgenommen. Der Leiter des Kunstdienstes der Landeskirche und Schriftleiter der Kirchenzeitung „Der Sonntag“ brachte vor allem seine künstlerische Begabung ein.

Anfang der 1970er Jahre vollzog sich im Domkapitel ein Generationswechsel. Domdechant Franz Lau, dessen Gesundheit stark angegriffen war, schlug Dr. Blaschke zu seinem Nachfolger vor. Dieser wurde am 14. Mai 1972 in das Domkapitel aufgenommen und, wie sein Vorgänger, sofort zum Dechanten gewählt. Blaschke war ein engagierter lutherischer Christ und einer der wenigen Historiker in der DDR, die sich den Vorgaben der sozialistischen Ideologie verweigerten. An den Universitäten der DDR hatte er aufgrund seiner Einstellung, die man als „bürgerlich“ diffamierte, keine Chance. Im Theologischen Seminar Leipzig, einer nicht 
staatlich anerkannten Ausbildungsstätte für Pfarrer, fand er einen Arbeitsplatz, der ihn frei von Eingriffen des Staates lehren und forschen ließ. Blaschke war über vierzig Jahre das prägende Gesicht des Meißner Domkapitels; er gehört ihm bis heute als außerordentlicher Domherr an. ${ }^{37}$ In den ersten zwanzig Jahren seiner Amtszeit wurden vorwiegend Theologen in das Domkapitel aufgenommen: 1973 der Leipziger Theologieprofessor Prof. Dr. Hans Bardtke (1906-1975), 1974 der Rektor des Theologischen Seminars in Leipzig und Vorgesetzte Blaschkes, Prof. Dr. Christoph Michael Haufe (1932-2011), 1975 der Leipziger Theologieprofessor Prof. Dr. Heinz Wagner (19121994), 1976 Pfarrer Werner Vogel (1917-1991), Direktor der Inneren Mission in Leipzig, 1983 der Oberlandeskirchenrat und frühere Meißner Superintendent Dieter Auerbach (geb. 1933) und 1987 der Studiendirektor und frühere Dresdner Superintendent Christoph Wetzel (geb. 1929). Damit bekam das Domkapitel, bedingt durch die äußeren Umstände, stärker den Charakter einer innerkirchlichen Einrichtung, während die ehemals sehr engen Bezüge zu Staat und Verwaltung entfielen. 1979 starb mit Dr. Benno von Heynitz das vorerst letzte adlige Mitglied des Domkapitels.

Nach dem Tod des Amtsgerichtsdirektors Gottfried von Hopffgarten hatte das Domkapitel keinen Stiftssyndikus mehr. Es war schwer, passende Nachfolger zu finden, da zahlreiche Juristen aus der sowjetischen Besatzungszone geflüchtet waren und die verbliebenen, die dem SED-Staat dienten, nicht der Kirche angehörten. Nach dem Tod des Stiftssekretärs Vetterling 1946 führte der zunächst als Domküster eingestellte und dann zum Stiftssekretär beförderte ehemalige Porzellanmaler Edwin Große (geb. 1892) die Domverwaltung. Er wurde 1955 fristlos entlassen, weil er mehr als 12.000 Mark unterschlagen hatte. 1955 wurde Dr. Paul Liebe zum Stiftssyndikus ernannt. Als Finanzreferent der Inneren Mission und promovierter Wirtschaftswissenschaftler waren ihm betriebswirtschaftliche Vorgänge vertraut. Da die Domherren seiner Hilfe dringend bedurften, wurde er 1973 in das Domkapitel aufgenommen. Als er 1981 mit 80 Jahren in den Ruhestand trat, hinterließ er eine große Lücke. Da man keinen geeigneten Juristen finden konnte, übernahm der langjährige Dombaumeister Dr.-Ing. Otto Baer (1913-1996), der immerhin auch schon 68 Jahre alt war, das Amt des Stiftssyndikus. Stiftssekretäre waren Walter Fugmann (geb. 1904) und seit 1969 Christa Schumann (geb. 1928). Über sie heißt es im Protokoll der Kapitelsitzung vom 6. und 7. Juli 1989: „Frau Schumann hält den Laden zusammen, sie poltert, daß es dann knallt.“

Mit der Währungsreform in der sowjetischen Besatzungszone waren die Guthaben des Hochstifts in Deutsche Mark (Ost) umgerechnet worden. Einige Geldanlagen waren wertlos geworden, andere erfuhren eine Abwertung. So hatte sich das Eigenkapital des Hochstifts 1955 auf 199.563,10 Deutsche Mark verringert. Das Geld der einzelnen
Fonds war auf Bankkonten angelegt. Der Präbendenfonds verfügte im Jahr 1967 über 4.245,31 Mark, der Vereinigte Stiftungsstock nur über 673,46 Mark, der Propsteifonds war mit immerhin 12.453,80 Mark bewertet. In der Bilanz 1986 waren der Präbendenfonds mit 1.369,42 Mark und der Propsteifonds mit 475,10 Mark bewertet. Der Vereinigte Stiftungsstock, der 1985 noch 1.140,45 Mark umfasste, wurde 1986 aufgelöst und dem Präbendenfonds zugeführt.

Die Propsteifelder bei Bautzen, deren Nießbrauch dem Hochstift Meißen zustand, gingen in den Jahren der DDR durch Enteignung verloren. Seit 1958 war die Bewirtschaftung der Flächen der Kircheneigenen Land- und Forstwirtschaft im Bistum Meißen übertragen. Das Ackerland wurde allerdings benötigt, um hier das Neubaugebiet Bautzen-Gesundbrunnen anzulegen. Daher wurde es 1974 und 1976 bis auf geringe Restflächen nach dem Aufbaugesetz der DDR enteignet. Dafür erhielt das Hochstift Meißen eine finanzielle Entschädigung, die aber nicht dem Grundstückswert entsprach. ${ }^{38}$ Die verbliebene Restfläche mit einer Größe von nur noch 0,75 Hektar war an eine Kleingartenanlage vergeben und erbrachte eine jährliche Pacht von 812,74 Mark. Zuletzt mussten 19921.290 Quadratmeter für den Ausbau der Kreuzung Muskauer Straße/Thomas-Müntzer-Straße abgegeben werden, wofür eine Entschädigung von $6.450,00$ DM gezahlt wurde.

Aus dem Präbendenfonds und der Propstei Bautzen wurden weiterhin Präbenden gezahlt. Nach der Währungsumstellung betrugen sie zunächst 100,00, dann 200,00, seit 1959 300,00 DM pro Kopfteil. Dompropst, Domdechant und Propst zu Bautzen erhielten zwei Kopfteile. 20 Prozent der Summe wurden automatisch abgezogen und als Steuer abgeführt.

Wenn man sich die mageren Erträge der Fonds bewusst macht, wird deutlich, dass die Einnahmen des Hochstifts Meißen, die 1959 128.739,73 DM betrugen, aus anderen Mitteln kommen mussten. Tatsächlich profitierte der Dom ganz maßgeblich von den seit den 1950er Jahren wachsenden Besucherströmen. Der Meißner Dom war eine der wichtigsten touristischen Ziele in der DDR geworden. Anfang der 1950er Jahre wuchsen die Besucherzahlen immens. 1952 besichtigten 76.813 Personen den Dom und 1954 schon 110.325. 1957 wurden 151.005 Besucher gezählt. Das Hochstift Meißen hatte den Führungsbetrieb selbst übernommen. Die Führungsgelder erbrachten 1959 60.686,00 DM, und durch den Verkauf von Postkarten nahm man 12.634,00 DM ein. Auch wenn davon die Führungskräfte zu bezahlen waren, blieb immer noch ein stattlicher Überschuss übrig. Er wuchs, weil vor allem zwischen 1969 und 1972 die Besucherzahlen steil anstiegen. Dies lässt sich vor allem mit Besuchern aus den Ostblockländern erklären, vor allem aus Polen und der Tschechoslowakei, die unter einfacheren Bedingungen Reisen in die DDR unternehmen konnten. 1976 war der Spitzenwert mit 228.032 Besuchern erreicht. So
37 Vgl. Auerbach 2002 (wie Anm. 6).

38 Für die 1974 in Anspruch genommenen 13 Hektar wurden 29.513,20 Mark gezahlt. Das Hochstift Meißen erhielt davon jährlich vier Prozent Zinsen. 
stiegen die Einnahmen aus dem Verkauf von Eintrittskarten bis 1976 auf 143.602,00 Mark. Der Umsatz des Verkaufsstandes verdreifachte sich und erreichte 1976 den Spitzenwert von 108.947,00 Mark. Neben Postkarten wurden Domführer und Diaserien verkauft, während die Produktion einer Schallplatte mit Musik aus dem Meißner Dom nicht genehmigt wurde. Seit 1976 gehen die Besucherzahlen zurück. Das war in den letzten Jahren der DDR insofern nicht zu spüren, weil die Einnahmen aus dem Eintrittskartenverkauf weiter anstiegen und 1984 den Spitzenwert von 163.147,82 Mark erreichten. Die Personalkosten betrugen hingegen 1986 nur 41,122,36 Mark. Damit erzielte das Hochstift allein durch den Führungsbetrieb einen Reinerlös von 119.753,27 Mark. Hinzu kam der Reinertrag des Verkaufsstands in Höhe von 22.962,23 Mark. Demnach ist eine weitreichende Verschiebung der Vermögenslage zu konstatieren. Während vor 1945 die Einnahmen vorwiegend durch Kapitalerträge und Pachten erzielt wurden, war das Domkapitel seit den 1950er Jahren vollkommen vom Tourismus abhängig.

\section{Neuregelung der Verfassung}

Seit den 1960er Jahren strebte Domdechant Franz Lau eine Änderung der Verfassung des Hochstifts Meißen an, weil die geänderten Verhältnisse in der DDR das Fortbestehen des Domkapitels bedrohten. Zum einen musste die Frage der „Domherren im Westen“ geklärt werden, die nicht mehr im Domkapitel mitwirken konnten, deren auf Lebenszeit vergebene Stellen aber laut Verfassung von 1924 nicht neu besetzt werden durften. Dazu

Domherr Hans Schulz-Blochwitz in der Kleidung eines Meißner Domherrn, um 1965 ๑ Hochstift Meißen schrieb Lau am 7. Februar 1966: „Dadurch, daß Mitglieder des Domkapitels im Jahre 1945 oder etwas später mindestens z. T. unfreiwillig Sachsen verließen, ist das Domkapitel auf 5 Mitglieder zusammengeschrumpft. Nachdem einer von den 3 von Sachsen abgängigen Domherren verstorben ist, ist seine Stelle wiederbesetzt worden, sodaß jetzt wieder 6 Domherren vorhanden sind. Die Frage der Zugehörigkeit der außerhalb Sachsens lebenden Domkapitulare ist aber nie geklärt worden. Einerseits wurden sie nicht mehr mitgezählt, andererseits blieben ihre Plätze offen. Eine klare Regelung scheint notwendig." Andererseits war eine Lösung für die beiden Stellen der Leipziger Theologieprofessoren zu finden, die bislang ohne Beteiligung des Domkapitels und des Stiftsherrn durch die Universität Leipzig besetzt worden waren. Diese legte aber keinen Wert mehr darauf, Mitglieder einer Einrichtung der Landeskirche zu ernennen. Lau fürchtete, „daß an der Stelle einmal außerkirchliche Kräfte in das Domkapitel einbrechen“ könnten. Das ließe sich nur verhindern, wenn auch für diese Stellen die Wahl durch das Domkapitel und die Bestätigung durch den Stiftsherrn eingeführt werde.

1967 schlug Lau vor, die im Westen lebenden Domherren zu „auswärtigen Mitgliedern (Ehrendomherren)“ zu ernennen, um ihre Stellen rechtzeitig vor der Jahrtausendfeier des Bistums Meißen neu besetzen zu können. Während der frühere Dechant Heynitz schweren Herzens zustimmte, weigerte sich der im Westteil Berlins lebende Jurist Schulz-Blochwitz, auf die vollen Rechte eines Domherrn zu verzichten. Dabei führte er in seiner ausführlichen Erläuterung Argumente an, die einem DDR-Bürger äußerst fremd erscheinen mussten: „Jetzt stehen wir als Meißner Domherren für die ,chefs du protocole' der westlichen Länder auf Grund der Königlich Sächsischen Hofrangordnung, - die insoweit heute noch gilt - im Rang unmittelbar hinter den Kammerherren und vor den Obersten bzw. vor dem Rektor der Universität, vor den Geheimen Räten, den Universitätsprofessoren, den Oberbürgermeistern von Dresden und Leipzig usw. Dann aber als Ehrendomherren sind wir eine neue Kategorie ohne gesichtliche Bevorrechtigung, ein novum, ohne historischen Rang. Das mag zwar für die Herren in Mitteldeutschland ohne Belang sein, für uns im Westen Wohnende ist das durchaus wichtig und von Belang." SchulzBlochwitz starb noch 1967. Damit war das Problem keinesfalls gelöst, denn im gleichen Jahr verlegte Dr. Thomas seinen Wohnsitz nach Bayern. Er weigerte sich ebenfalls, auf seine Domherrenstelle zu verzichten. 1973 reiste schließlich Dr. Rietschel, der das Rentenalter erreicht hatte, in den Westen aus. Das Domkapitel hielt die Verbindung aufrecht, indem die Teilnehmer der Kapitelsitzungen regelmäßig Grüße an die im Westen lebenden Domherren richteten.

1970 begannen Gespräche zwischen dem Domkapitel und dem Landeskirchenamt zur Neuregelung der Verfassung des Hochstifts. Am 19. Januar 1970 
trug Dr. Blaschke als Bevollmächtigter des Domkapitels, dem er noch gar nicht angehörte, vor, „eine Neuordnung solle nicht von den Einkünften der Domherren her gesehen werden, sondern von ihren Aufgaben und Pflichten her. Der der Einrichtung der Professorenkanonikate zugrundeliegende Gedanke - Aufbesserung der Professoreneinkünfte - sei nicht mehr aktuell.“39 Als Domdechant setzte sich Blaschke mit Nachdruck für eine Regelung der offenen Fragen ein. Auf sein Betreiben erhielt das Hochstift am 30. Januar 1976 eine neue, mit dem Landeskirchenamt abgestimmte Verfassung. Geändert wurde der $\S 4$, der die Vorrausetzungen für die Mitgliedschaft im Domkapitel benannte, wobei das Erfordernis von Verdiensten um die Landeskirche ersatzlos entfiel. Dafür mussten die Mitglieder ,ihren ständigen Wohnsitz in der DDR haben.“ Das Recht der Universität Leipzig, zwei Kanonikate zu besetzen, wurde gestrichen. Dafür hieß es: „Es soll darauf Bedacht genommen werden, daß mindestens zwei Mitglieder des Domkapitels Lehrer der evangelischen Theologie im Bereich der Landeskirche sind." Hier wurde absichtlich eine weitgefasste, schon 1970 von Blaschke vorgeschlagene Formulierung gewählt, um auch Lehrern des Theologischen Seminars und anderer kirchlicher Bildungseinrichtungen den Eintritt in das Domkapitel zu ermöglichen. Weiterhin führte die Verfassung vom 30. Januar 1976 den Status eines außerordentlichen Domherrn ein. So hieß es: „Wenn ein Domherr seinen ständigen Wohnsitz nicht mehr in der DDR hat, wird er außerordentlicher Domherr, auch sonst kann ein Domherr in den Stand eines außerordentlichen Domherrn treten.“

\section{Leben im und am Dom in der DDR}

Die Jahre nach dem Zweiten Weltkrieg waren durch die Beseitigung der Kriegsschäden bestimmt. ${ }^{40}$ Dombaumeister Dr. Hubert Ermisch, der zugleich als Zwingerbaumeister den Wiederaufbau des Dresdner Zwingers leitete, sorgte dafür, dass Beschussschäden behoben wurden. 1948 kehrte die Johannesglocke, die zum Glück nicht eingeschmolzen worden war, unter abenteuerlichen Umständen nach Meißen zurück. Am 17. Oktober 1948 nahm sie wieder ihren angestammten Platz im Nordwestturm ein. Dr. Ermisch starb 1951, und Oberbaurat Dr. Walter Zimmermann (18811962) trat sowohl als Zwingerbauleiter als auch als Dombaumeister dessen Nachfolge an. Unter seiner Aufsicht erfolgte 1952/53 eine Einrüstung der Domtürme, so dass auch an sonst unzugänglichen Stellen die Kriegsschäden beseitigt werden konnte. 1960 erhielt der Meißner Dom drei neue Glocken. Die Glockenritzzeichnungen führte der spätere Domherr Dr. Rietschel im Juni 1959 in der Glockengießerei in Apolda aus. Am 11. Juni 1960 feierte man die Glockenweihe. ${ }^{41}$

Als 1962 Max Zimmermann starb, musste die Verbindung zur Zwingerbauhütte in Dresden gelöst werden, da der Nachfolger, Arthur Frenzel, den christlichen Glauben ablehnte. So wurde der Dresdner Architekt Fritz Steudtner (1896-1986), der als kirchlicher Baupfleger die evangelischen Kirchen im Bezirk Dresden betreute, stellvertretend mit den Aufgaben des Dombaumeisters betraut. Obwohl das Landeskirchenamt seine Berufung zum Dombaumeister und sogar seine Aufnahme in das Domkapitel wünschte, lehnte das Domkapitel ab, was Domdechant Lau am 19. Juli 1968 wie folgt begründete: „Schon bei dem letzten Dombaumeister Dr. Zimmermann hat es Schwierigkeiten gegeben wegen seiner fragwürdigen kirchlichen Einstellung. Als Nachfolger hätte ein ganz eindeutiger Atheist bestellt werden müssen. Davon hat das Domkapitel Abstand genommen und den kirchlichen Baupfleger für den Bezirk Dresden gebeten, vorläufig stellvertretend das Amt des Dombaumeisters zu übernehmen. Dann stellte sich heraus, daß Herr Architekt Steudtner praktisch deshalb nicht zurechtkam, weil er mit der Zwingerbauhütte nicht zusammenarbeiten konnte, was aber für die Beschaffung von Baumaterial unerläßlich ist. " ${ }^{42}$ Am 8. Mai 1968 wurde der Baureferent der sächsischen Landeskirche, Dr.Ing. Otto Baer, zum Dombaumeister berufen. Obwohl er trickreich und mit „Fischelanz“ fehlende Baumaterialien beschaffte und eine domeigene Baubrigade gründete, die Dach- und Putzreparaturen vornahm, konnte er den fortschreitenden Verfall nicht aufhalten. 1984 zerstörte ein Sturm Teile der Dachdeckung, was man nicht sofort beheben konnte. Von der Westturmfront fielen lockere Steinteile hinab. Deshalb sperrte die staatliche Bauaufsicht Teile des Domplatzes und die Domtürme mit der Auflage, die Schäden noch 1984 zu beheben. Doch dafür hatte man weder Gerüste, Material noch Arbeitskräfte. Während sich die Notlage immer mehr zuspitzte, untersuchte die am 15. September 1979 mit Hilfe des Instituts für Denkmalpflege gegründete Restaurierungswerkstatt des Hochstifts Meißen ${ }^{43}$ die wertvollen Ausstattungsteile des Meißner Doms auf Spuren ihrer mittelalterlichen Farbigkeit. Auf dieser Grundlage erfolgte die Wiederherstellung der Farbigkeit des Westportals im Zustand des 14. Jahrhunderts. Weil alle verinnerlicht hatten, dass die Bedingungen der DDR-Mangelwirtschaft nicht zu ändern waren, fiel niemandem die absurde Situation auf, dass einerseits Teile des Daches einzustürzen drohten, andererseits unter diesem Dach genaueste wissenschaftliche Forschungen betrieben wurden.

Nach der Tausendjahrfeier Meißens, die man 1929 festlich begangen hatte, stand für das Jahr 1968 das Jubiläum „1000 Jahre Bistum Meißen“ an. Dazu planten Landeskirche und Hochstift einen Landeskirchentag in Dresden und Meißen. Doch von Seiten staatlicher Stellen war eine öffentliche Darstellung christlichen Glaubens nicht erwünscht. Der Rat des Bezirks Dresden teilte mit, dass man keinen Kirchentag wünsche, weshalb keine Unterstützung bei Unterkunft, Verpflegung und Verkehr gewährt werden könne. Auch ein kleineres Veranstaltungsformat ließ sich nicht rea-
39 Landeskirchenarchiv Dresden, Bestand 2, Nr. 3892.

40 Vgl. Donath 2008 (wie Anm. 8), S. 253-255.

41 Vgl. Peter 2011/2012 (wie Anm. 6), S. 15-18.

42 Landeskirchenarchiv Dresden, Bestand 2, Nr. 3892.

43 Vgl. Elisabeth Hütter: Die Restaurierungswerkstatt am Dom zu Meißen 1979-1993. In: Ecclesia Misnensis 2 (1999), S. 72-75. 
44 Vgl. die Beiträge in Triangel. Das Programmjournal des Mitteldeutschen Rundfunks 2 (1997), Heft 10, ferner Das Meissner Tedeum. Eine deutsch-deutsche Dialog-Komposition zum 1000jährigen Bestehen des Meißner Doms (1968). In: Matthias Hermann (Hrsg.): Die Dresdner Kirchenmusik im 19. und 20. Jahrhundert. Laaber 1998, S. 517-530.

45 Siegfried Bräuer: Das Zensurverfahren bei der Festschrift zur Tausendjahrfeier des Bistums Meißen 1968. In: Herbergen der Christenheit. Jahrbuch für deutsche Kirchengeschichte 18 (1993/1994), S. 131-146.

46 Franz Lau (Hrsg.): Das Hochstift Meißen. Aufsätze zur sächsischen Kirchengeschichte. Leipzig 1973.

47 Heinrich Magirius: Orgeln im Meißner Dom. In: Ecclesia Misnensis 4 (2001), S. 113-121, hier S. 119-121; Armin Zuckerriedel: Zur Generalüberholung der Meißner Domorgel. In: Ecclesia Misnensis 3 (2000), S. 133135.

48 Landeskirchenarchiv Dresden, Bestand 2, Nr. 3892.

49 Auerbach 2002 (wie Anm. 6), S. 8 mit einer Übersicht der Tagungsthemen.

Dompropst Ernst Sommerlath, der neu aufgenommene Domherr Christoph Michael Haufe und Domdechant Karlheinz Blaschke zum Kapiteltag am 26. Mai 1974 (๑) Hochstift Meißen lisieren, so dass schließlich am 23. Mai 1968 nur ein Gottesdienst und ein Empfang durchgeführt werden konnten. Dabei trugen die Domherren erstmals ihr neu gestaltetes Ornat. Es ersetzte die schwarzen Chormäntel, die in dieser Gestalt seit dem 19. Jahrhundert in Gebrauch gewesen waren, sowie eine um 1960 eingeführte geistliche Tracht, bestehend aus Soutane, Chorhemd, Schulterkragen und Barett. Nach einem „Gutachten zur Neugestaltung der gottesdienstlichen Gewänder der Domkapitulare des Hochstifts Meißen“ von Domherr Dr. Rietschel beriet das Domkapitel am 31. Januar, 23. März, 4. Mai und 17./18. Mai 1968 über die Neugestaltung der Ornate. Rietschel hatte vorgeschlagen, über der Soutane oder dem schwarzen Gesellschaftsanzug einen langen weißen Chormantel und darüber eine farbige Almutia (Schulterkragen), eventuell mit Pelzbesatz, zu tragen. Dieser Vorschlag war von der Chorkleidung der Domherren vor der Reformation abgeleitet. Bei der letzten Beratung wurden eine lilafarbene Almutia und die Verwendung von Pelz verworfen und dafür beschlossen, über dem weißen Chormantel eine Almutia aus gelblicher Seide zu tragen. Dem Gottesdienst folgten ein Empfang des Domkapitels, zu dem Domdekan Dr. Heinrich Bulang (1914-1976) als Vertreter der katholischen Kirche eine Ansprache hielt, sowie eine öffentliche Vorlesung im Kapitelsaal. Der katholische Bischof Otto Spülbeck (1904-1970) war nicht anwesend, denn die katholische Kirche beging das Jubiläum des Bistums Meißen separat.

Höhepunkt der Tausendjahrfeier war die Aufführung des „Meißner Tedeums“, einer modernen Komposition des Kirchenmusikers Wolfgang Hufschmidt (geb. 1934), am 26. Mai 1968. Domkantor Dr. Schmidt hatte durch Kontakte nach Westdeutschland erwirkt, dass der in Essen lehrende Hufschmidt einen Kompositionsauftrag erhielt.

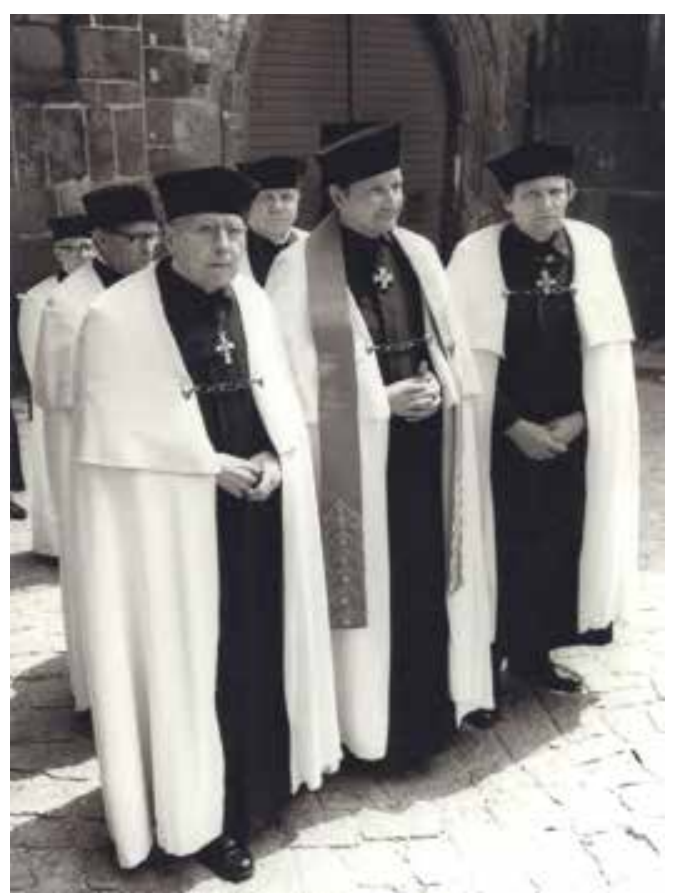

Das Stück zeichnet sich dadurch aus, dass dem Text des „Tedeum laudamus“ von Martin Luther (14831546) ein antiphonischer Text von Günter Grass (1927-2015) entgegengesetzt war. Grass' Worte äußerten bittere Zweifel an Gott, weshalb Landesbischof Noth und andere Beteiligte dem Stück vorwarfen, es hole den Teufel in die Kirche. Das Domkapitel nahm an der Generalprobe am 18. Mai 1968 teil und stimmte daraufhin einer Aufführung zu. Das von der Meißner Kantorei 1961 aufgeführte „Meißner Tedeum“ war ein Meilenstein in der Entwicklung der modernen Kirchenmusik. ${ }^{44}$

Zum Jubiläum sollte eine Festschrift mit wissenschaftlichen Beiträgen zur Geschichte des Bistums und Hochstifts Meißen erscheinen. Die staatlichen Behörden verhinderten jedoch ein Erscheinen. ${ }^{45}$ Man warf der Publikation vor, dass sie „der Propagierung und Durchsetzung interkonfessioneller Bestrebungen dienen soll, an denen die Staatsorgane der DDR kein Interesse haben." Die Aufsatzsammlung konnte erst 1973, fünf Jahre nach dem Jubiläum, als Sonderband der Zeitschrift „Herbergen der Christenheit" erscheinen.$^{46}$ Auch der Festschrift des katholischen St. Benno-Verlags wurde die Druckerlaubnis verweigert.

Seit Anfang der 1950er Jahre wünschten Organisten und Kantoren einen Neubau der Orgel des Meißner Doms. 1963 erhielt die Bautzener Orgelfirma Eule den Auftrag. Die Ausführung verzögerte sich, weil lange um den Standort der Orgel und die Gestaltung des Orgelprospekts gerungen wurde. Schließlich wurde die Orgel auf der Lettnerbühne vor der Nordwand des östlichen Querhausarms angeordnet. Am 1. Oktober 1972 wurde die mit einem bewusst schlichten Prospekt versehene Orgel eingeweiht. ${ }^{47}$

Das Domkapitel kam seiner Aufgabe, den Meißner Dom als evangelisches Gotteshaus zu erhalten, nach, indem Dompfarrer und Domprediger Sonntagsgottesdienste anboten. Die Zahl der jährlichen Gottesdienste schwankte, denn nicht jeden Sonntag wurde ein Gottesdienst gehalten. In den Wintermonaten wurden die Gottesdienste im leichter beheizbaren Kapitelsaal in der Dompropstei gefeiert oder sie fielen ganz aus. So klagte Domdechant Lau am 15. Juli 1965 beim Landeskirchenamt: „Daß der Dom im Winter einfach brachliegen bleibt, halte ich für völlig untragbar." Die Landesbischöfe Hahn und Noth predigten dreimal, seltener viermal im Jahr im Dom. Der 1972 eingeführte Landesbischof Johannes Hempel konnte hingegen keine Zuneigung zum Meißner Dom entwickeln. Er kam deutlich seltener nach Meißen, auch interessierten ihn die Angelegenheiten des Domkapitels nur wenig. Manche Jahre hielt er keine oder nur eine einzige Bischofspredigt im Meißner Dom. Die übergemeindliche Bedeutung des Meißner Doms kam dadurch zum Ausdruck, dass sich zahlreiche Hochzeitspaare im Meißner Dom trauen ließen. Auch wurden jährlich mehrere Kinder getauft, wohl vor allem deshalb, weil die Eltern den festlichen Rahmen der gotischen Kathedrale wünschten. Als Domprediger Ackermann 1982 
seinen Dienst antrat, wurden im Winterhalbjahr keine Gottesdienste angeboten. In den Sommermonaten fand der Gottesdienst um 14:00 Uhr statt, meist als Abschluss einer Tagung der evangelischen Akademie. Seit 1980 wurde jeden Mittwochvormittag eine Andacht gehalten.

Die „Unternutzung“ des Doms - trotz seines Rangs als Bischofskirche, der Verbindung mit der Evangelischen Akademie und der regen kirchenmusikalischen Arbeit - wurde in den Jahren der DDR wiederholt angesprochen. Domdechant Lau meinte am 15. Juli 1965 pessimistisch: „Daß der Dom, um es einmal hart auszudrücken, für die Stadt Meißen überflüssig ist, ist aber immer wieder kund geworden.“48 Domprediger Ackermann beklagte 1985 vor dem Domkapitel die „Diskrepanz zwischen Größe und Bedeutung des Domes zu einer fehlenden Gemeinde und kirchlichen Bestimmung z.B. für die Sächs. Landeskirche“. Damit verbunden wurde auch die Existenzberechtigung des Domkapitels in Frage gestellt. So berichtete Domdechant Blaschke in der Kapitelsitzung am 29./30. Mai 1976 von einem Gespräch mit Oberlandeskirchenrat Dietrich Mendt (1926-2006): „OLKR Mendt warf die Frage auf, ob eine Fusion mit der Evangelischen Akademie möglich sei. Er habe den Eindruck, das Domkapitel suche krampfhaft nach Aufgaben. Er hält das Kapitel für nicht nötig und meint sogar, man solle die Ornate verbrennen."

Domdechant Blaschke legte am 8. April 1977 „Gedanken über die weitere Entfaltung des geistlichen Lebens am Meißener Dom“. Er war sich bewusst, dass der Dom auch in Zukunft keine eigene Gemeinde haben werde. Man könne aber die Besucher durch Führungen mit geistlichen Inhalten und durch Kurzandachten für den christlichen Glauben gewinnen. Außerdem sollten im Dom grafisch gestaltete Worte als „Sichtwerbung“ angebracht werden. Blaschke schlug ferner die Darbietung alter und moderner Kunst in einem Ausstellungsraum sowie „eine Ausstellung zur Landeskirchengeschichte (Dommuseum)“ vor. Weiterhin sollten Tagungen, Gespräche und Veranstaltungen zum Thema „Kirche in der Zeit“ bzw. „Kirche und Geschichte“ angeboten werden.

Nur ein Teil dieser Ideen ließ sich umsetzen. Dazu gehörte die Nutzung des Doms als Ausstellungsort des Kunstdienstes der evangelischen Landeskirche. Seit den 1970er Jahren wurden an den Wänden des Kirchenschiffs Werke moderner Kunst mit kirchlichem Bezug gezeigt. Dagegen wurde der Vorschlag, den Dom zu einer „Sammlungsstätte kirchlicher Kunst“ zu machen, gemeint war ein Depot für Kunstwerke aus aufgegebenen Kirchen, nicht umgesetzt. 1978 begründete Domdechant Blaschke die Begegnungstagung „Kirche und Geschichte“, zu der sich einmal im Jahr an einem Wochenende im Herbst evangelische wie katholische Teilnehmer einfanden, um die Bedeutung der Geschichte für die Herausforderungen der Gegenwart zu diskutieren. Bis 1990 fanden insgesamt 13 thematische Tagungen statt. ${ }^{49}$ Um die Verbindungen zur evangelischen Kirche im Westen Deutsch-

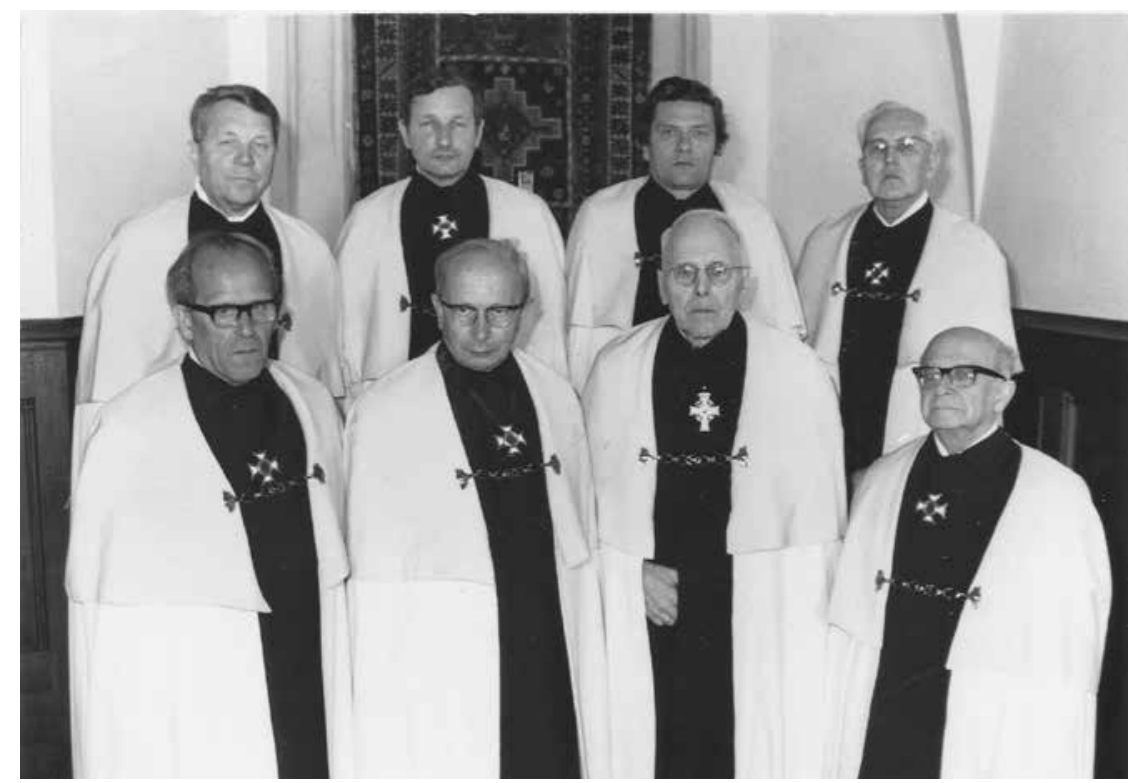

lands nicht abbrechen zu lassen, wurden Anfang der 1980er Jahre Kontakte zum Kloster Loccum in Niedersachsen aufgenommen. Dort besteht seit der Reformation ein evangelischer Konvent, der das Erbe der Zisterzienser fortführt. Mehrfach kamen Angehörige des Loccumer Konvents nach Meißen, während Meißner Domherren, die in den Westen reisen durften, an Tagungen in Loccum teilnahmen.

Der Meißner Domkapitel setzte sich zwar aus Personen zusammen, die dem Staat eher kritisch gegenüberstanden und sich durchaus um die Entwicklung der Gesellschaft sorgten. Aber da die Domherren nur selten zusammenkamen und zudem darauf bedacht waren, den Betrieb des Meißner Doms ohne Konflikte mit staatlichen Stellen aufrechtzuerhalten, konnten sich am Meißner Dom keine Strukturen einer DDR-Opposition entwickeln. In der Restaurierungswerkstatt waren mehrfach Mitarbeiter angestellt, die Ausreiseanträge gestellt hatten, doch diese verließen die DDR. Domküster Stephan Nierade versuchte, den Dom für alternative Veranstaltungen zu öffnen. So wurde 1985 auf sein Betreiben im Meißner Dom die Fotoausstellung „Die Elbe“ gezeigt, die die Umweltverschmutzung in der DDR anprangerte. Nach Einwirken staatlicher Stellen und einer Vorladung von Vertretern des Landeskirchenamts musste die Ausstellung wieder abgebaut werden. Es erstaunt, dass sich das Domkapitel nicht schützend vor den Domküster stellte, sondern selbst von „stark staatsfeindlichen“ Inhalten redete. Im Protokoll der Kapitelsitzung vom 10. Mai 1986 heißte es: „Am 28.3. [1985] war in der Dienstbesprechung seitens des Küsters vorgeschlagen worden, das alljährliche Jazz-Konzert durch einen Bilderzyklus ,Die Elbe', unter den Thema Umweltschutz zu unterstützen. Die Ausstellung enthielt stark staatsfeindlich gefärbte Tendenzen und z.T. unverständliche, vom Thema völlig abweichende Formulierungen. Diese negativen Inhalte waren durch zahlreiche Bürgereingaben unterstützt zum Anlaß
Kapiteltag am 26. Mai 1974. Oben von links nach rechts Christian Rietschel, Christoph Michael Haufe, Karlheinz Blaschke, Hans Bardtke, unten Hans Nadler, Paul Liebe, Ernst Sommerlath, Ernst Wäntig (- Hochstift Meißen 
50 Vgl. dazu Steinecke 2007/ 2008 (wie Anm. 6), S. 105.

51 Landeskirchenarchiv Meißen, Bestand 2, Nr. 3889, dort auch die folgenden $\mathrm{Zi}-$ tate.

52 Gemeint ist die Neugründung des Bistums Meißen 1921.

53 Vgl. auch Seifert 1997 (wie Anm. 9), S. 349-350. einer Anfrage geworden, die in gleicher Weise auch das LKA seitens des Rates des Bezirkes erhielt. Die Herren OLKR. Fritz und OLKR. Schlichter waren in Dresden zur Aussprache gebeten worden. Durch Zusage der sofortigen Entfernung konnten Weiterungen abgewendet werden."

Unter den Mitarbeitern des Hochstifts Meißen gab es keine inoffiziellen Mitarbeiter des Staatssicherheitsdienstes der DDR. Das belegte eine Überprüfung, die 1993 durchgeführt wurde.

\section{Das Verhältnis zur römisch-katholischen Kirche}

Die Öffnung des Meißner Doms gegenüber Mitchristen anderer Konfessionen ist ausgerechnet der FDJ zu verdanken. 1946 gegründet, entwickelte sich der anfangs überparteiliche Jugendbund rasch zur einzigen Jugendorganisation der DDR und zur „Kaderreserve“ der SED. Doch im Mai 1947, beim II. Parlament der FDJ in Meißen, gab sich die Jugendorganisation noch pluralistisch. Der FDJ-Kreisverband, dem auch der Jugenddiakon Walter Birkner von der Frauenkirchgemeinde und Gerhard Wippler von der katholischen Pfarrei St. Benno angehörten, hatte dem Organisationsstab einen ökumenischen Gottesdienst im Meißner Dom vorgeschlagen. Nach anfänglichem Widerstand wurde dafür die Genehmigung erteilt, vor allem, weil sich die katholische Meißner CDULandtagsabgeordnete Many Jost (1897-1992) und der evangelische CDU-Landesvorsitzende und stellvertretende Domdechant Hugo Hickmann dafür ausgesprochen hatten. An dem Gottesdienst am 25. Mai 1947 nahmen 1.800 Jugendliche teil. Der evangelische Jugendpfarrer Hanisch und der katholische Domvikar Lange hielten die Predigten, während der Evangelische Singekreis mit dem „Magnificat“ von Dietrich Buxtehude für einen festlichen musikalischen Rahmen sorgte..$^{50}$

In diesem Umfeld wurden mehrere Stimmen laut, die eine mehrkonfessionelle Nutzung des Meißner Doms forderten. ${ }^{51}$ Der evangelische Pfarrer Dr. Karl August Busch (1886-1952), Mitglied der Landesleitung der Freien Volkskirchlichen Vereinigung, schrieb im „Sächsischen Tageblatt“ am 19. April 1947 im Hinblick auf den Meißner: „Ist es nicht schade um diesen wundervollen einsamen Bau? Es genügt nicht, daß er wie ein Museum nur von Fremden besucht wird. [...] Könnte nicht dieses ehrwürdige Gotteshaus beiden Konfessionen geöffnet werden und offen stehen? [...] Wär es nicht eine große echt christliche, brüderliche und für den dauernden künftigen Frieden unter den Konfessionen in Sachsen und vielleicht darüber hinaus entscheidende und wegweisende Tat, wenn die evangelische Kirche sich großherzig entschließen würde, den bis jetzt evangelischen Dom auch der katholischen Schwesterkonfession zur Verfügung zu stellen, so daß sonntäglich beide Konfessionen in ihm ihre Gottesdienste feiern könnten?" Busch beantragte am 22. März 1948 beim Landeskirchenamt, den Dom für andere christliche Kon- fessionen zu öffnen. Zuvor hatte der frühere Meißner Superintendent Dr. Neuberg gewettert: „Die römische Kirche kann nicht anders als darauf ausgehen, den Meissner Dom für das Bistum Meissen als dessen Kathedrale zurückzuerobern. In der Überlassung des Domes zu einem Messgottesdienst und Hochamt sehe ich eine grosse Gefahr." 1956 setzte sich Oskar Pinkert aus Leipzig beim CDU-Vorsitzenden Otto Nuschke (1883-1957) dafür ein, den Dom zu einer Simultankirche zu machen. Domdechant Lau, von Nuschke zu einer Antwort aufgefordert, schrieb am 23. Oktober 1956, dass „aus grundsätzlichen Erwägungen heraus“ ein Zuverfügungstellen des Meißner Doms nicht erfolgen könne. Der Dom sei Landeskathedrale der Evangelisch-Lutherischen Landeskirche Sachsens, während die katholische Kirche in Meißen ein eigenes Gotteshaus besitze.

Am 8. September 1954 bat der Meißner katholische Pfarrer Erzpriester Paul Kneschk (gest. 1960) Dompropst Hickmann um Überlassung des Doms für eine Bonifatiusfeier zum Gedenken an den 1200 Todestag des „Apostels der Deutschen“. Das Landeskirchenamt beschloss jedoch eine Ablehnung. Kneschke unternahm zwei Jahre später einen neuen Versuch, indem er einen Antrag auf die Überlassung des Doms für eine St. Benno-Feier stellte. 1956 erinnerte die katholische Kirche an den 950. Todestag des früheren Meißner Bischofs, dessen Gebeine bis 1539 im Meißner Dom verehrt wurden. Dass Domkapitel beriet am 13. Mai 1956 und gab die Anfrage an das Landeskirchenamt weiter. Propst Sommerlath notierte: „So sehr man aus Gründen der brüderlichen Hilfe geneigt sein könnte, den Dom zu überlassen, hielt das Landeskirchenamt es dennoch für ratsam, den Dom nicht zur Verfügung zu stellen. Wie auch schon in der Sitzung des Domkapitels zu Exaudi zur Sprache gekommen war, hat der Dom für die sächsische Landeskirche eine besondere und herausgehobene Bedeutung. Eine Überlassung des Domes für eine katholische Feier erhält dadurch ein über den Einzelfall hinausgehendes Gewicht. Auch ist darauf Rücksicht zu nehmen, daß eine Überlassung des Domes zu einer katholischen Feier in weiten Kreisen der Landeskirche und der Pfarrerschaft nicht verstanden werden würde, sondern Ärger erregen könnte." Der Vorschlag, eine andere Meißner Kirche zu überlassen, war nicht im Sinne der katholischen Pfarrer, der es ja bewusst darum ging, im Meißner Dom, der Wirkungsstätte Bennos, des heiligen Bischofs zu gedenken.

Eine fortdauernde Verbindung mit dem Domkapitel St. Petri in Bautzen war dadurch gegeben, dass die Meißner Domherren die Propst zu Bautzen aus ihren Reihen wählten und das Hochstift Meißen das Nießbrauchsrecht an der Propstei Bautzen ausübte. Die Neuwahl eines Propstes zu Bautzen wurde pflichtgemäß dem katholischen Domkapitel angezeigt. 1968 brachte das Bautzener Domkapitel erstmals zum Ausdruck, dass es die Besetzung der Propstei mit einem Meißner Domherr nicht ablehne, sondern hoffe, dass der Propst zu Bautzen zu 
einem Verbindungsmann zwischen den Domkapiteln werde. Domdekan Dr. Heinrich Bulang (19141976) schrieb am 15. Juni 1968 an Domdechant Lau: „Im Namen unseres Kapitels danke ich Ihnen verbindlichst für die freundliche Mitteilung, daß Herr Superintendent i. R. Herbert Böhme Nachfolger des im vergangenen Oktober heimgesuchten Dompropstes zu Bautzen geworden ist. Wenn ihm sein hohes Alter auch nicht gestattet, tätig zu werden, so begrüße ich doch insbesondere Ihren glücklichen Gedanken, dieser Dompropst könnte in Zukunft zufolge des gegebenen fundamentum in re einmal der geborene Verbindungsmann zwischen unseren Institutionen sein.“ Dieses Angebot ist vom Meißner Domkapitel nicht angenommen worden. Auf Herbert Böhme folgte als vorerst letzter Propst von Bautzen 1972 der Zwickauer Oberkirchenrat Ernst Wäntig. Es ist nicht bekannt, dass dieser das Gespräch mit den Mitgliedern „seines“ Domkapitels suchte, das 1980 seinen Sitz von Bautzen nach Dresden verlegte.

Nachdem Wäntig 1987 auf die Propstei Bautzen verzichtet hatte, wurde die Stelle nicht mehr besetzt. Domdechant Blaschke sah in diesem Amt ein überholtes Relikt, das einer Versöhnung der Konfessionen im Wege stand. Aus Anlass des 775-Jahrfeier des Domkapitels St. Petri richtete er am 29. Juni 1996 an den Domdekan Weihbischof Georg Weinhold (1934-2013) folgendes Schreiben: „Mit Rücksicht auf diese Neugründung ${ }^{52}$, auf die Trennung der Konfessionen und auf den in den vergangenen Jahrzehnten erreichten Stand der ökumenischen Beziehungen halten wir diese traditionsbedingt Regelung nicht mehr für angemessen. Das Domkapitel zu Meißen hat daher mit dem Ausscheiden des Domherrn Ernst Wäntig, der als letzter den Titel eines Dompropstes zu Bautzen geführt hat, seit dem Jahre 1987 diese Stelle nicht wieder besetzt und betrachtet seitdem die Funktion eines Dompropstes zu Bautzen innerhalb des Domkapitels zu Meißen als erloschen. Das gleiche gilt für alle Rechte, Einkünfte und Besitzungen, die mit dem Amt des Bautzener Propstes innerhalb des Meißner Domkapitels verbunden waren." ${ }^{53}$ Er meinte, damit eine endgültige Ablösung des Meißner vom Bautzener Domkapitel vollzogen zu haben. Allerdings hatte Blaschke das Schreiben aufgesetzt, ohne sich der Zustimmung des Domkapitels und des Landeskirchenamts versichert zu haben. Erst nachträglich fragte er am 2. November 1996 das Domkapitel, das seinem Antrag einstimmig zustimmte. Bei der Neufassung der Verfassung des Hochstifts Meißen, die das Domkapitel am 25. Mai 1998 verabschiedete, war demzufolge jeder Hinweis auf die Propstei Bautzen entfallen.

Diese Änderung wurde indes vom Landeskirchenamt nicht genehmigt. Hans-Dieter Hofmann, der Präsident des Landeskirchenamtes, brachte in seinem Schreiben vom 20. Februar 1999 mehrere Argumente vor. Das Hochstift Meißen sei eine rechtsfähige kirchliche Stiftung unter Aufsicht des Landeskirchenamts und unterliege dem Stiftungsund dem Stiftungsaufsichtsgesetz. Der einseitige
Verzicht auf die Propstei Bautzen komme einer Schenkung gleich. Das verstoße gegen den Grundsatz der Bestandserhaltung des Stiftungsvermögens. Das Hochstift Meißen habe als öffentlichrechtliches Stift streng auf Bestandswahrung und -mehrung zu achten. Es könne mit dem Stiftungsvermögen nicht wie ein Eigentümer verfahren und es einfach verschenken. Darüber hinaus trug Hofmann auch bemerkenswerte theologische Einwände vor: Der Dienst des Domkapitels umfasse „das Streben nach sichtbarer Einheit der Kirche ebenso wie die Sorge um die Reinheit der Verkündigung und die Evangeliumsgemäßheit allen kirchlichen Handelns. Es ist dem Hochstift infolgedessen verwehrt, gegenüber anderen Konfessionen, die sich ebenfalls auf das Evangelium berufen, Gleichgültigkeit zu zeigen oder sich bewusst mit einer gegenseitigen Abgrenzung zufrieden zu geben. [...] Die einseitige Aufgabe der Stellung des Propstes zu Bautzen durch das Hochstift Meißen wäre nicht etwa ein Zeichen ökumenischer Gesinnung. Sie würde vielmehr die Spaltung der abendländischen Kirche gerade an einer Stelle vertiefen, an der sie bis heute institutionell überbrückt ist. Die Stellung des Propstes zu Bautzen im Domkapitel zu Meißen ist eine ständige und heilsame Erinnerung und Mahnung an beide beteiligte Konfessionen, sich ihre jahrhundertelange gemeinsame Geschichte zu vergegenwärtigen, die Reformation als die ganze Kirche betreffend zu erkennen und dem Missverständnis zu begegnen, die Inhalte des Evangeliums ließen sich in statisch abgeschlossenen Kirchentümern zementieren." Die katholische Seite habe das Fortbestehen der Propstei Bautzen nie angetastet und werde durch sie nicht in ihrer Handlungs- und Repräsentationsfreiheit beeinträchtigt.

Nach diesem Einwand blieb die Propstei Bautzen in der Verfassung des Hochstifts Meißen bestehen, und das Domkapitel musste zur Kenntnis nehmen, dass der 1996 ausgesprochene Verzicht unwirksam war. Er ist auch nie vollzogen worden, denn

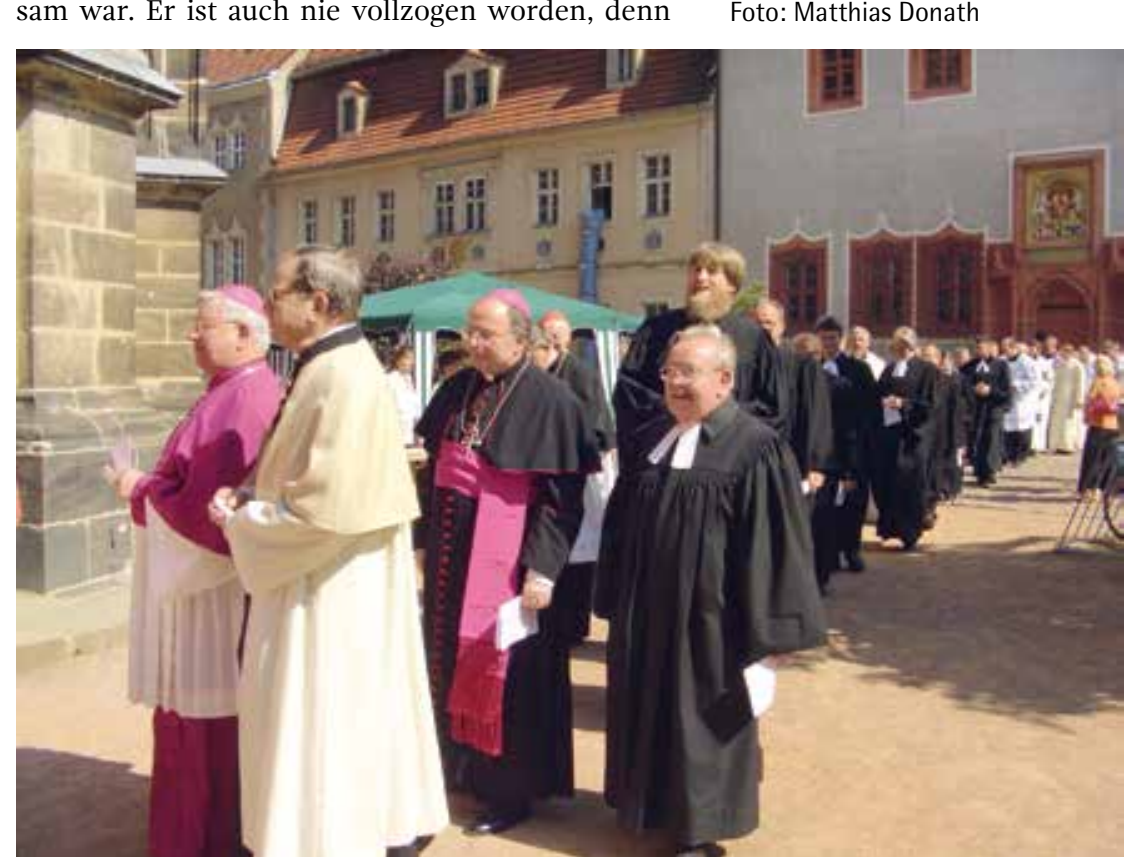

Einzug katholischer und evangelischer Geistlicher, darunter Kardinal Friedrich Wetter aus München, zur Bennofeier am 16. Juni 2006 im Meißner Dom Foto: Matthias Donath 
54 Auerbach 2002 (wie Anm. 6), S. 11.

55 Vgl. Günter Donath (Hrsg.): Die Restaurierung des Doms zu Meißen 1990-2002. Stuttgart 2003, sowie die ausführlichen Dombauberichte in den Jahrbüchern „Ecclesia Misnensis“ und „Monumenta Misnensia“.

56 Vgl. Katharina Flügel: Das neue Dommuseum: Der Dom zu Meißen und die Kirche in Sachsen. In: Ecclesia Misnensis 3 (2000), S. 136-138. das Hochstift Meißen bezieht bis heute die Einnahmen der Propstei Bautzen. Diese sind allerdings durch die Enteignungen in der DDR zu einer kläglichen Summe zusammengeschmolzen. Heute beträgt der jährliche Erlös 765,92 Euro, die der Bautzener Kleingartenverein Land in Sonne e.V. an das Hochstift Meißen entrichtet. Die Stelle des Propstes zu Bautzen ist dennoch nicht wieder besetzt worden.

Dass sich ein Wandel in Beziehungen der Konfessionen vollzogen hat, ist daran zu erkennen, dass seit 1990 regelmäßig ökumenische Gottesdienste im Meißner Dom stattfinden. Schon am 3. Oktober 1990 zum Tag der Deutschen Einheit wurde ein solcher gefeiert. Mehrfach kam der Bischof des Bistums Dresden-Meißen in den Meißner Dom. So predigte Bischof Joachim Reinelt (geb. 1936) am 5. September 1993 und am 12. Mai 2002 in der Domkirche. Das Domkapitel St. Petri nahm mehrmals an Festgottesdiensten zu Kapiteltagen teil. Dompropst Dieter Auerbach bemerkte dazu: „An dem Ort zu beten, zu singen und zu predigen, an dem unsere gemeinsamen Wurzeln offen liegen, bleibt den Bischöfen beider Konfessionen ein wichtiges Anliegen." ${ }^{\text {45 }}$ Ein neuer Grad an Gemeinsamkeit wurde 2006 erreicht, als im Rahmen des Bennojubiläums katholische und evangelische Christen zu einer Bennofeier im Meißner Dom zusammenkamen - 50 Jahre, nachdem das Domkapitel eine solche Veranstaltung noch verboten hatte. Meißner Domherren setzten sich persönlich dafür ein, einen neuen Stand ökumenischer Beziehungen zu erreichen. So engagierte sich Prof. Dr. Ulrich Kühn für ein gemeinsames Abendmahl von katholischen und evangelischen Christen. Als Lutheraner lehrte er an der Päpstlichen Universität Gregoriana in Rom.

\section{Neue Chancen}

Das Meißner Domkapitel hat nicht zur Friedlichen Revolution beigetragen, auch wenn sich einzelne Domherren 1989/90 durchaus mutig zu Wort gemeldet haben. So beteiligte sich Domdechant Blaschke mit zahlreichen Beiträgen an der Diskussion um die Wiedereinführung der Länder in der DDR und die Wiedergewinnung sächsischer Staatlichkeit. Er war es auch, der die Festrede zur Wiedergründung des Landes Sachsens am 3. Oktober 1990 in der Meißner Albrechtsburg hielt.

Für den Meißner Dom eröffnete die Wiedervereinigung großartige Chancen. Durch Fördermittel, die Dombaumeister Dr.-Ing. Otto Baer und sein Nachfolger Günter Donath (geb. 1950) geschickt einwarben, gelang eine vollständige Innen- und Außensanierung des Meißner Doms, die 2002 weitgehend abgeschlossen war. ${ }^{55}$ In den folgenden Jahren wurden weitere Nebenräume und Kunstschätze restauriert. Auch die Häuser des Hochstifts am Domplatz konnten in einen guten Zustand gebracht werden. Bisher unbeachtete Nebenräume des Meißner Doms erhielten eine neue Nutzung. In der Großen Sakristei und im Kapitelhaus östlich des Hohen Chors wurde 1999/2000 das Dommuseum einge- richtet. ${ }^{56}$ Damit konnte Blaschke, der entscheidenden Einfluss auf die Inhalte des Museums hatte, eine Idee verwirklichen, die bereits in seinem Konzept von 1977 enthalten war. Unter der Überschrift „Der Dom zu Meißen und die Kirche in Sachsen“ sollte das Dommuseum die Kirchengeschichte Sachsens erklären und zeigen. Seit 1998 verfügt der Meißner Dom über eine eigene Fachzeitschrift. Gemeinsam mit dem Dombau-Verein Meißen, der 1994 wiedergegründet wurde, gab das Hochstift das Jahrbuch „Ecclesia Misnensis“ heraus. Dieses wurde unter Beteiligung des Freundeskreises Albrechtsburg 2003 unter dem Titel „Monumenta Misnensia“ zum „Jahrbuch für Dom und Albrechtsburg Meißen" erweitert.

Die Währungsumstellung am 1. Juli 1990 wertete das Vermögen des Hochstifts auf, da sich auf den Konten nun nicht mehr Mark der DDR, sondern DM befanden. Andererseits wurden die Geldbeträge durch die Umstellung 1:2 halbiert. Auch die Präbenden wurden in DM umgerechnet. Aus 600 Mark der DDR wurden 300 DM. Ohne dass über die Ausschüttung der Präbenden jemals wieder grundsätzlich diskutiert worden wäre, erfolgte 1999 die Umstellung in Euro. Die Domherren erhalten heute jährlich 153,39 Euro, Dompropst und Domdechant je 306,78 Euro. Das bedeutet, dass der 1959 eingefrorene Jahresbetrag unverändert noch heute gilt, obwohl sich die Kaufkraft der Präbende deutlich reduziert hat. Auf der anderen Seite sind aber auch die Einnahmen aus den Guthaben, die früher dem Präbendenfonds und der Propstei Bautzen zugeordnet waren, zurückgegangen. Die wichtigste Einnahme des Hochstifts Meißen blieben, wie in den Jahren der DDR, die Eintrittsgelder, die die Besucher an der Domkasse entrichten. Während in den 1990er Jahren jährlich rund 150.000 Besucher in den Dom kamen, setzte nach 2010 ein Wandel im Besucherverhalten der Touristen ein, der mit einem anhaltenden, dramatischen Rückgang der Besucherzahlen einherging. Die Erhöhung der Eintrittsgelder konnte das nicht ausgleichen. Die Domführerinnen mussten sich immer wieder fragen lassen, warum für den Besuch einer Kirche Eintritt erhoben wird. Auch um dem Vorwurf zu begegnen, das Gotteshaus sei nur gegen Geld zu betreten, wurde die Allerheiligenkapelle am Kreuzgang als „Raum der Stille" für Besucher geöffnet.

Hinsichtlich der Gottesdienste ist eine deutliche Verbesserung gegenüber der Situation in der DDR zu beobachten. 1990 wurde nur alle zwei Wochen ein Gottesdienst gehalten, im Winter nutzte man dazu den Kapitelsaal. Seit etwa 1997 wird an jedem Sonntag um 12:00 Uhr ein Gottesdienst angeboten, auch in den Wintermonaten. So stieg die Zahl der Gottesdienste von 43 im Jahr 1996 auf 59 im Jahr 1998. Auch die Zahl der Gottesdienstbesucher stieg von durchschnittlich 52 auf 69 je Gottesdienst. Außerdem können die Besucher in den Sommermonaten täglich um 12:00 Uhr an einer Orgelmusik teilnehmen, die zu Andacht und Besinnung einlädt. Der Landesbischof der Evangelisch-Lutherischen Landeskirche Sachsens predigt üblicherweise zwei- 
mal jährlich im Meißner Dom: am Pfingstmontag und am Reformationstag.

Das Domkapitel hat sich in den 1990er Jahren, wie auch in den Jahrzehnten zuvor, überwiegend durch kirchliche Mitarbeiter oder Mitglieder der Kirchenleitung der Landeskirche ergänzt. Aufgenommen wurden Dr. Kurt Domsch, der in den Ruhestand getretene Präsident des Landeskirchenamts, der Leipziger Theologieprofessor Prof. Dr. Ulrich Kühn (1932-2012), Dr.-Ing. Rainer Gaebler (geb. 1938), langjähriges Mitglied der Synode und der Kirchenleitung, und Oberlandeskirchenrat Peter Zweynert (geb. 1943), ein Kirchenjurist. Das einzige Mitglied, das eine staatliche Anstellung hatte, war der Landeskonservator Prof. Dr. Heinrich Magirius (geb. 1934). Mit seiner Aufnahme sicherte man sich eine fachkundige Beratung bei der Restaurierung des Meißner Doms. Dr.-Ing. Rainer Gaebler leitete nach seinem Engagement in der Landeskirche eine Behörde zur Rehabilitierung von SED-Opfern. Einige ältere Domherren, wie Dr.-Ing. Hans Nadler, kamen nur noch selten zu Kapitelsitzungen oder machten von der 1976 eingeführten Regelung Gebrauch, in den Status eines außerordentlichen Domherrn überzutreten. Die Stellen der außerordentlichen Domherren konnten neu besetzt werden. Karlheinz Blaschke blieb bis 2003 Domdechant. Der betagte Dompropst Prof. Dr. Heinz Wagner gab sein Amt 1993 an den Oberlandeskirchenrat Dieter Auerbach ab. Das Domkapitel überarbeitete mit Beschluss vom 23./24. Mai 1998 die Verfassung des Hochstifts Meißen. Der überholte Hinweis auf den Wohnsitz in der DDR wurde gestrichen. Der § 4, der die Aufnahmevoraussetzungen regelt, erhielt eine Neufassung. Seitdem heißt es: „Zu Domherren können auf Lebenszeit Glieder der Evangelisch-Lutherischen Landeskirche Sachsens ernannt werden, die zur Erfüllung der ihnen obliegenden Aufgaben geeignet und willens sind und das 30 . Lebensjahr vollendet haben.“ Die Formulierung „Glieder“ statt „Männer“ wurde absichtlich gewählt, um auch Frauen die Aufnahme in das Domkapitel zu ermöglichen. Das Landeskirchenamt kritisierte diese Änderung am 10. Februar 1999 als „Bruch mit der Tradition“, genehmigte die Formulierung aber dann doch. Dompropst Auerbach bestätigte 2002 in einem Beitrag zum 75. Geburtstag des Domdechanten Karlheinz Blaschke, dass mit der Formulierung eine weitere Öffnung des Domkapitels ermöglicht werden sollte: „Damit ist ein erster Versuch eingebracht, das Kapitel auch für Frauen zu öffnen. Freilich ist eine ,Domherrin' in Meißen noch kaum vorstellbar." Bisher ist noch keine Frau in das Domkapitel aufgenommen worden. Allerdings enthielt ein Dreiervorschlag zur Neubesetzung einer Domherrenstelle den Namen einer Frau. Der Stiftsherr hat jedoch diesen Vorschlag nicht berücksichtigt.

1990 wurde der noch in der DDR ausgebildete Jurist Michael Gilbert (geb. 1956) zum Stiftsyndikus berufen. Stiftssekretärinnen waren nach dem Eintritt Christa Schumanns in den Ruhestand Helga Schulz (geb. 1940) und Martina Gasch (geb. 1960).

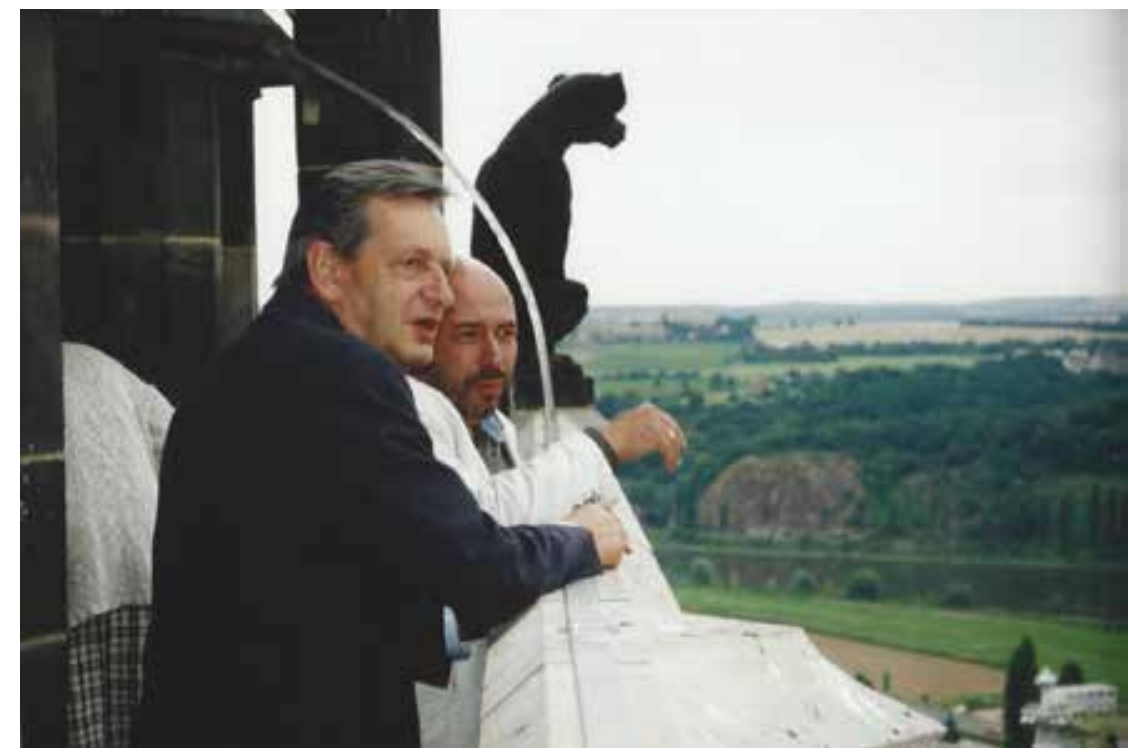

Bilanz

Staat und Kirche waren im 20. Jahrhundert enormen Veränderungen unterworfen. Die EvangelischLutherische Landeskirche Sachsens wandelte sich von einer Staatskirche zu einer vom Staat unabhängigen Volkskirche, war über Jahrzehnte der kirchenfeindlichen Politik des NS-Regimes und der DDR ausgesetzt und muss sich heute in einer pluralistischen Gesellschaft behaupten, in der sich die Mehrheit nicht mehr zum christlichen Glauben bekennt. Das Meißner Domkapitel hatte auf diese gesellschaftlichen Veränderungen $\mathrm{zu}$ reagieren. Hochstift und Domkapitel überlebten, was keinesfalls selbstverständlich ist. Die Revolution 1918, die Vermögensverluste oder die Eingriffe des NS-Staates hätten jederzeit zu einem Ende führen können. Das Meißner Domkapitel hat bis heute eine zentrale Aufgabe, nämlich die Aufrechterhaltung des Gottesdienstes im Meißner Dom. Lange suchte man nach weiteren Aufgaben und nach Nutzungsmöglichkeiten für den Meißner Dom. Viele Ideen haben sich zerschlagen. Immerhin wird der Meißner Dom stärker als früher als geistlicher Ort genutzt und ist zugleich ein „Hotspot“ des Kulturtourismus geblieben. Dennoch ist zu konstatieren, dass dem Meißner Dom nicht mehr die landesweite Bedeutung zukommt, die früher als selbstverständlich galt. Das Meißner Domkapitel hat gegenüber den anderen evangelischen Domkapiteln im mitteldeutschen Raum einen vergleichsweise schwachen gesellschaftlichen Einfluss, zumal es sich keine neuen Aufgabenfelder erschlossen hat. Ein Grund sind sicherlich auch die mangelnden Ressourcen. Die Stiftung besteht weiter, obwohl praktisch kein Stiftungsgut mehr vorhanden ist. So hat sich die Finanzierung des laufenden Betriebs eng an den Tourismus koppeln müssen, ohne den der Haushalt zusammenbrechen würde.

Eine bahnbrechende Aufgabe des Meißner Domkapitels ist in seiner Geschichte begründet. Als Einrichtung, die auf der vorreformatorischen Reichskirche wurzelt, könnte es verstärkt für eine
Domherr Heinrich Magirius und Dombaumeister Günter Donath auf den Westtürmen des Meißner Doms, August 2000 Foto: Matthias Donath 
ökumenische Verständigung werben. Insbesondere die fortbestehende Verklammerung der konfessionsverschiedenen Domkapitel in Meißen und Dresden ist ein einmaliges ökumenisches Zeichen. Mit einer Neubesetzung des Amtes des Propstes zu Bautzen und einer beidseitigen Anerkennung dieser konfessionsüberschreitenden institutionellen „Brücke“ könnte das Domkapitel für eine Annäherung der evangelisch-lutherischen und der römischkatholischen Kirche wirken. Hier könnte sich eine Symbolwirkung entfalten, für die man keine finan- ziellen Ressourcen braucht, sondern nur das symbolische Kapital, das sich auf eine 1050-jährige Vergangenheit gründet. Das Meißner Domkapitel mahnt zugleich die evangelische Kirche der Gegenwart, dass ihre Geschichte nicht erst mit Martin Luther und der Reformation beginnt, sondern tiefere und ältere Wurzeln hat, auf die sich die evangelische Kirche legitim beziehen darf. Vielleicht könnte das Meißner Domkapitel im 21. Jahrhundert damit ein Signal der Versöhnung und Hoffnung aussenden, das über Sachsen wahrgenommen wird.

\section{Mitglieder des Meißner Domkapitels im 20. Jahrhundert}

in der alphabetischen Reihung der Nachnamen. Als Tag der Aufnahme zählt die Einführung in das Domkapitel, während Wahl, Ernennung oder Präsentation hier keine Berücksichtigung finden.

Prof. Lic. theol. Dr. jur. h. c. Dr. phil. h. c. Dr. phil. h. c. Albrecht Alt (20.9.1883-24.4.1956), Professor für Alttestamentliche Wissenschaft an der Universität Leipzig, lebte in Leipzig, aufgenommen 1935

Oberlandeskirchenrat Superintendent i. R. Dieter Auerbach (geb. 30.6.1933), 1973 - 1983 Superintendent in Meißen, 1983 Oberkirchenrat, 1989 Oberlandeskirchenrat im Landeskirchenamt der Ev.-Luth. Landeskirche Sachsens, lebte in Meißen und Radeberg, aufgenommen am 7.6.1993, 31.10.1992-31.10.2009 Dompropst, seitdem außerordentlicher Domherr

Prof. Lic. theol. Dr. theol. h. c. Hans Bardtke (22.9.19068.3.1975), Professor für Alttestamentliche Wissenschaft an der Universität Leipzig, lebte in Leipzig, aufgenommen 3.6.1973

Exzellenz Staatsminister D. Dr. Dr.-Ing. e. h. Heinrich Gustav Beck (seit 1918 von Beck) (11.4.1854-9.1.1933), 1908-1918 Minister des Kultus und öffentlichen Unterrichts, 1914-1918 Vorsitzender des Gesamtministeriums, 1918 in den Adelsstand erhoben, lebte in Dresden, aufgenommen 21.10.1912, 14.10.1923-13.5. 1928 Domdechant, 13.5.1928-9.1.1933 Dompropst

Prof. Dr. phil. Karlheinz Blaschke (geb. 4.10.1927), Dozent am Theologischen Seminar in Leipzig, Leiter des Leiter des Referats für Archivwesen beim Sächsischen Staatsministerium des Innern, Professor für Sächsische Landesgeschichte an der TU Dresden, lebt in Friedewald bei Moritzburg, aufgenommen am 14.5.1972, 14.5.1972-31.10.2003 Domdechant, seit 2003 außerordentlicher Domherr

Superintendent i. R. Herbert Böhme (2.8.1879-7.6. 1971), 1933 - 1950 Superintendent in Meißen, lebte im Ruhestand in Dresden, aufgenommen 13.5.1956, 1967-1971 Propst zu Bautzen

Geheimer Kirchenrat Prof. Dr. phil. et Lic. theol. Dr. theol. h. c. Theodor Brieger (4.6.1842-9.6.1915), Professor für Kirchengeschichte an der Universität Leipzig, lebte in Leipzig, aufgenommen 1.6.1908

Exzellenz Wirklicher Geheimer Rat Rudolf Carl Toussaint von Charpentier (18.9.1822-13.12.1903), Regierungsrat im Ministerium des Innern, lebte in Dresden, aufgenommen 30.5.1897, als Vertreter des Hochstifts Meißen 1899-1904 Mitglied der Ersten Kammer des Sächsischen Landtags
Oberingenieur Dr. jur. h. c. Kurt Domsch (18.5.19285.2.1999), 1975-1989 Präsident des Landeskirchenamts und stellvertretender Vorsitzender der Kirchenleitung der Ev.-Luth. Landeskirche Sachsens, aufgenommen 5.6.1990, Rücktritt 31.12.1998

Prof. Dr. theol. et phil. Karl Otto Frenzel (31.12.186520.1.1934), Professor für Praktische Theologie und Pädagogik an der Universität Leipzig, lebte in Leipzig, aufgenommen 16.5.1926

Geheimer Kirchenrat Prof. Dr. theol. et phil. Gustav Adolf Fricke (22.8.1822-30.3.1908), Professor für Neutestamentliche Wissenschaft an der Universität Leipzig, lebte in Leipzig, aufgenommen 19.5.1890

Dr.-Ing. Rainer Gaebler (geb. 30.3.1938), 1959-1991 wissenschaftlicher Mitarbeiter von Forschungsinstituten in Freiberg und Leipzig, 1991-1994 Mitarbeiter der DBI Gas- und Umwelttechnik GmbH Leipzig, 1994-1996 Referatsleiter im Sächsischen Staatsministerium für Soziales, Gesundheit und Familie, 1997 bis 2003 Leiter der Rehabilitierungsbehörde des Freistaats Sachsen für das Zweite SED-Unrechtsbereinigungsgesetz im Sächsischen Landesamt für Familie und Soziales in Chemnitz, 1972-1996 Mitglied der Landessynode und 1978-1996 Mitglied der Kirchenleitung der Ev.-Luth. Landeskirche Sachsens, 1983-84 Präsident der Landessynode, 1986-1990 Präses der Bundessynode des Bundes Evangelischer Kirchen in der DDR und Mitglied der Konferenz der Evangelischen Kirchenleitungen in der DDR, aufgenommen 31.10.1999, 2013 außerordentlicher Domherr

Prof. Dr. theol. Hans Haas (3.12.1868-10.9.1934), Professor für Religionsgeschichte und Leiter des Religionswissenschaftlichen Seminars an der Universität Leipzig, aufgenommen 1930

Oberstudiendirektor a. D. Otto Hartlich (4.5.186912.4.1947), Rektor der Fürsten- und Landesschule St. Afra, lebte in Dresden, aufgenommen 18.6.1937

Geheimer Rat Prof. Dr. theol. et jur. Dr. phil. h. c. Albert Hauck (9.12.1845-7.4.1918), Professor für Theologie an der Universität Leipzig, lebte in Leipzig, aufgenommen 5.6.1916

Prof. Dr. theol. Christoph Michael Haufe (18.5.193219.2.2011), 1973-1992 Rektor des Theologischen Seminars und der Kirchlichen Hochschule in Leipzig, 1992-1997 Professor für Ökumenik, Missionswissenschaft und Konfessionskunde an der Universität Leipzig, lebte in Pönitz bei Taucha, aufgenommen 25.4.1974, 2007 außerordentlicher Domherr

Dr. jur. Benno von Heynitz (16.9.1887-29.1.1979), Besitzer der Rittergüter Heynitz und Wunschwitz, 1945 enteignet und vertrieben, lebte in Heynitz, Gröm- 
itz und Hannover-Kirchrode, aufgenommen 1.6.1929, 1.1.1941-7.6.1956 Domdechant, 1967 Verzicht auf Domherrenstelle, seitdem außerordentlicher Domherr

Prof. Dr. theol. h. c. Hugo Hickmann (3.9.187730.5.1955), Professor am Königin-Carola-Gymnasium in Leipzig, Vizepräsident der Synode der Ev.-Luth. Landeskirche Sachsens, 1922 - 1936 als Abgeordneter der Deutschen Volkspartei Mitglied im Sächsischen Landtag, 1945 Mitbegründer der CDU in Sachsen, 1948-1950 stellvertretender Vorsitzender der CDU in der Sowjetischen Besatzungszone und DDR, 19461950 als Vertreter der CDU Mitglied des Sächsischen Landtags, 1946 Vizepräsident des Sächsischen Landtags, Vorsitzender der Sächsischen Hauptbibelgesellschaft, lebte in Leipzig und Langebrück bei Radeberg, aufgenommen am 21.3.1933, 1946-1949 Propst zu Bautzen, 29.5.1949-30.5.1955 Dompropst

Geheimer Rat Prof. Dr. phil. et theol. Lic. theol. h. c. Dr. theol. h. c. Rudolf Hofmann (3.1.1825-19.2.1917), Professor für Theologie an der Universität Leipzig, lebte in Leipzig, aufgenommen 23.5.1902, als Vertreter des Hochstifts Meißen 1905-1910 Mitglied der Ersten Kammer des Sächsischen Landtags

Prof. Dr. theol. Ludwig Ihmels (29.6.1858-7.6.1933), Professor für Dogmatik an der Universität Leipzig, lebte in Leipzig, aufgenommen Mai 1918, ausgeschieden 1922 infolge der Wahl zum Landesbischof der Ev.Luth. Landeskirche Sachsens, 1922-1933 Stiftsherr des Hochstifts Meißen

Geheimer Rat Carl von Kirchbach (2.7.184715.1.1929), 1899-1910 Generaldirektor der Königlich Sächsischen Staatseisenbahnen, aufgenommen 13.5. 1907, 1910-14.10.1923 Domdechant, 1927-1929 Propst zu Bautzen, 1911-1918 als Vertreter des Hochstifts Meißen Abgeordneter der Ersten Kammer des Sächsischen Landtags

Geheimer Kirchenrat Prof. D. Dr. Rudolf Kittel (28.3.1853-20.10.1929), Professor für Alttestamentliche Wissenschaft an der Universität Leipzig, lebte in Leipzig, aufgenommen 21.5.1917, 1925 wegen Emeritierung ausgeschieden

Exzellenz Dr. jur. Richard Leo Graf von Könneritz (29.7.1828-4.7.1910), Rittergutsbesitzer in Lossa bei Wurzen, Ehrenbürger der Stadt Wurzen, 1875-1906 Mitglied der Ersten Kammer des Sächsischen Landtags, 1891-1904 Präsident der Ersten Kammer des Sächsischen Landtags, 1891-1901 Präsident der Landessynode der Ev.-Luth. Landeskirche Sachsens, lebte in Lossa und Wurzen, aufgenommen 6.5.1894, 22.5.18982.7.1906 Domdechant, 2.7.1906-4.7.1910 Dompropst

Prof. Dr. theol. Ulrich Kühn (16.3.1932-29.11.2012), Dozent am Theologischen Seminar Leipzig, Professor für Systematische Theologie an der Universität Wien, Professor für Systematische Theologie an der Universität Leipzig, lebte in Leipzig, aufgenommen am 31.10.1992, 2007 außerordentlicher Domherr

Prof. Lic. theol. Franz Lau (18.2.1907-6.6.1973), 19451947 Landessuperintendent und Leiter der Ev.-Luth. Landeskirche Sachsens, Professor für Kirchenge-schichte an der Universität Leipzig, 1952-1971 Präsi-dent des Gustav-Adolf-Werks, lebte in Markkleeberg, aufgenommen 21.10.1956, 21.10.1956-3.4.1972 Dom-dechant

Prof. Dr. theol. habil. et Dr. phil Johannes Leipoldt (20.12.1880-22.2.1965), Professor für Neutestamentliche Wissenschaft an der Universität Leipzig, Mitglied der CDU in der DDR und Abgeordneter der Volkskammer 1953-1963, lebte in Leipzig, am 13.5.1934 in das Meißner Domkapitel und 1949 in das Wurzener Domkapitel aufgenommen, seit 13.5.1955 stellvertretender Dechant, 21.7.1956 Rücktritt als stellvertretender Dechant und Domherr

Dr. rer. oec. Paul Liebe (30.3.1901-7.10.1989), 19471971 Finanzreferent der Inneren Mission der Ev.-Luth. Landeskirche Sachsens, 16.11.1955-1981 Syndikus des Hochstifts Meißen, lebte in Radebeul und Dresden, aufgenommen 3.6.1973

Regierungsrat a. D. Clemens Graf zur Lippe-BiesterfeldWeißenfeld (seit 1916 Prinz zur Lippe-Weißenfeld) (15.7.1860-29.4.1920), Besitzer des Ritterguts Döberkitz bei Bautzen, Landesältester des Markgraf-tums Oberlausitz, 1901-1918 Mitglied und 1905-1918 Sekretär der Ersten Kammer des Sächsischen Landtags, Kommendator des Johanniterordens, lebte in Döberkitz, Bautzen und Proschwitz, aufgenommen 28.5.1914

Prof. Dr. theol. Ernst Luthardt (22.3.1823-21.09.1902), Professor für Lutherische Theologie an der Universität Leipzig, lebte in Leipzig, aufgenommen vor 1889

Prof. Dr. phil. Dr. h.c. Heinrich Magirius (geb. 1.2.1934), 1958-1992 Mitarbeiter im Institut für Denkmalpflege, Arbeitsstelle Dresden, dort 19621992 Leiter der Abteilung Forschung, 1992-1999 Leiter der Abteilung Wissenschaftliche Dienste im Landesamt für Denkmalpflege Sachsen, 1994-1999 Landeskonservator, 1989 Honorarprofessor an der Hochschule für Bildende Künste Dresden, lebt in Radebeul, aufgenommen am 31.10.1994, 2012 außerordentlicher Domherr

Exzellenz Staatsminister Georg von Metzsch-Reichenbach (seit 1916 Graf von Metzsch-Reichenbach) (14.7.1836-7.9.1927), Besitzer der Rittergüter Brunn und Reuth bei Reichenbach, 1891-1906 Minister des Innern, 1892-1906 Minister für Auswärtige Angelegenheiten, 1901-1906 Vorsitzender des Gesamtministeriums, 1901-1918 Minister des Königlichen Hauses, Ehrenbürger der Stadt Dresden, Mitglied der Ersten Kammer des Sächsischen Landtags, lebte in Dresden, aufgenommen 15.5.1904, 2.7.1906-1910 Domdechant, 1910-1927 Dompropst

Prof. Dr. theol. et phil. Alfred Dedo Müller (12.1.18904.8.1972), Professor für Praktische Theologie an der Universität Leipzig, lebte in Leipzig, aufgenommen am 21.10.1956

Prof. Dr.-Ing. Hans Nadler (1.7.1910-8.10.2005), Leiter des Instituts für Denkmalpflege, Arbeitsstelle Dresden, lebte in Dresden, aufgenommen 18.5.1969

Exzellenz Staatsminister Hermann von Nostitz-Wallwitz (30.3.1826-10.1.1906), Besitzer des Ritterguts Sohland/Spree, 1866-1891 Minister des Innern, 18691871 und 1882-1895 Minister des Königlichen Hauses, 1876-1882 Minister für Auswärtige Angelegenheiten, Mitglied des Reichstags, 1891-1904 Mitglied der Ersten Kammer des Sächsischen Landtags, Ehrenbürger von Dresden, aufgenommen vor 1860, 1860-1872 Propst zu Bautzen, 28.2.1886-17.1.1906 Dompropst

Geheimer Regierungsrat Dr. jur. Rudolf von Oppen (10.4.1855-1927), Amtshauptmann in Marienberg und Plauen, 1909 - 1913 Kreishauptmann in Dresden, ab 1914 Präsident des Oberverwaltungsgerichts Dresden, lebte in Dresden, aufgenommen vor 1914, 19141927 Propst zu Bautzen 
Geheimer Studienrat Dr. phil. Hermann Peter (7.9. 1837-16.2.1914), 1874 - 1905 Rektor der Fürsten- und Landesschule St. Afra in Meißen, lebte in Meißen, aufgenommen 31.5.1908, 1911-1914 Propst zu Bautzen, 1909/10 Vertreter des Hochstifts Meißen in der Ersten Kammer des Sächsischen Landtags

Major a. D. Kammerherr Bernhard Edler von der Planitz (7.1.1828-23.11.1907), Besitzer des Ritterguts Naundorf bei Oschatz, 1869 - 1902 Mitglied der Ersten Kammer des Sächsischen Landtags, aufgenommen am 22.5.1882, 1906-1907 Propst zu Bautzen

Geheimer Kirchenrat Prof. Dr. theol. Dr. jur. h. c. Franz Rendtorff (1.8.1860-17.3.1937), Professor für Praktische Theologie und Neutestamentliche Wissenschaft an der Universität Leipzig, Vater des mecklenburgischen Landesbischofs Heinrich Rendtorff, lebte in Leipzig, aufgenommen 1922, ausgeschieden 1930 infolge Emeritierung

Kammerherr Carl Graf von Rex (23.4.1825-21.10. 1905), Besitzer der Rittergüter Ober Oertmannsdorf bei Lauban und Zedtlitz bei Borna, 1871-1905 Mitglied der Ersten Kammer des Sächsischen Landtags, lebte in Ober Oertmannsdorf und Dresden, Jahr der Aufnahme nicht bekannt, 1893-1905 Propst zu Bautzen

Dr. theol. Christian Rietschel (5.3.1908-3.9.1997), Urenkel des Bildhauers Ernst Rietschel, 1950-1973 Leiter des Kunstdienstes der Ev.-Luth. Landeskirche Sachsens und Schriftleiter der Kirchenzeitung „Der Sonntag“, lebte in Radebeul und seit 1973 in Bad Salzuflen, aufgenommen am 19.12.1967, mit Wirksamwerden der Verfassung des Hochstifts Meißen am 30.1.1976 außerordentlicher Domherr, Rücktritt am 15.5.1984

Kammerherr Dr. jur. Leo Sahrer von Sahr (17.10.18527.8.1925), Besitzer des Ritterguts Dahlen, 1895-1904 Mitglied und 1901-1904 Sekretär der Ersten Kammer des Sächsischen Landtags, lebte in Dahlen, aufgenommen 27.10.1906

Geheimer Rat Ministerialdirektor a. D. Dr. jur. Dr.-Ing. Dr. med. vet. Georg Schmaltz (9.6.1862-vor 1945), Vortragender Rat im Ministerium des Kultus und öffentlichen Unterrichts, Ministerialdirektor im Ministerium für Volksbildung, aufgenommen vor 1928, 13.5. 1928-28.5.1933 Dechant, 28.5.1933-1940 Propst

Geheimer Rat Prof. Dr. jur. Alfred Schultze (25.2.18643.7.1946), Professor für Rechtswissenschaft an der Universität Leipzig, lebte in Leipzig, aufgenommen vor 1929, 1933-1946 Propst zu Bautzen

Oberkirchenrat bacc. jur. utr. Hans Schulz-Blochwitz (14.3.1888-17.6.1967), Städtischer Juristischer Direktor beim Rat der Stadt Dresden, 1945-1948 Oberkirchenrat im Landeskirchenamt der Ev.-Luth. Landeskirche Sachsens, seit 1951 Jurist in der Senatsverwaltung für Sozialwesen des Landes Berlin, lebte in Dresden und seit 1951 in Berlin (West), aufgenommen in das Wurzener Domkapitel am 7.3.1946 und in das Meißner Domkapitel am 9.5.1948

Exzellenz Staatsminister a. D. Dr. phil. h. c. Dr. jur. h. c. Dr. theol. h. c. Dr.-Ing. e. h. Paul von Seydewitz (3.5. 1843-17.12.1910), 1892-1905 Minister des Kultus und öffentlichen Unterrichts, Minister des Königlichen Hauses, Rechtsritter des Johanniterordens, aufgenommen 2.7.1906, 1908-1910 Propst zu Bautzen

Dr. Matthias Dona Vorsitzender des Dombau-Vereins Meißen und Herausgeber der "Sächsischen Heimatblätter"
Universität Leipzig, lebte in Markkleeberg, am 17.10.1937 in das Wurzener Domkapitel und am 9.5.1948 in das Meißner Domkapitel aufgenommen, Onkel der Königin Silvia von Schweden, geb. Sommerlath, 16.11.1955-4.3.1983 Dompropst

Oberkirchenrat Dr. jur. Walther Thomas (26.4.188110.3.1973), 1925-1926 Oberregierungsrat im Landeskonsistorium der Ev.-Luth. Landeskirche Sachsens, 1926-1956 Kirchenamtsrat in Bautzen, 19471949 Aberkennung der Dienstbezeichnung Oberkirchenrat und betraut mit Bearbeitung juristischer Angelegenheiten, lebte in Bautzen, 1967 Übersiedlung nach Bayern, lebte seitdem in Sonthofen, Oberstdorf und Bad Reichenhall, aufgenommen 30.5.1965

Hans Dietrich Konrad von Trützschler (seit 1900 von Trützschler Freiherr zum Falkenstein) (20.2.183012.5.1907), Besitzer des Ritterguts Dorfstadt, 18771907 Mitglied der Ersten Kammer des Sächsischen Landtags, aufgenommen 14.5.1899

Generalleutnant a. D. Exzellenz Woldemar Graf Vitzthum von Eckstädt (7.9.1863-26.11.1936), 19281933 Präsident der Landessynode der Ev.-Luth. Landeskirche Sachsens, aufgenommen vor 1929

Pfarrer Werner Vogel (21.8.1917-23.6.1991), Direktor der Inneren Mission, lebte in Leipzig, aufgenommen 29.5.1976

Oberkirchenrat Ernst Wäntig (auch Waentig) (25.3. 1898-9.9.1990), Kirchenamtsrat, lebte in Zwickau, aufgenommen 18.5.1969, 1972 - 1987 Propst zu Bautzen

Prof. Dr. theol. Heinz Wagner (22.11.1912-10.4.1994), Professor für Praktische Theologie an der Universität Leipzig, aufgenommen 11.5.1975, 14.5.1983-31.10.1992 Dompropst

Oberkirchenrat Superintendent i.R. Richard Weidauer (3.11.1867-18.10.1967), 1917-1934 Superintendent in Grimma, lebte in Grimma, 1925 in das Wurzener Domkapitel aufgenommen, dort 1927 Dechant, 9.5. 1948 in das Meißner Domkapitel aufgenommen, 19561967 Propst zu Bautzen

Exzellenz Wirklicher Geheimer Rat Dr. jur. h. c. Johann Georg Freiherr von Welck (1.11.1839-18.2.1912), Kreishauptmann in Leipzig, lebte in Niederlößnitz, aufgenommen 29.5.1911

Geheimer Regierungsrat a. D. Kammerherr Alfred Freiherr von Welck (13.12.1866-22.4.1963), 19061911 Amtshauptmann in Annaberg und Glauchau, 1911-1916 Rat im Landeskonsistorium der Ev.-Luth. Landeskirche Sachsens, 1916-1923 Geheimer Regierungsrat im Ministeriums des Innern, 1926-1930 Kirchenamtsrat im Kirchenkreis Dresden, Rechtsritter des Johanniterordens, lebte in Dresden, Radibor, Laubach und Bad Godesberg, 1945 enteignet und vertrieben, aufgenommen 26.5.1926, 13.5.1928-31.12.1940 Domdechant, 1.1.1941-30.12.1947 Dompropst

Dr. theol. Christoph Wetzel (geb. 6.7.1929), 1976-1983 Superintendent des Kirchenbezirks Dresden-Nord, seit 1983 Studiendirektor an der Kirchenmusikschule, später Hochschule für Kirchenmusik in Dresden, lebt in Dresden, aufgenommen 30.5.1987, 2004 außerordentlicher Domherr

Oberlandeskirchenrat Peter Zweynert (geb. 13.12.1943), Oberlandeskirchenrat im Landeskirchenamt der Ev.Luth. Landeskirche Sachsens, aufgenommen am 16.5. 1999, 2017 außerordentlicher Domherr 